\title{
THE
}

\section{SHORTER CATECHISM}

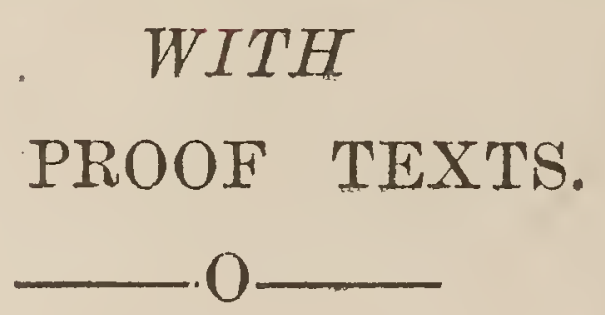

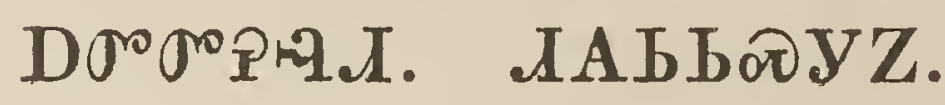

Compiled, And Translated

$\mathrm{By}$,

Rev. A. N. Chamberlin.

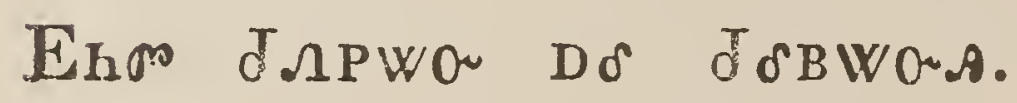

1892 
Wicrotomed by

Pruscruation

Sorvioss

$$
\frac{c}{1100795}
$$




\section{PrEFACE.}

\section{¿תFWOA SEOAЛOET.}

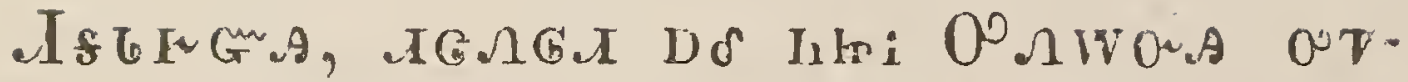

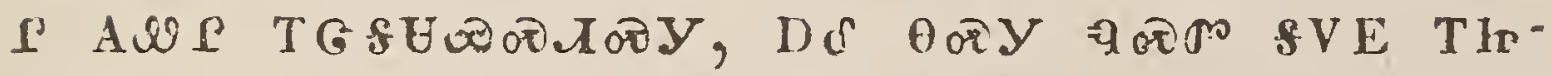

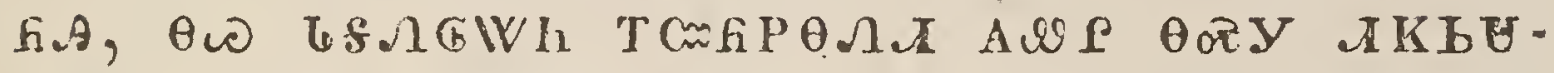

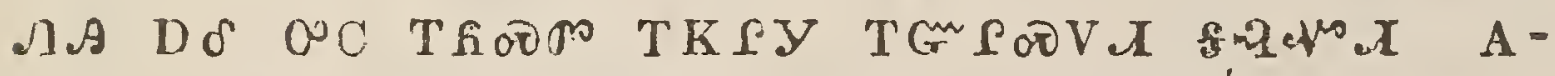

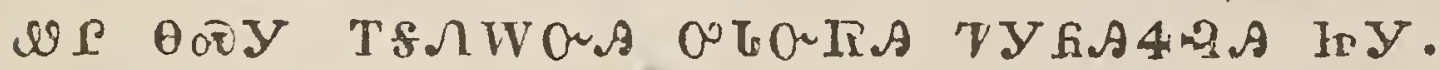

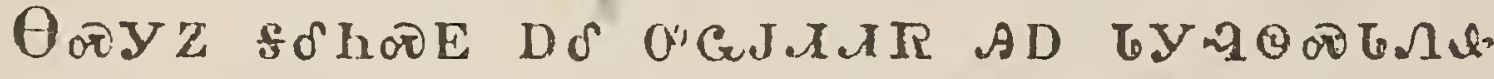

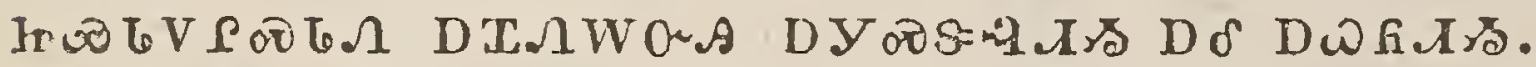

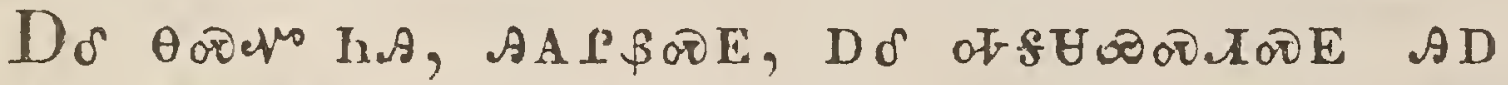
AWP,

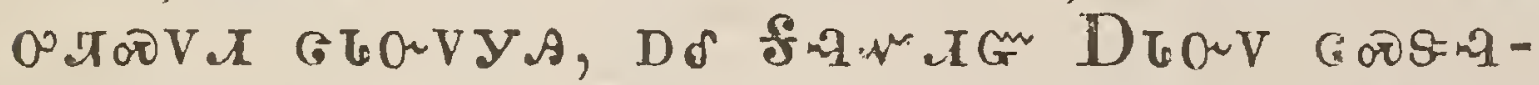
I AWfAPOD. D. Dh REA hróhVof, TASWOF

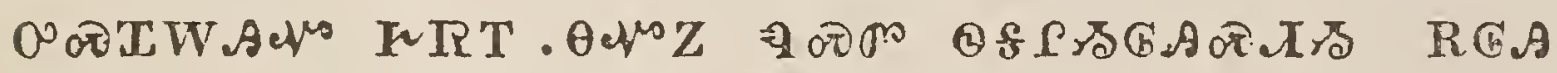
TYGீ ON $\Omega W O U A$ O゚LOURA.

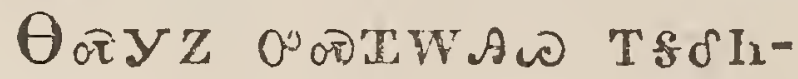

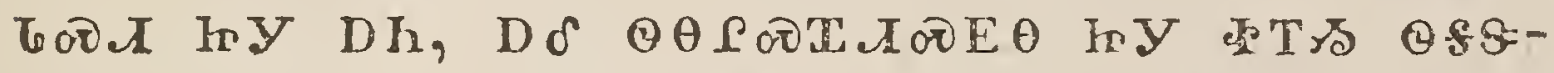

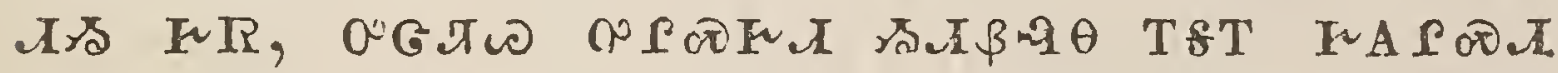

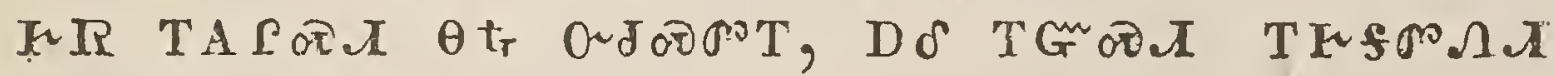

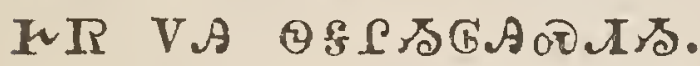

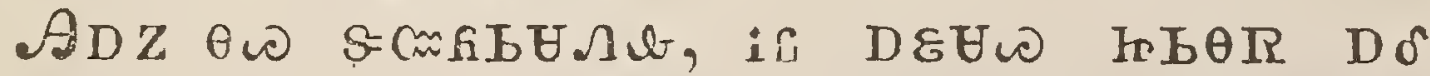

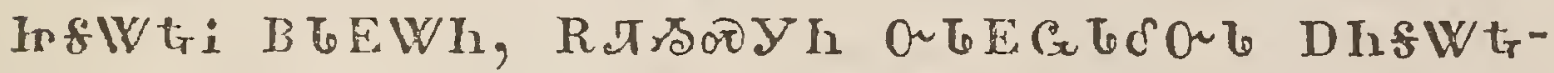

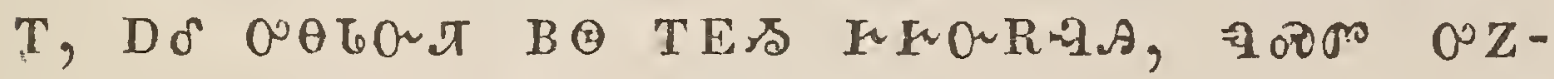
$P C$ Do SZBUO GS $\Omega$ PWh O C TET.

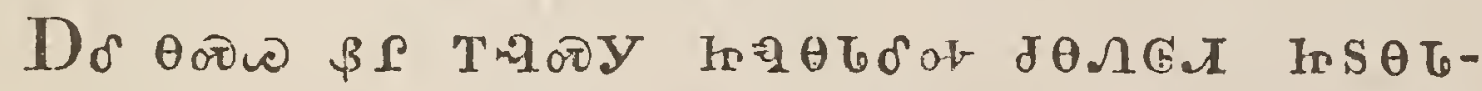

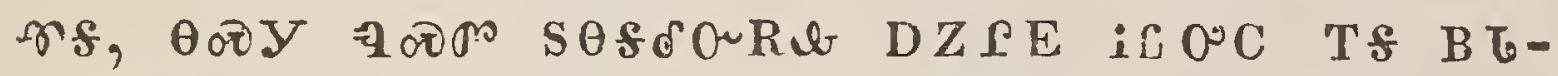

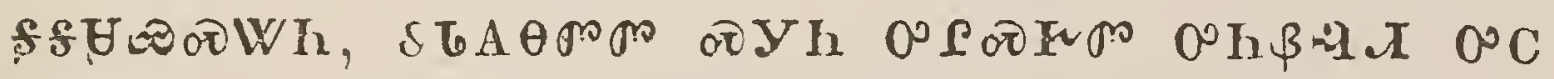

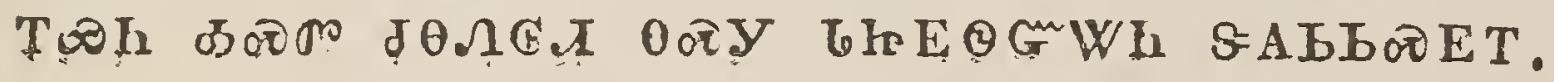


$A \mathrm{DZ}$ D roppra $A \mathrm{AbB}$

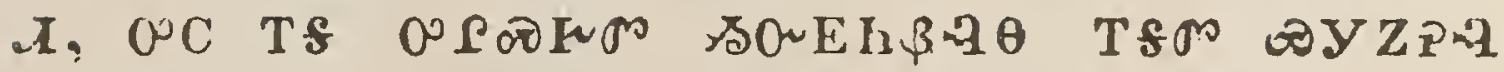

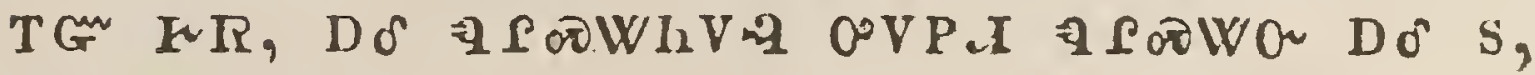
I $\beta P$ SOOWO T .

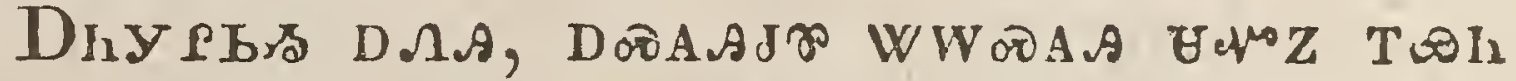

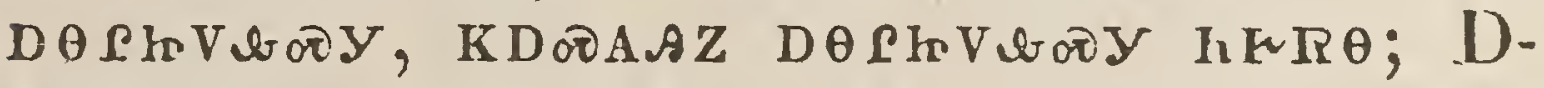
hôf I

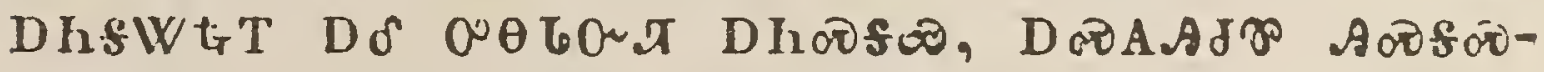

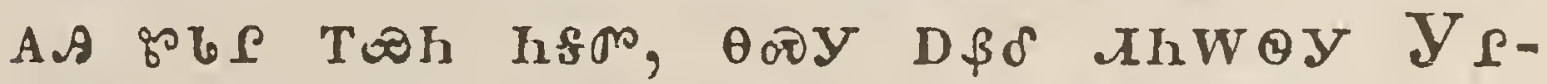

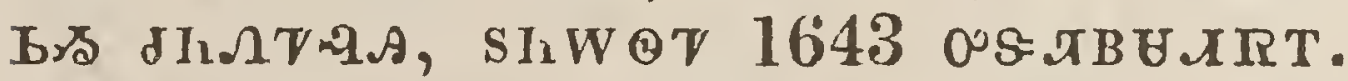

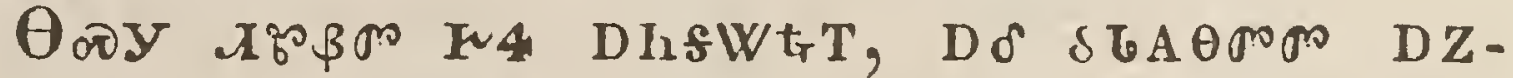

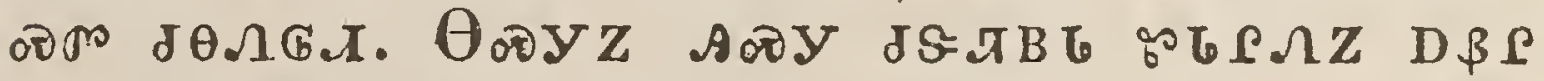
TAS 0ొ

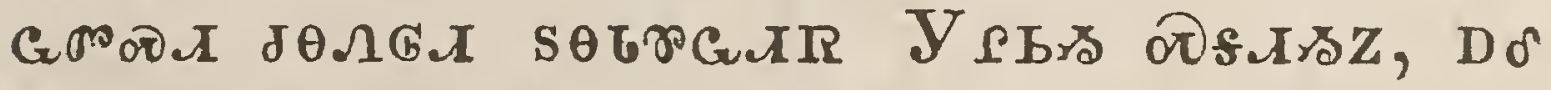

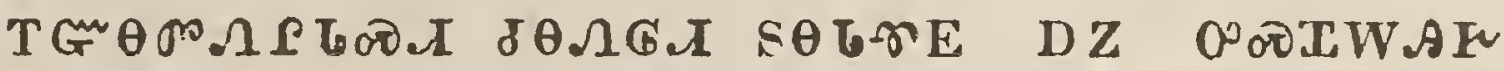

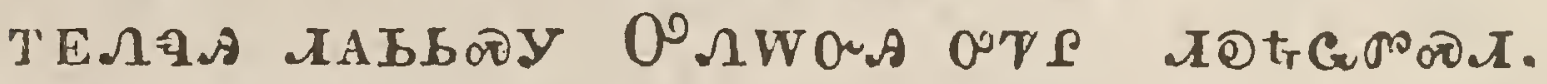

$\theta_{00 \mathrm{YZ}}$ च०ठ⿻尸

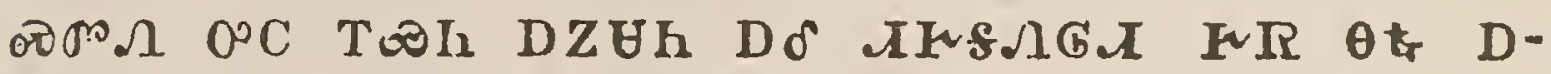
$\beta P D^{\circ} \theta V P T R$.

ӨФYZ In

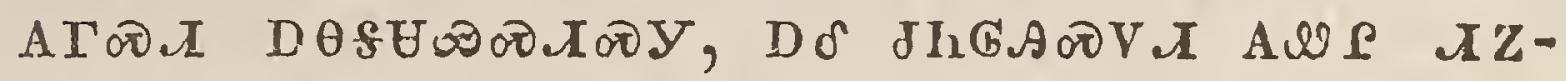
P०O .

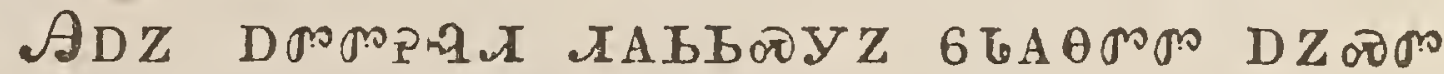

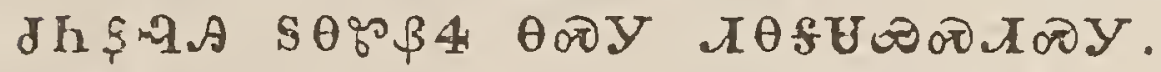

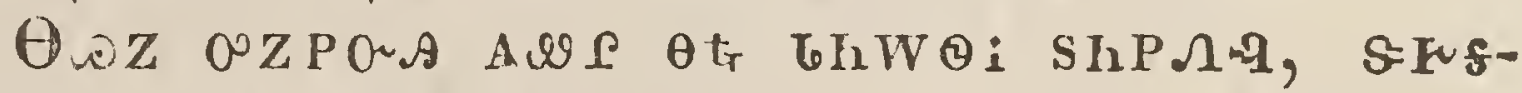

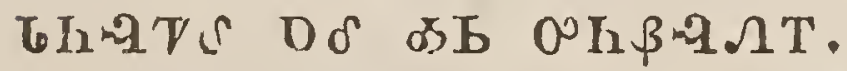

1647 ors:

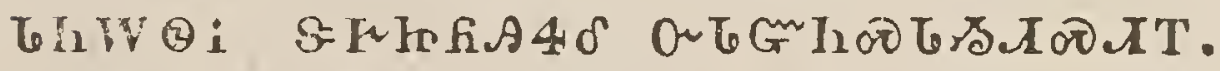

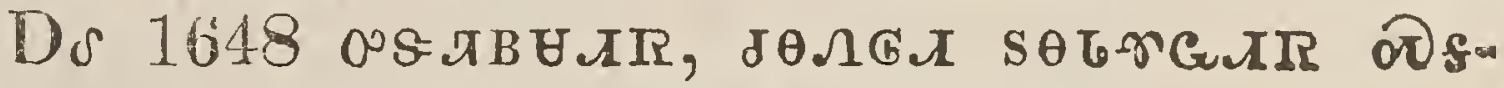
在为 


\section{5

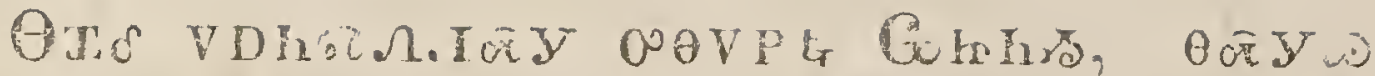

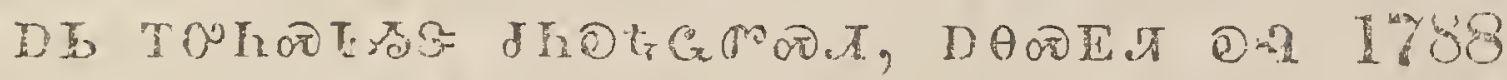
OSTBU.

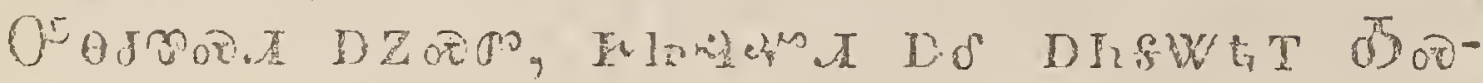

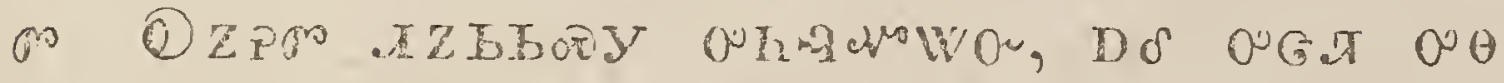

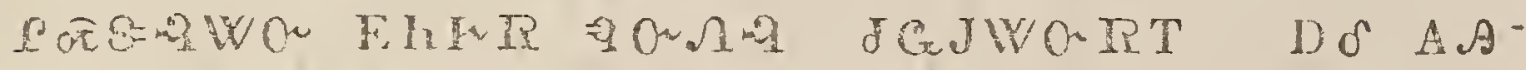

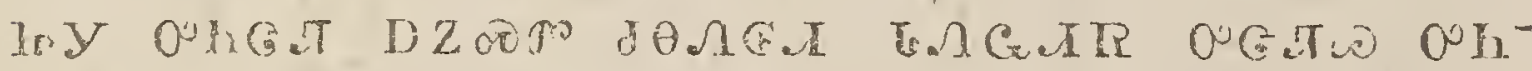

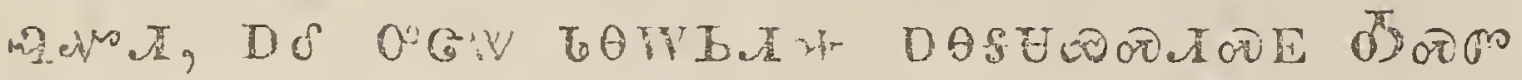

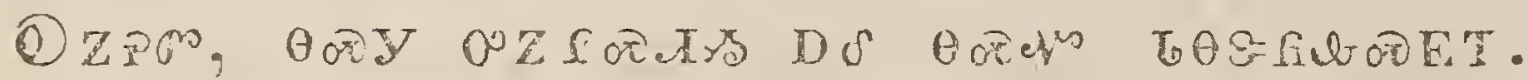

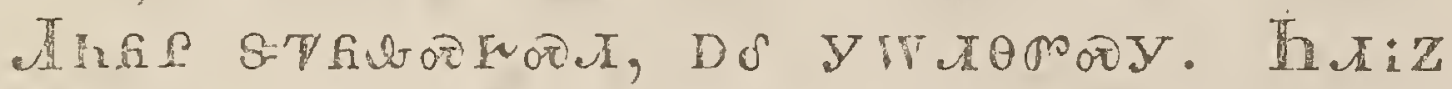

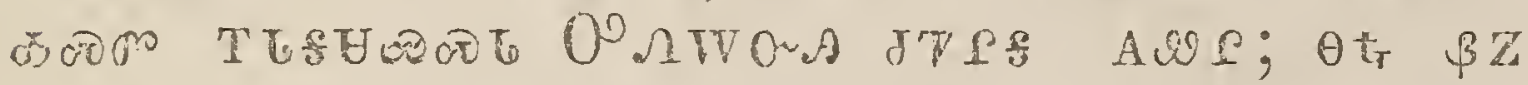

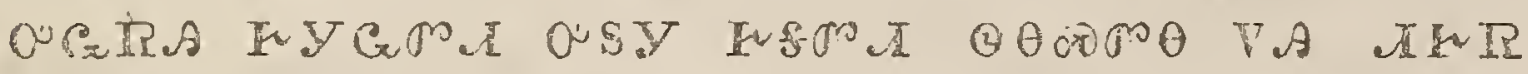

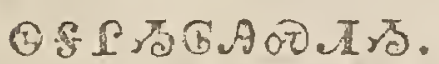

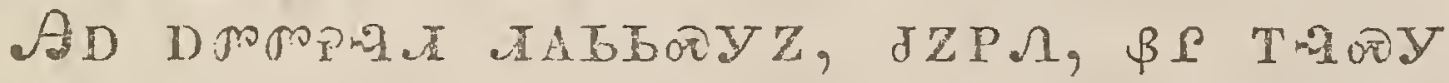

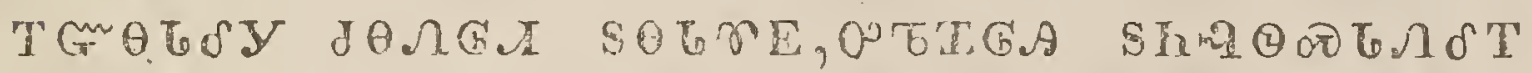

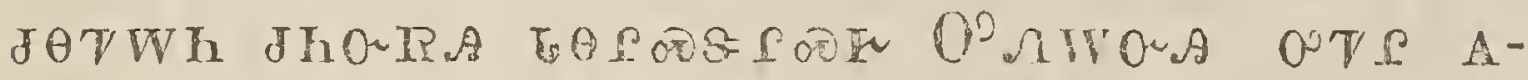
W

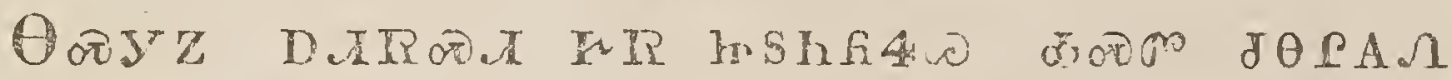
OHfib a क力

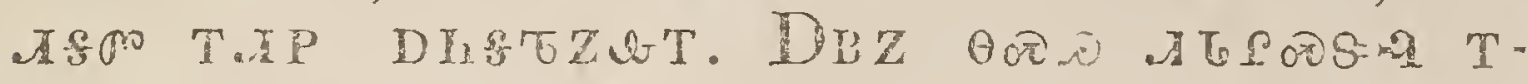

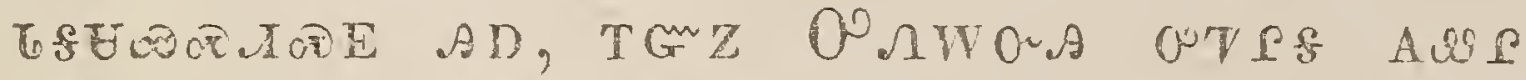

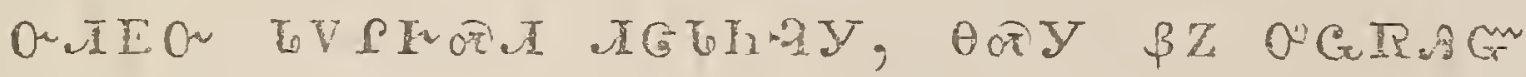

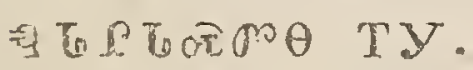

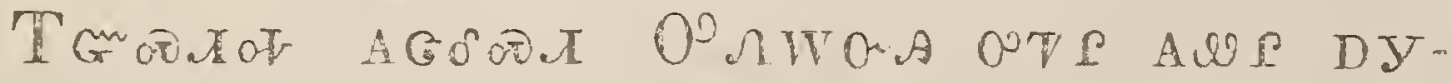

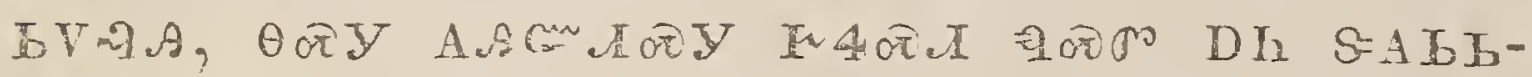
oथ $\mathrm{ET}$.

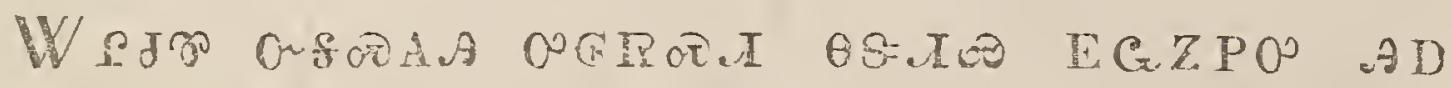

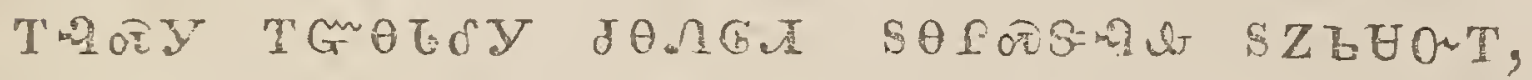

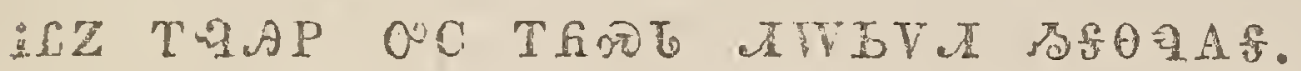




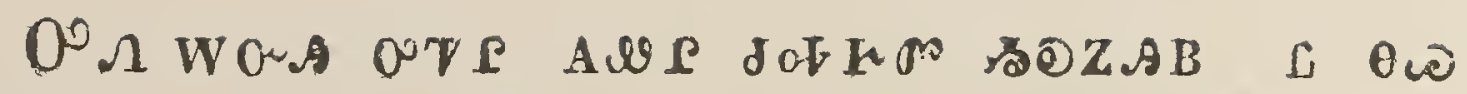

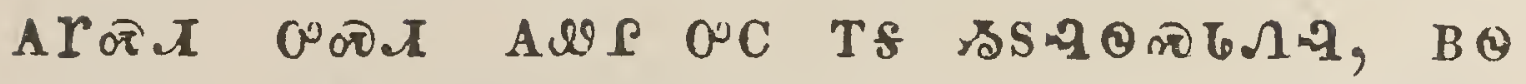

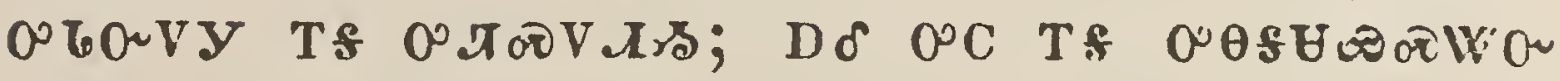

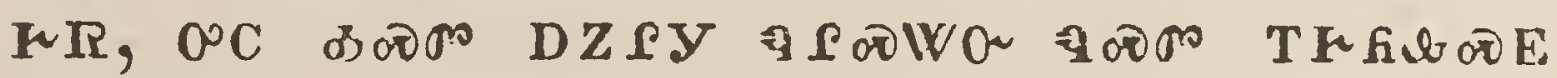
$0^{\circ} \Omega W O \sim A$.

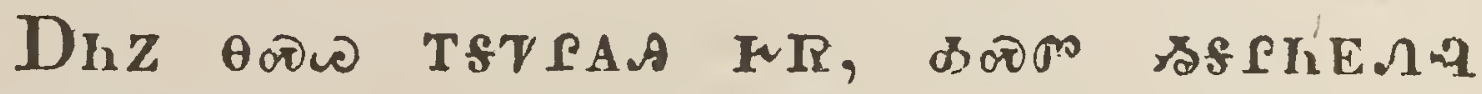

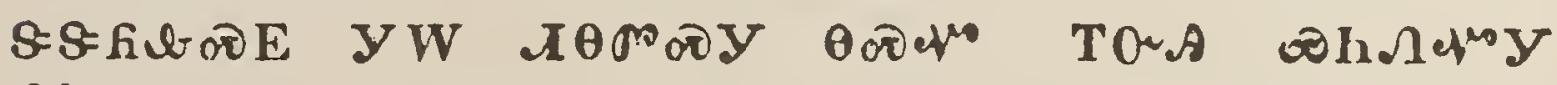

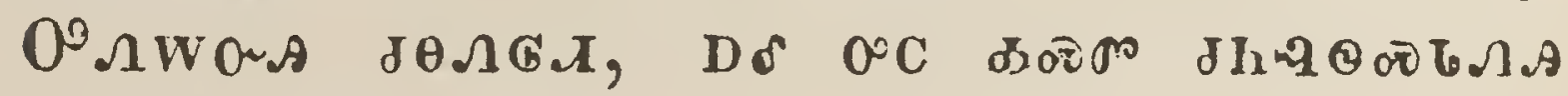

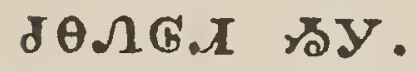

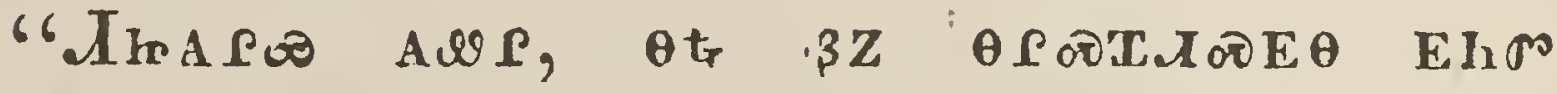

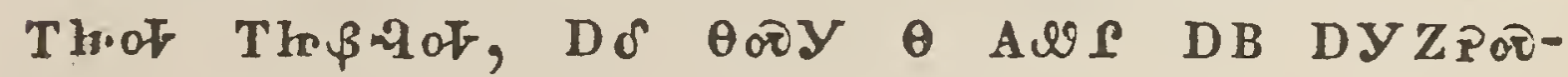
y". G G $\mathrm{T} .39$.

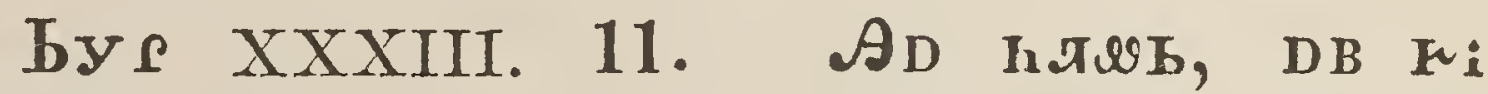

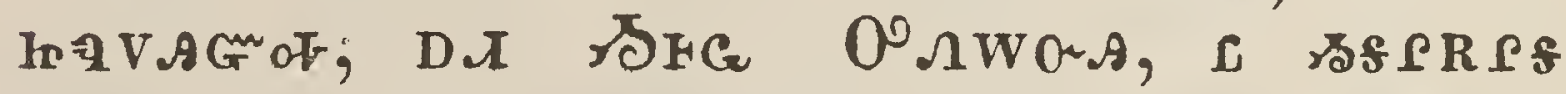

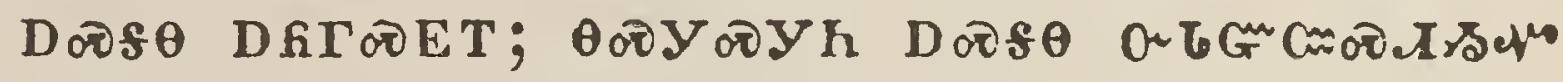

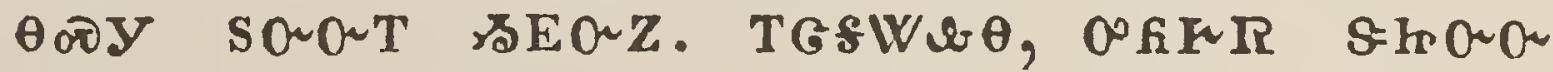

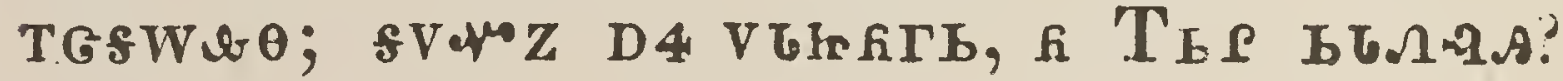




\section{7 \\ CATECHISH; AND TEXTS}

Dromet 1

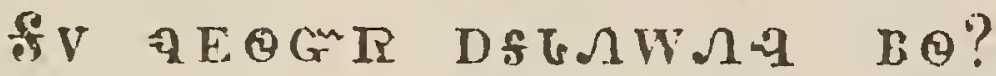

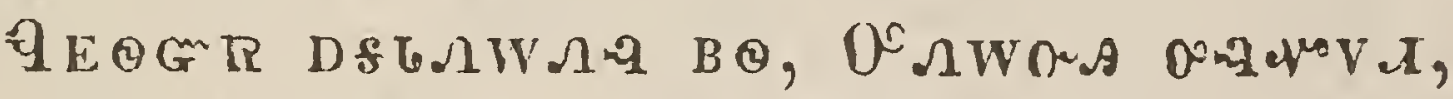

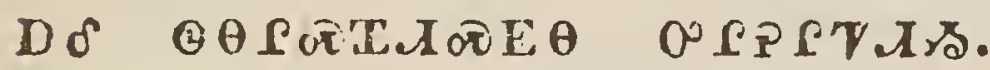

\section{A. $A G^{n} V I$.}

$0^{\circ} \Omega W O A$ ON⿴囗十VI

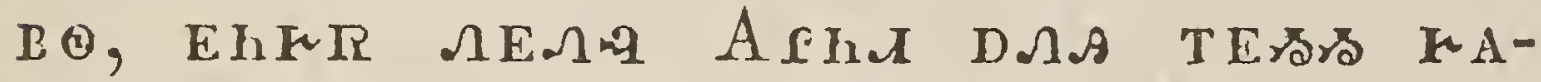

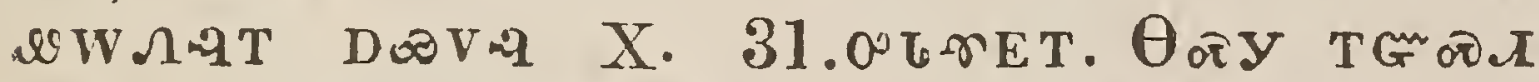

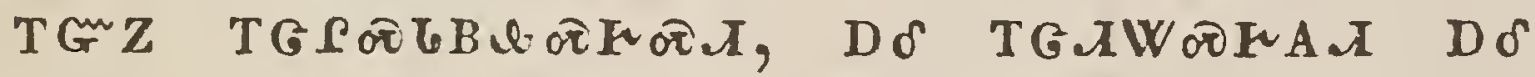

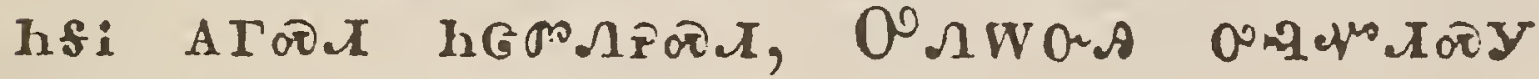
I 400 I I \&: IGO゚AGT.

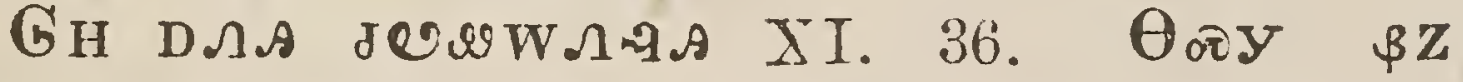
FIR O.

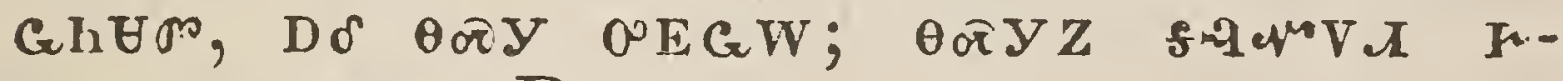

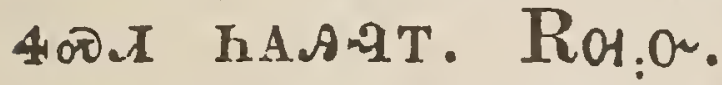

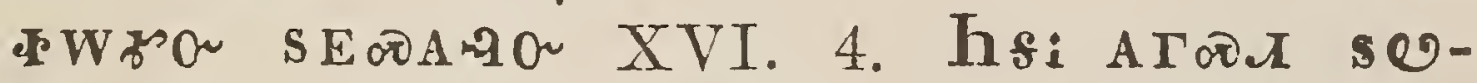

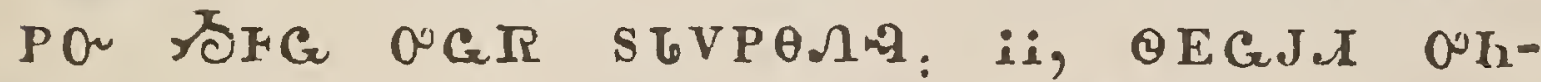

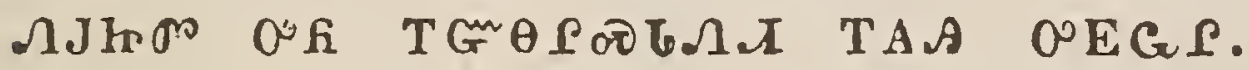

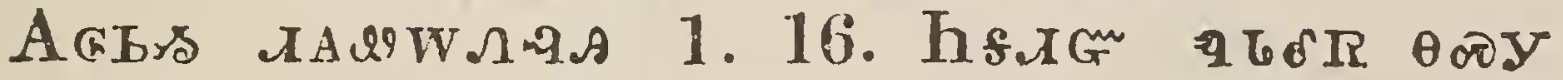

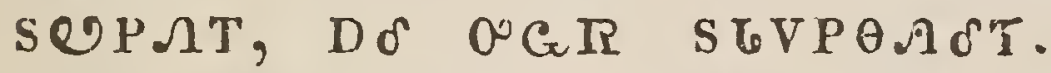

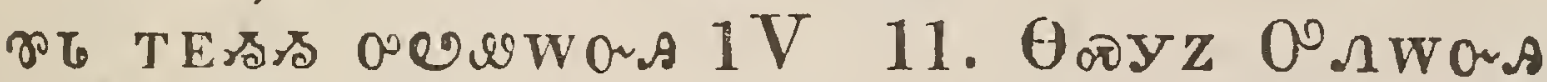
Thfi STr F.

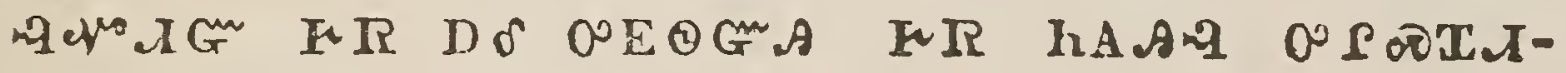

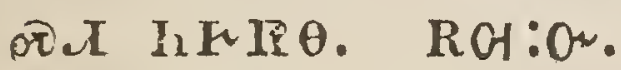




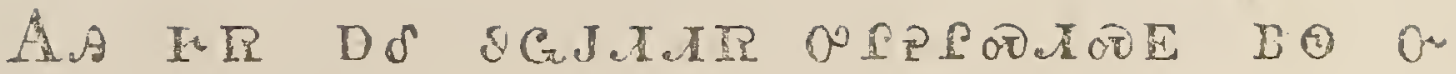
A POOVIOF $0^{\circ} \Omega W$ W

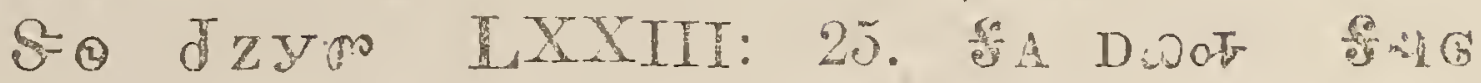

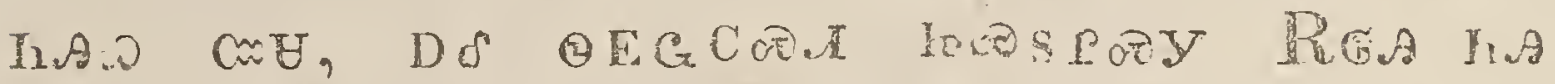

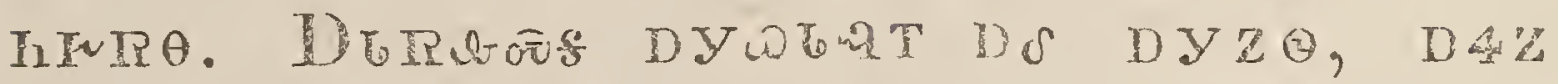

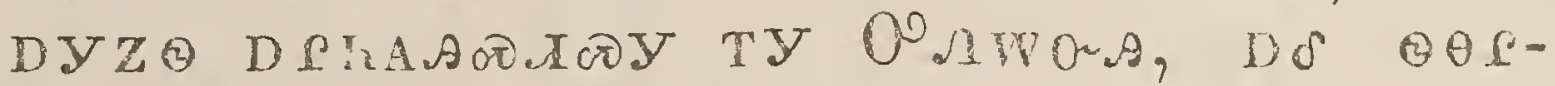

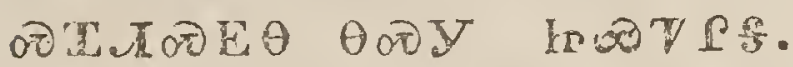

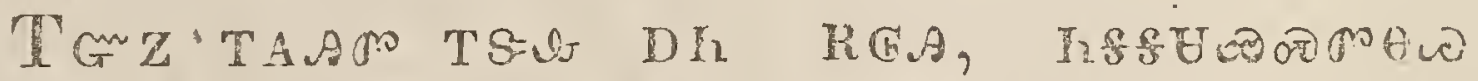

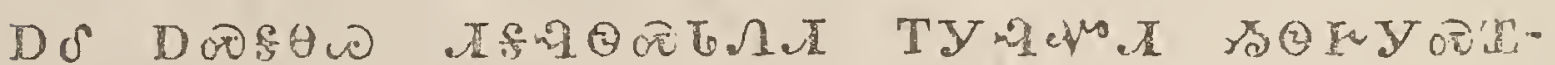

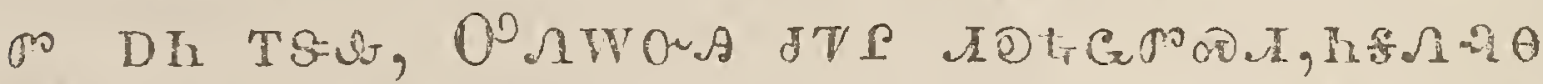

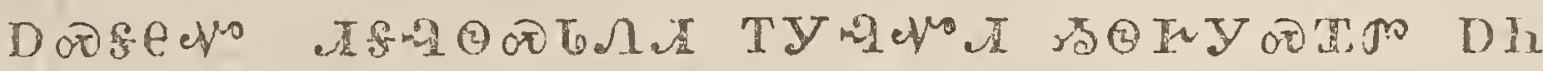

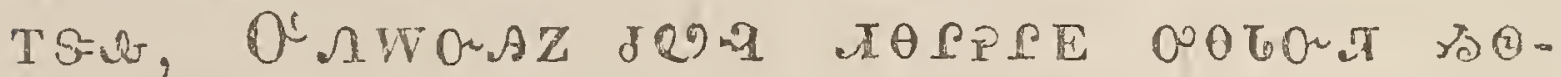

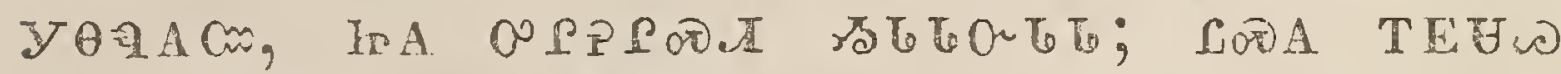

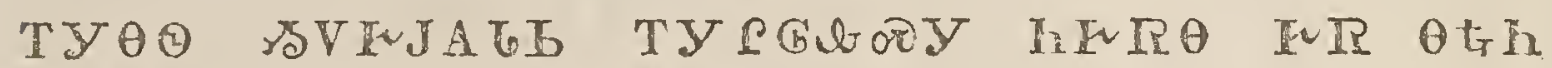
Drems. 11.

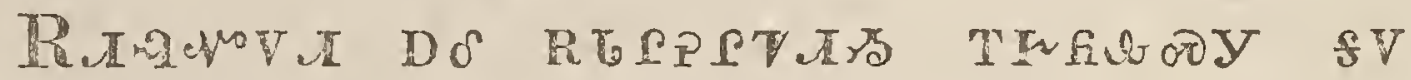

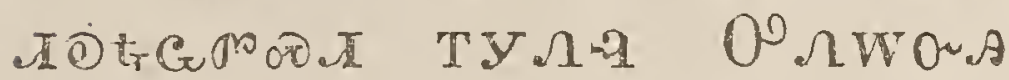

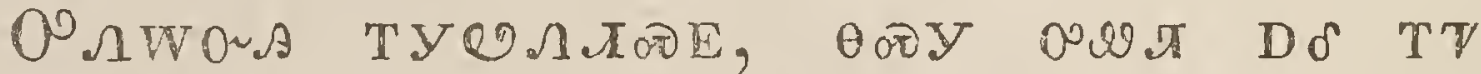

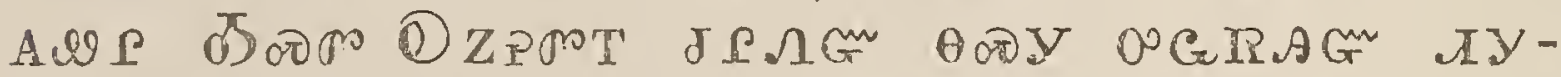

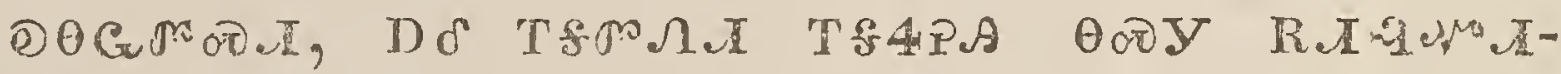
OD Do RGTPPUT.

\section{A. $A$ TOOY.}

OAVOUA TYOSATOEE OOMA DO TV AWR

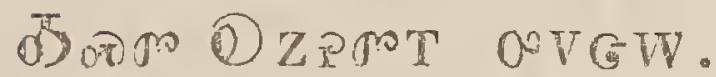

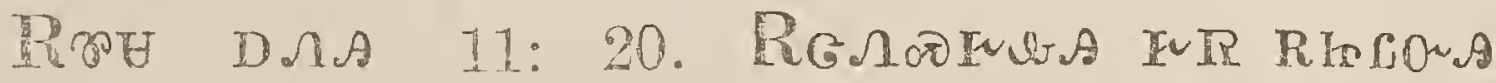

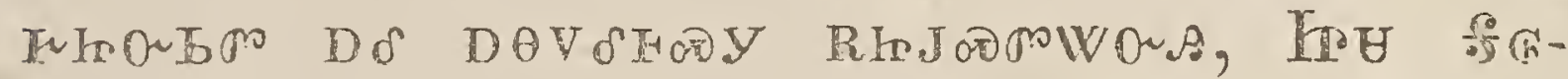

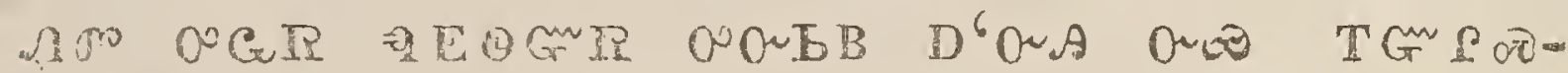
WOW.A. 


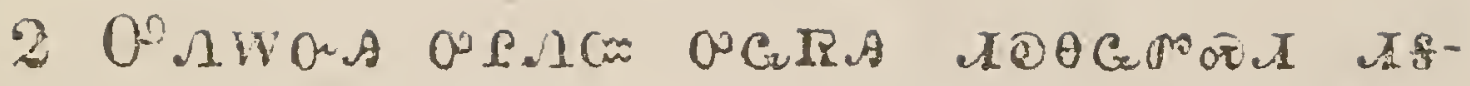

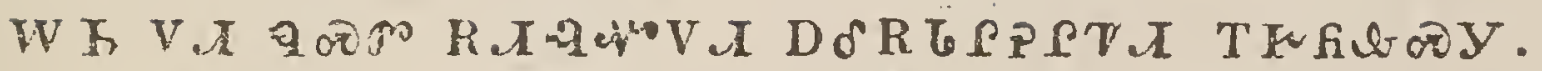
.

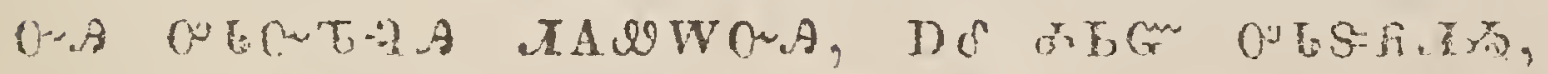

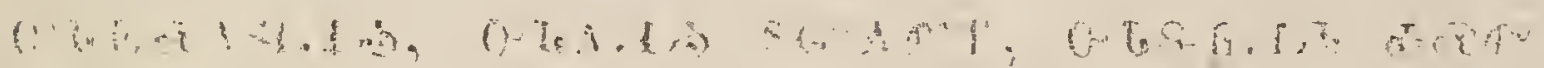
J.

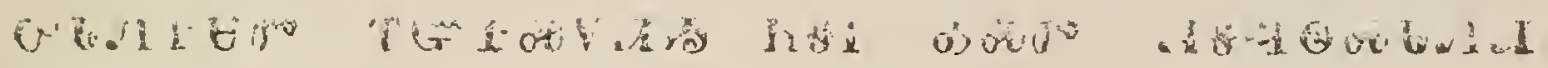
Is IXT.

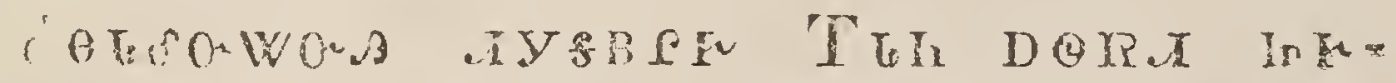

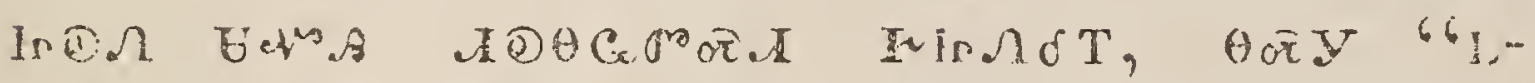

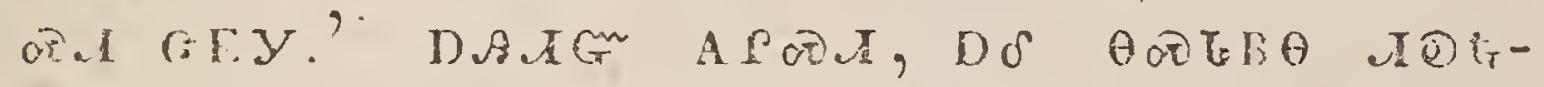
Cr. Do Ohos

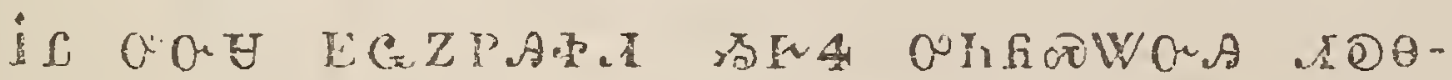

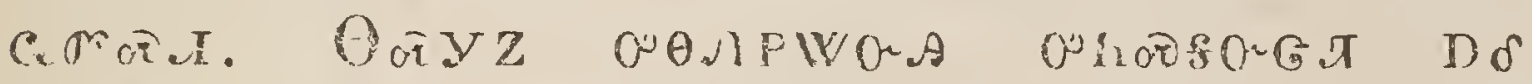

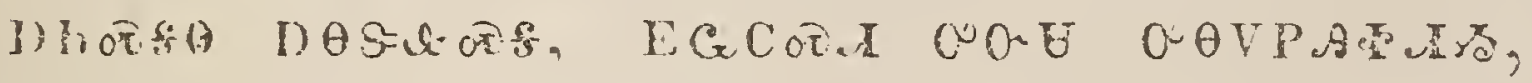

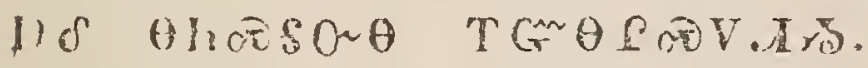

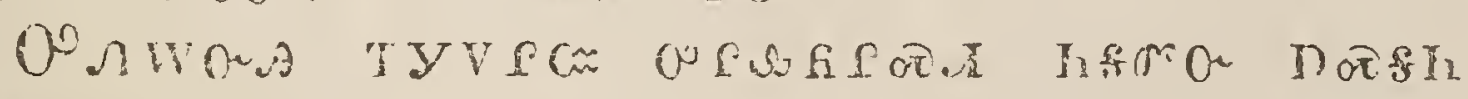

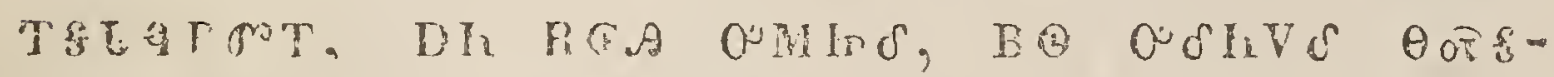

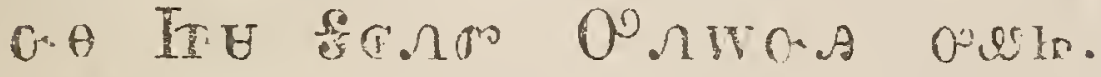

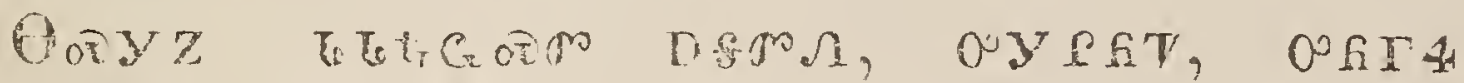

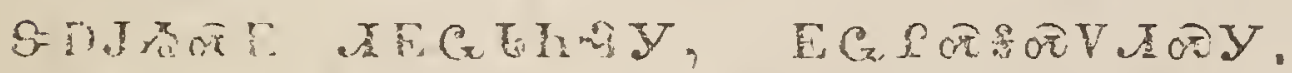

W

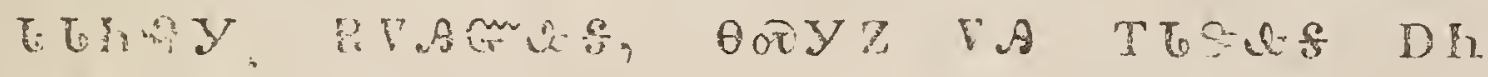

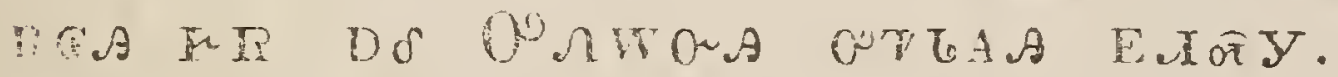

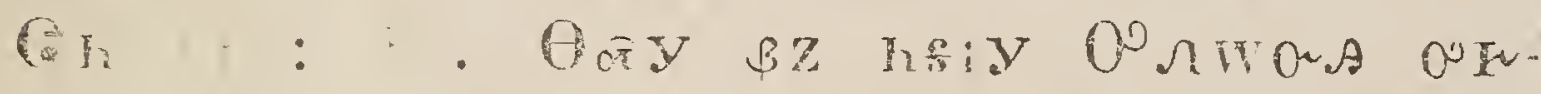

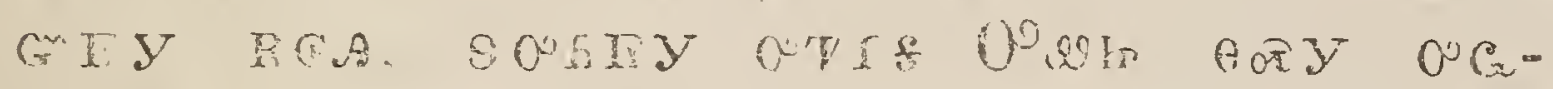

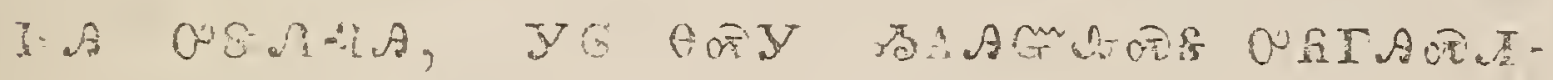

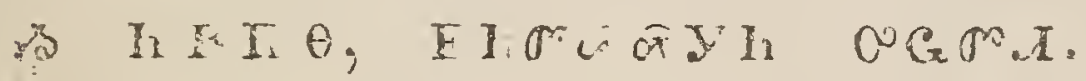




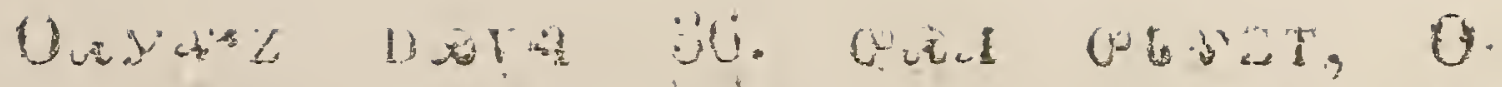

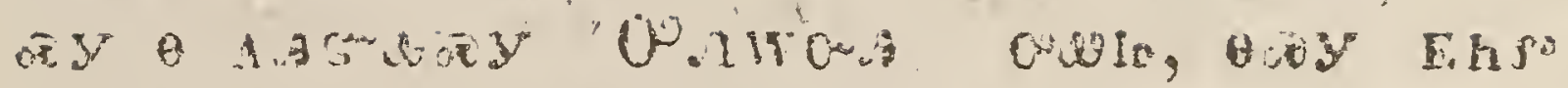

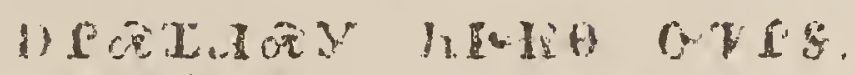

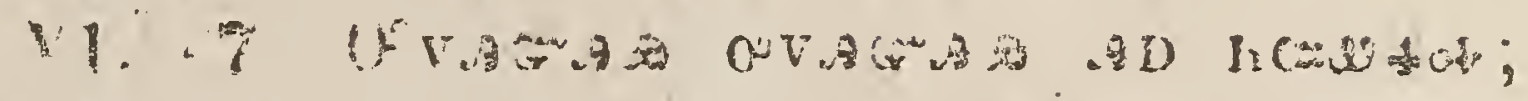

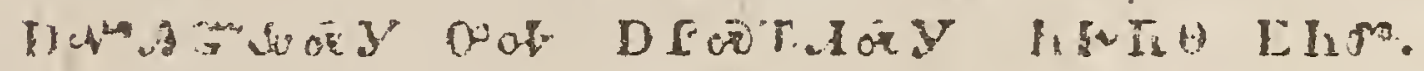

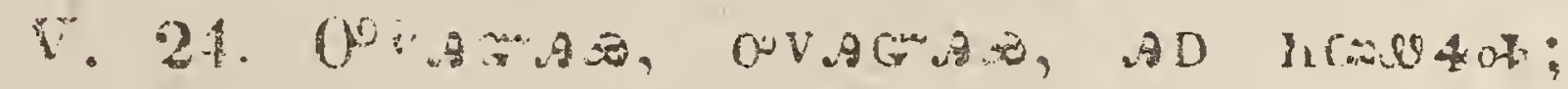

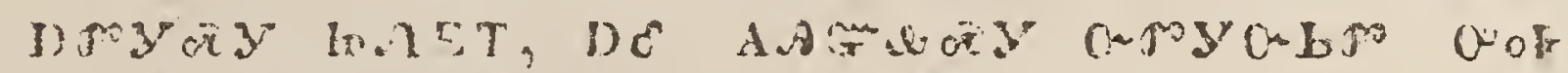

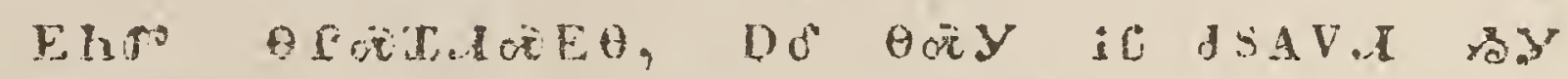

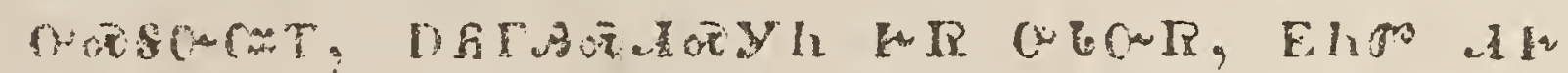

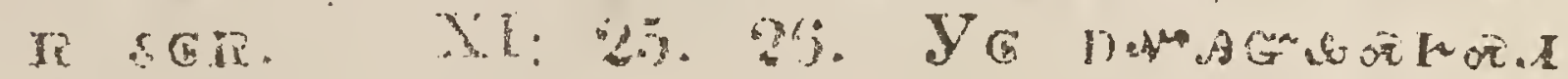

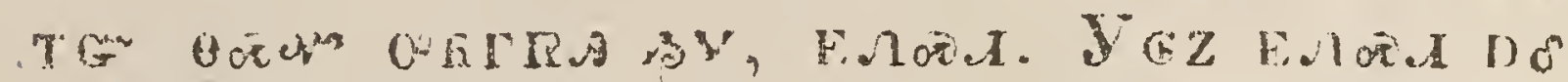
1) D) 111 ,

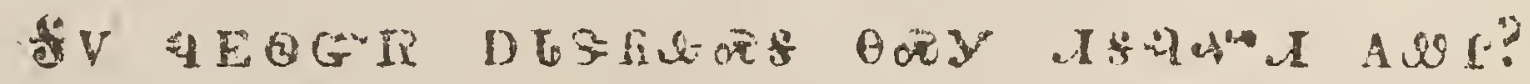

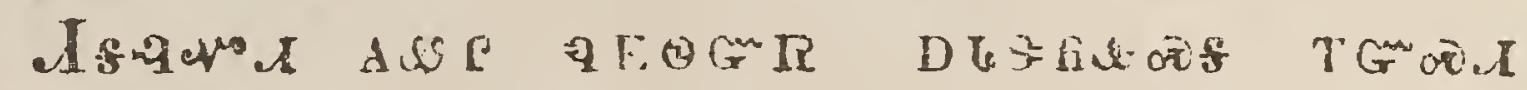

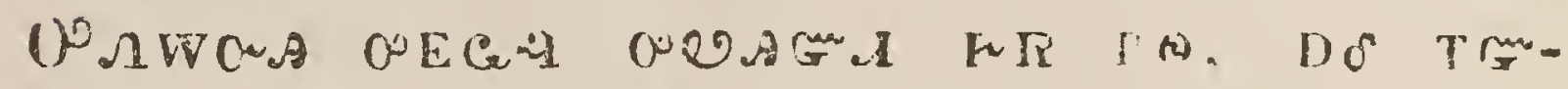

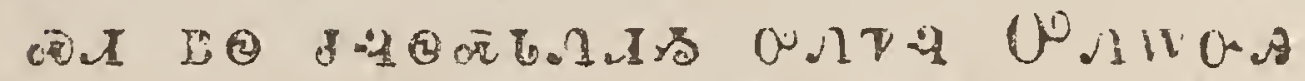

$$
\text { A } \sin ^{+\infty} v \text {. }
$$

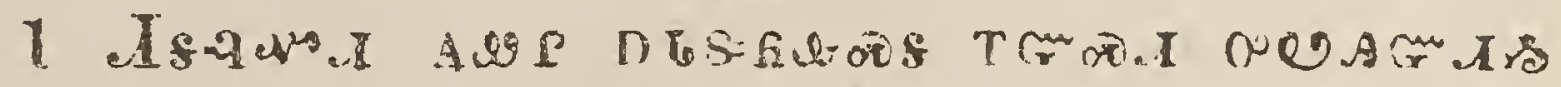

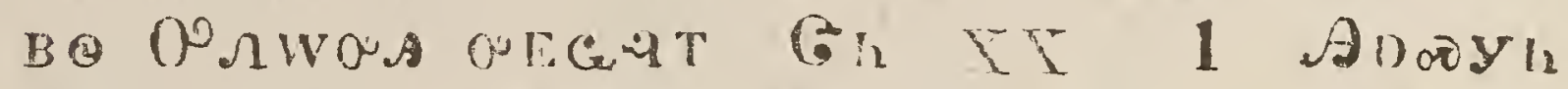

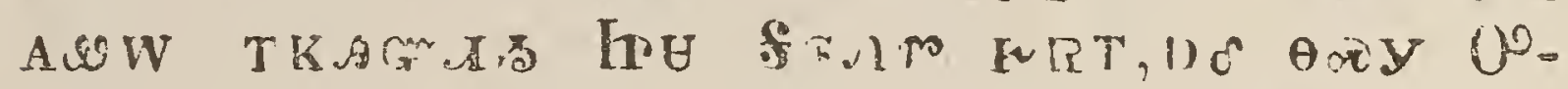

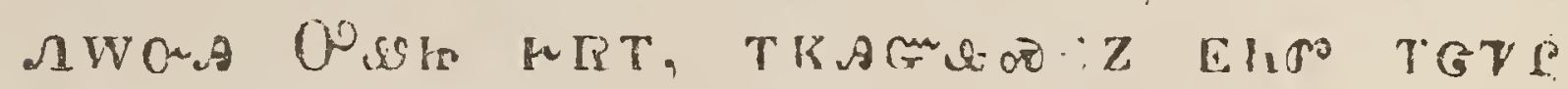

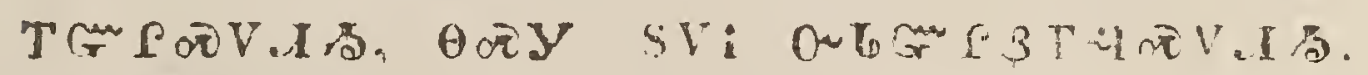

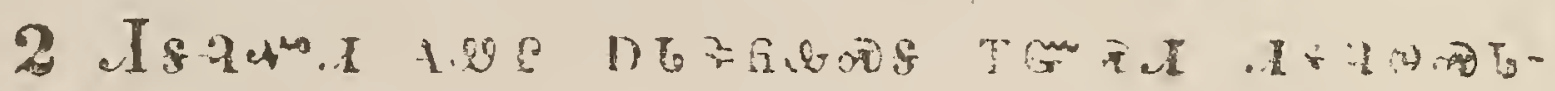

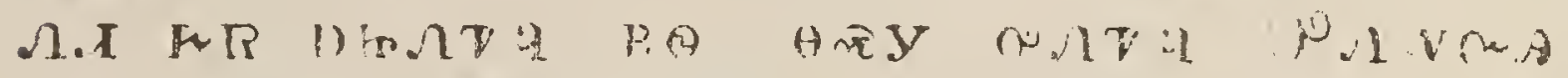

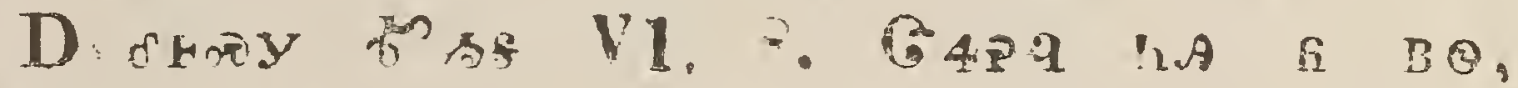

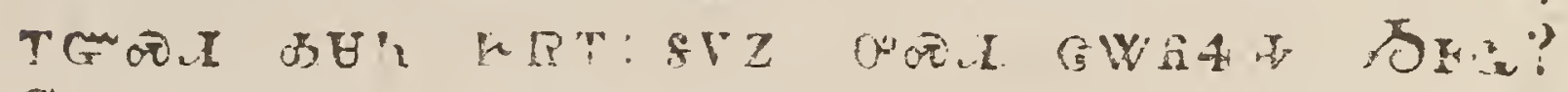
SGA pevo

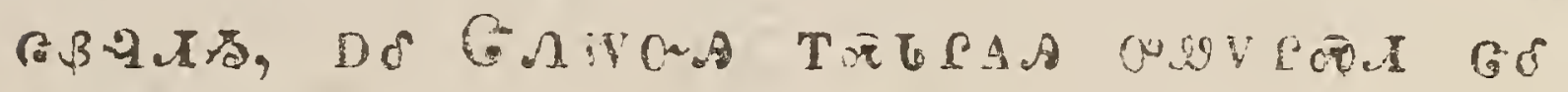

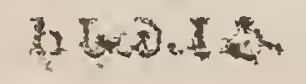


Kro IX:

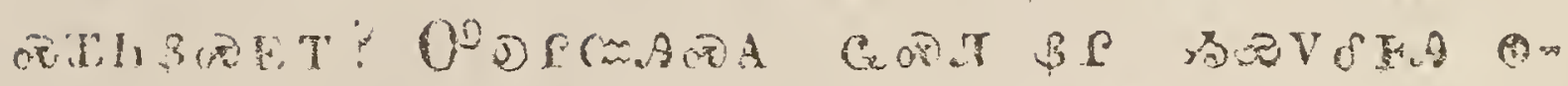

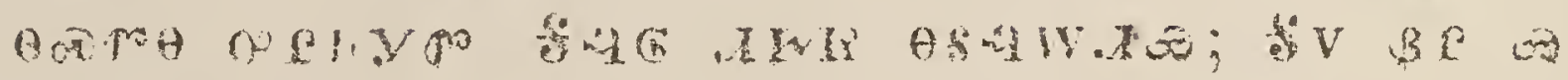

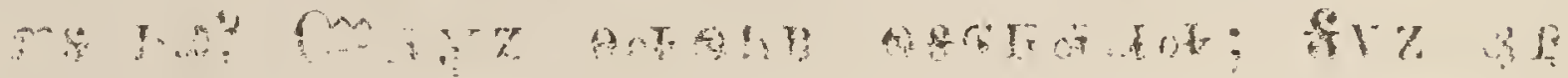

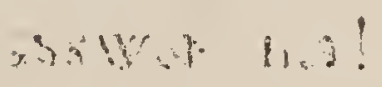

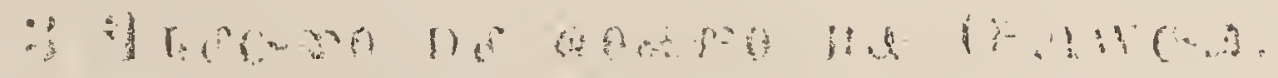

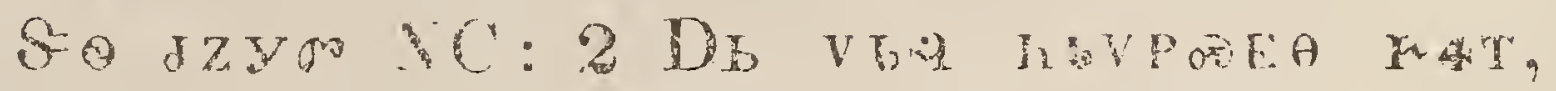

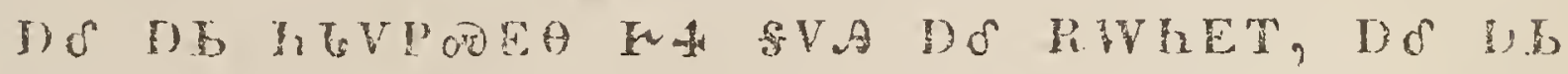

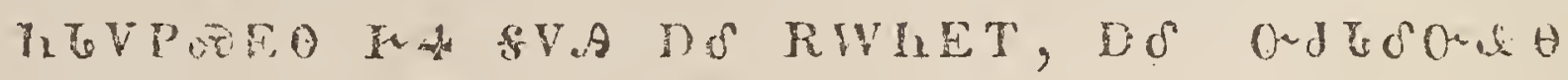

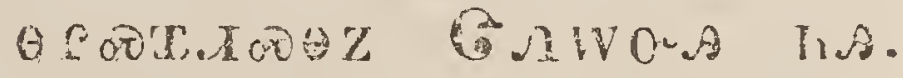

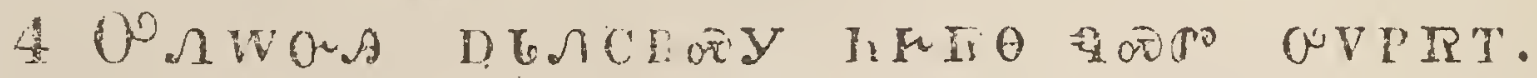

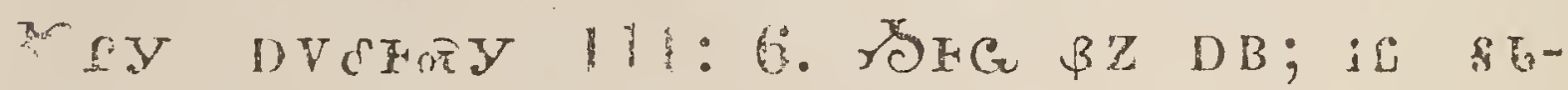
ACBOEY ДY: RIITOWOU II R

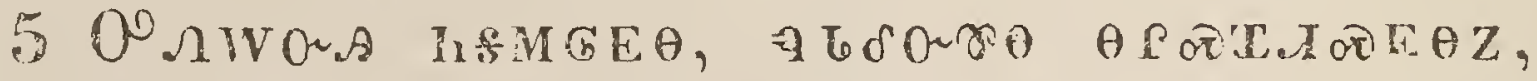

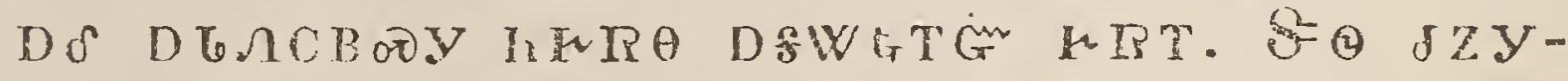

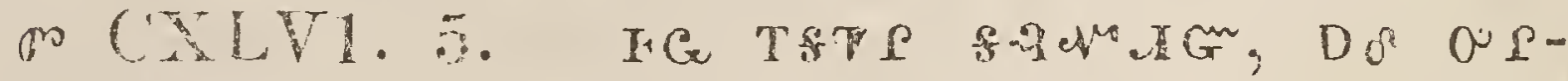
IYIG; h\&MGE

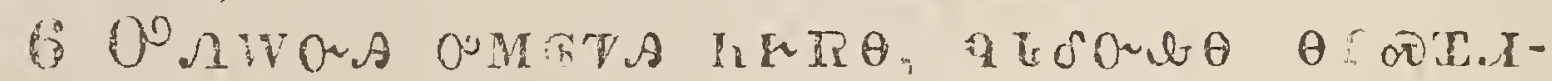

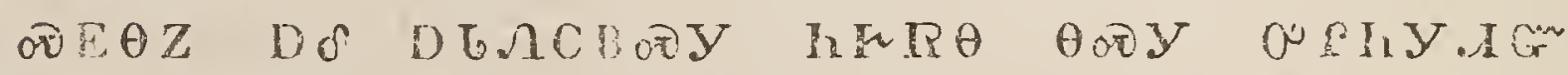

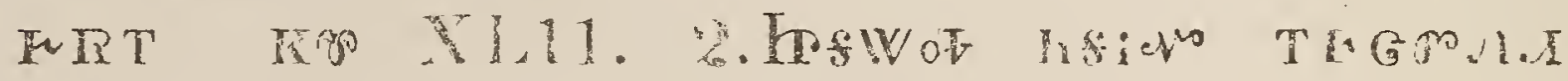

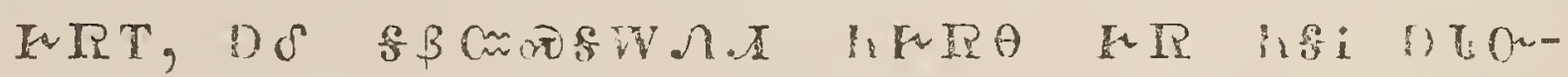

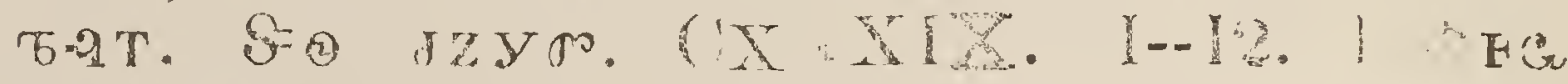

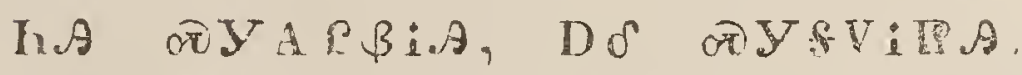

2 LA ARWOF

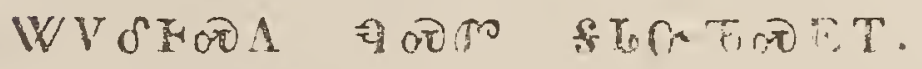

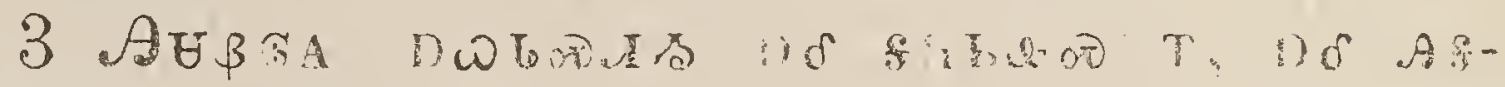

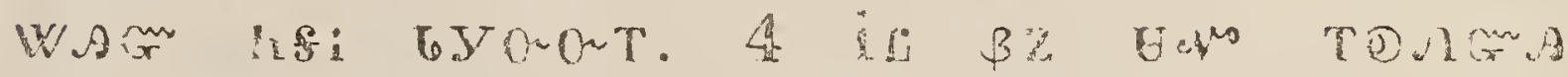

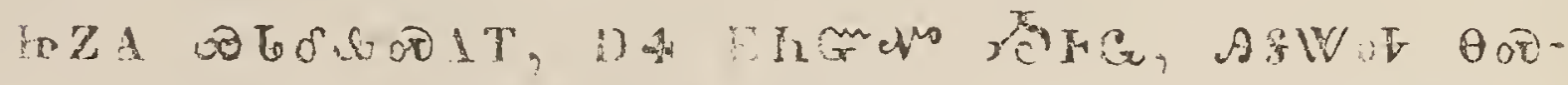
Y ILAM 


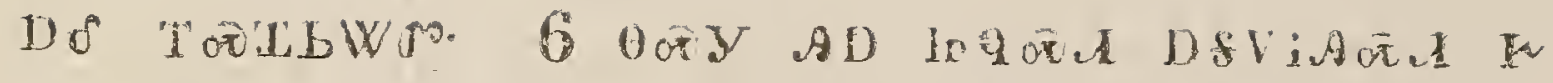

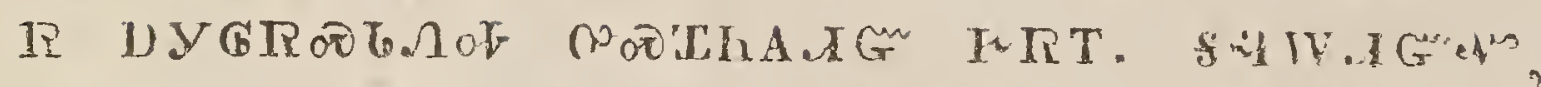

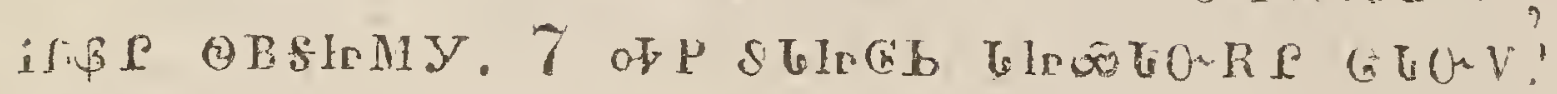

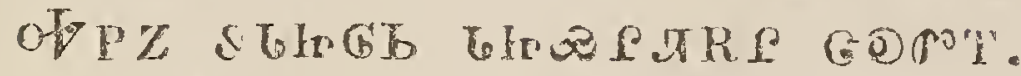

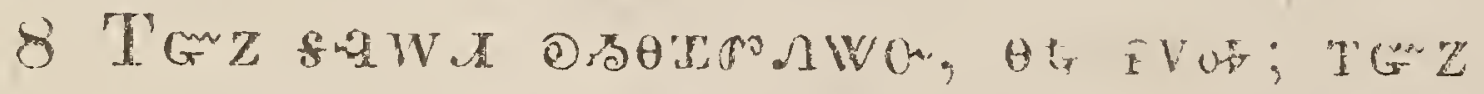

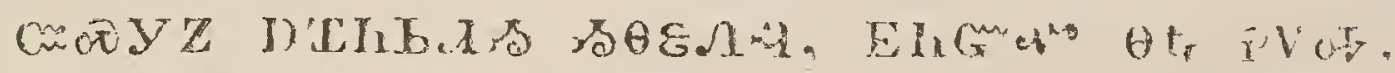

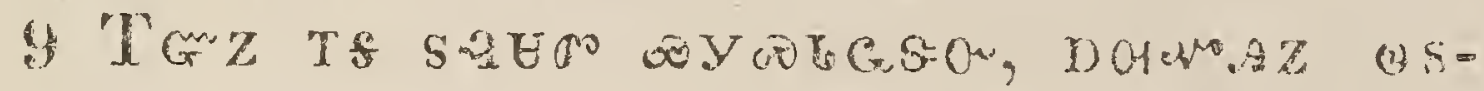

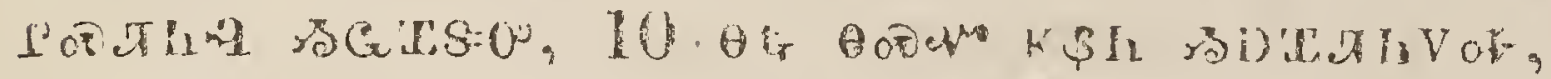

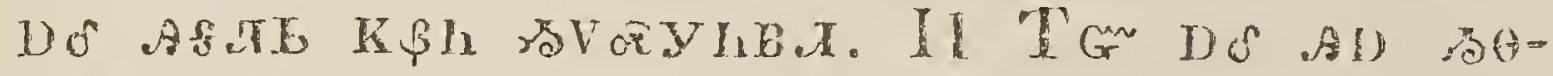

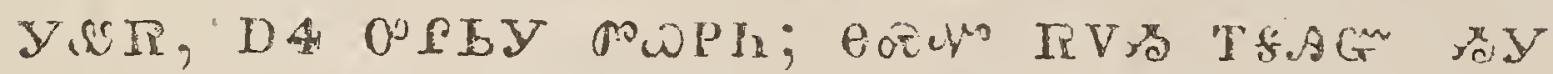

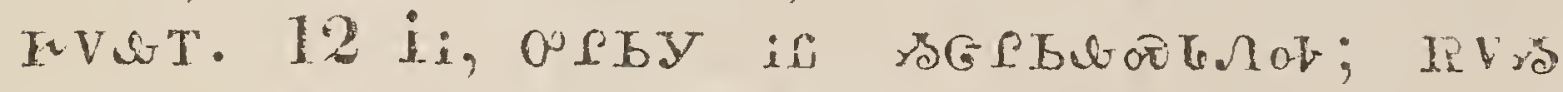

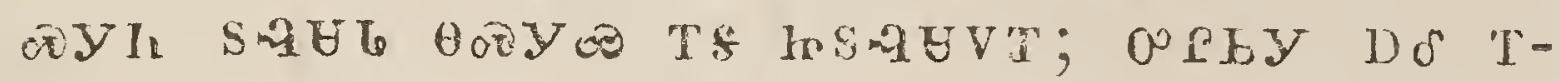
คf

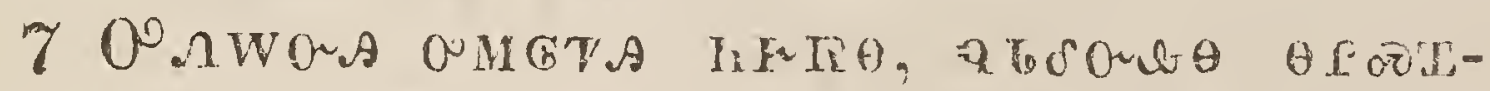

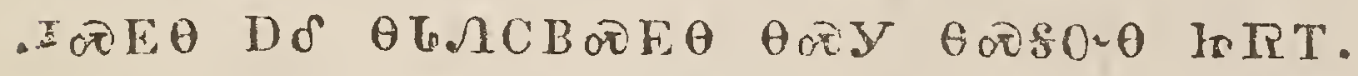

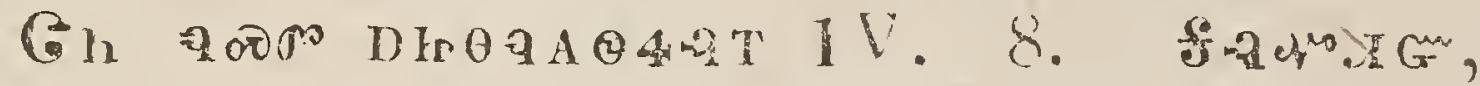

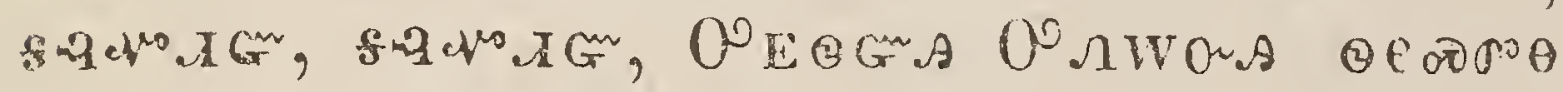

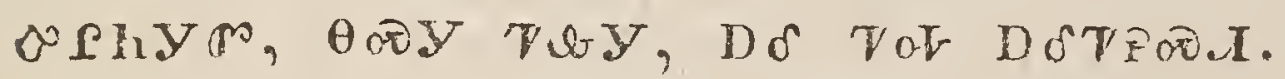

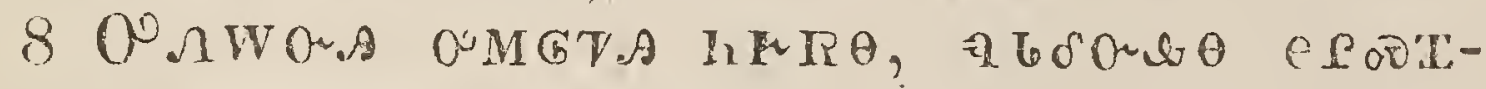

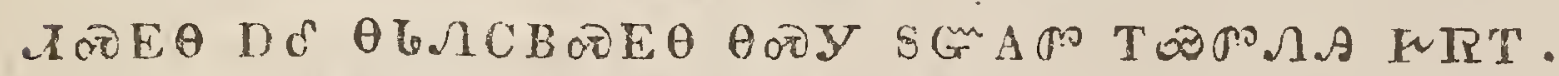

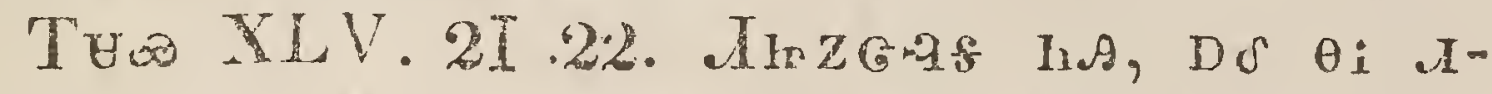

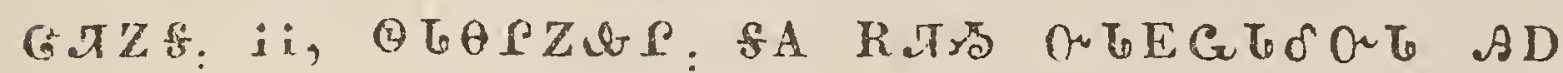

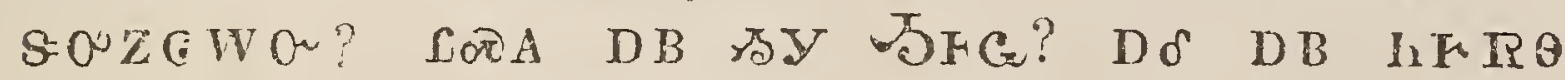

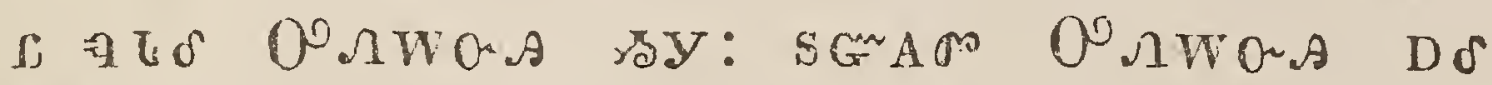

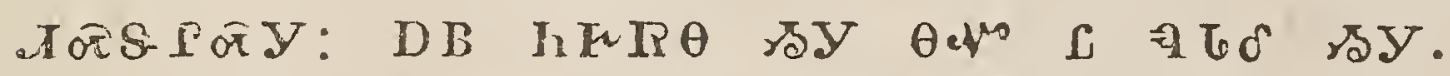

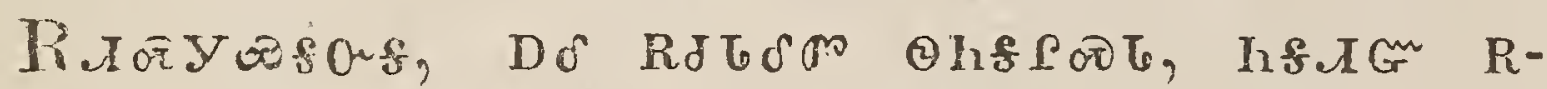

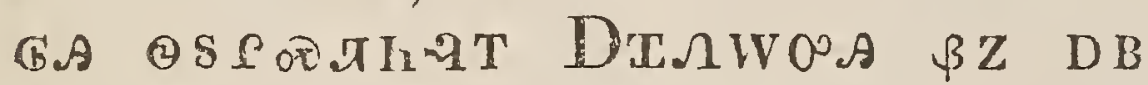

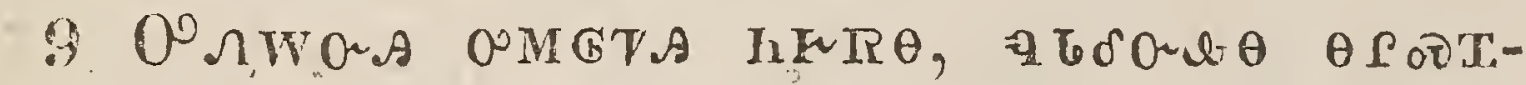

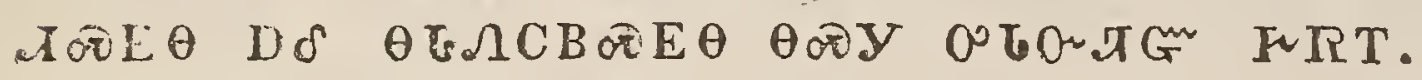


11

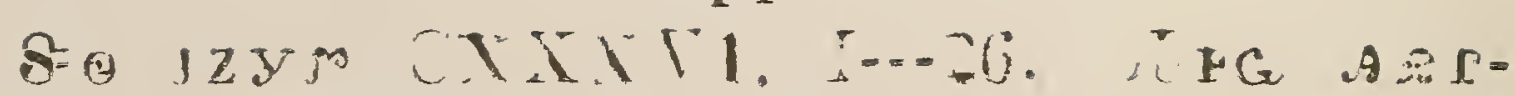

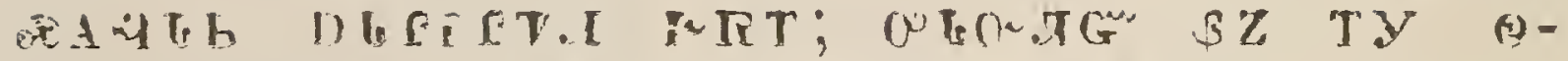

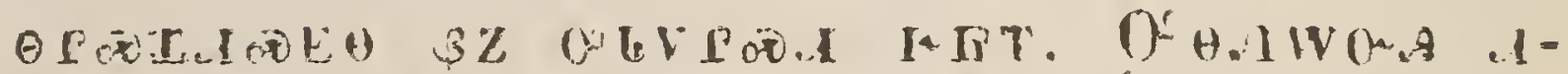

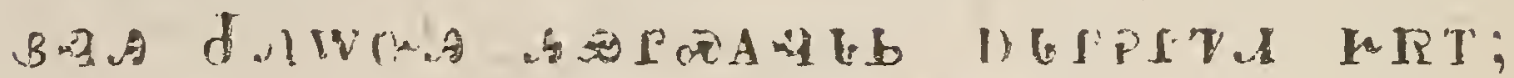

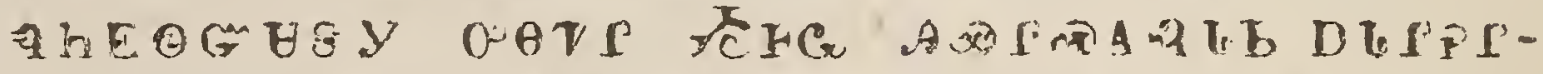

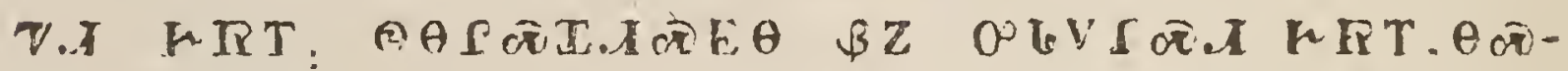

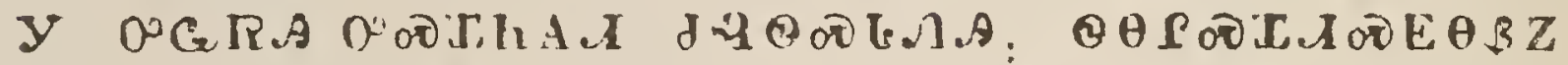

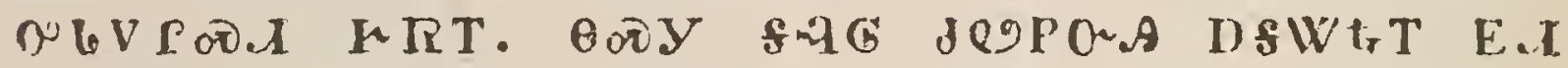

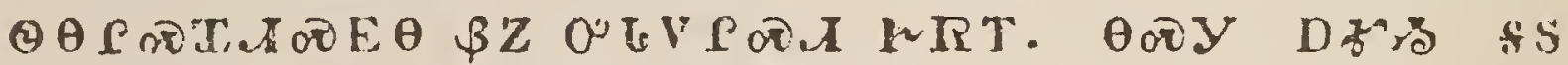

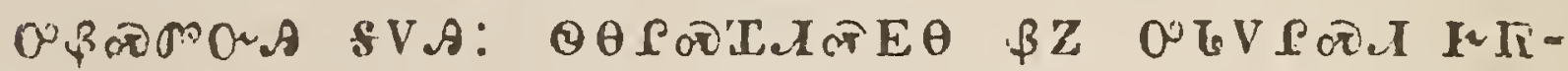

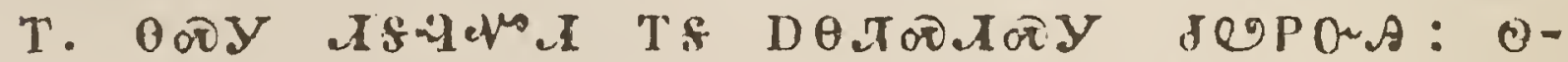

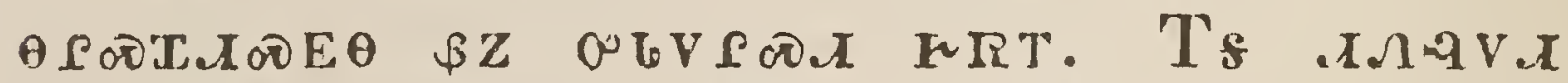

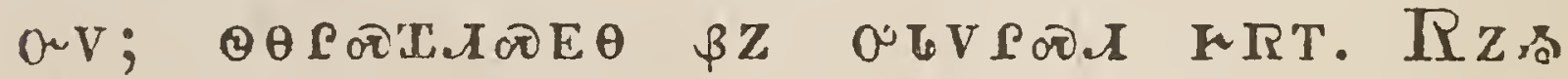

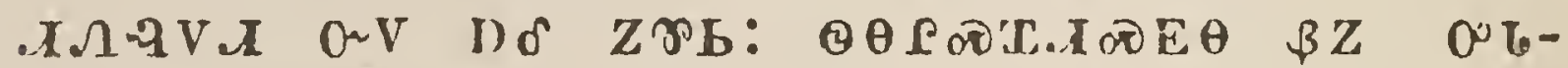

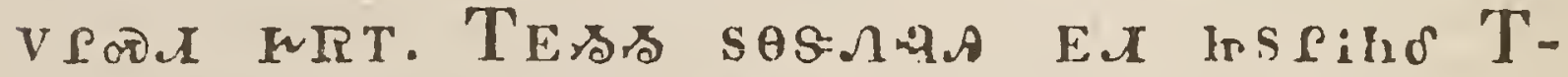
Ir.

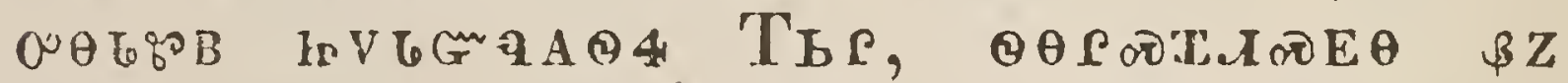

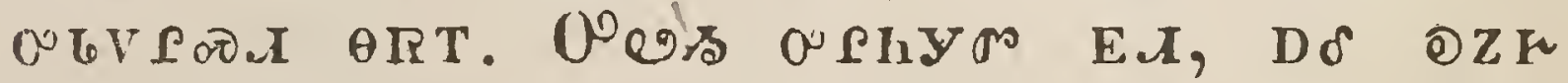

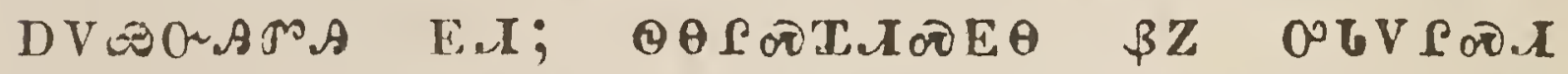

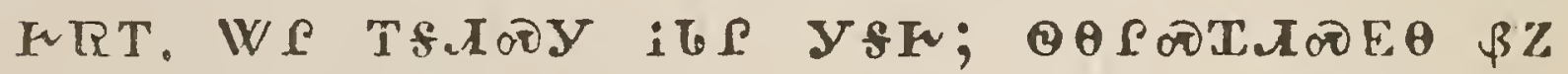

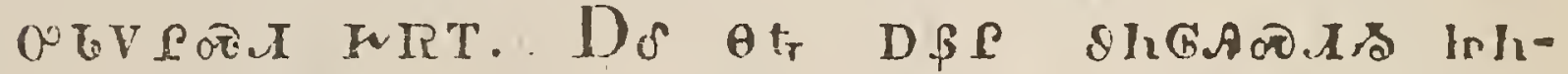

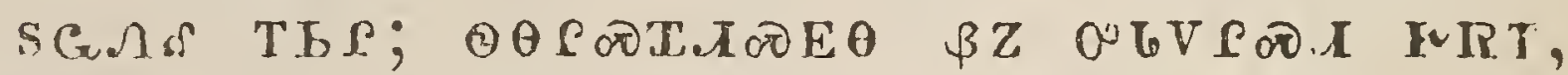

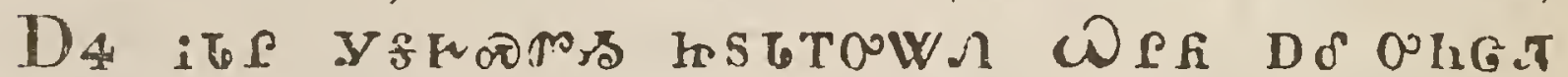

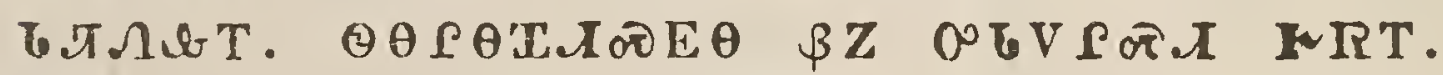

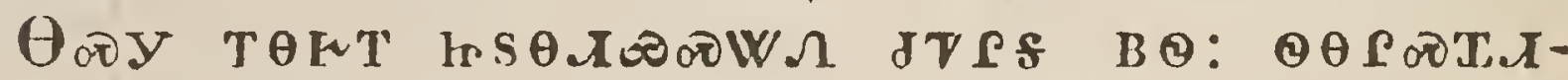

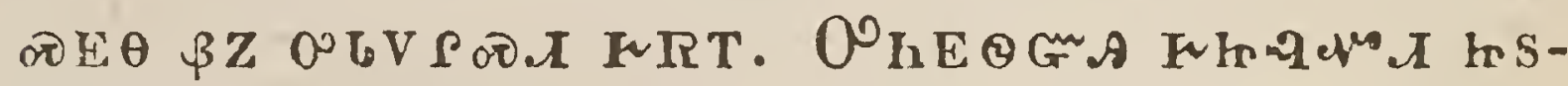

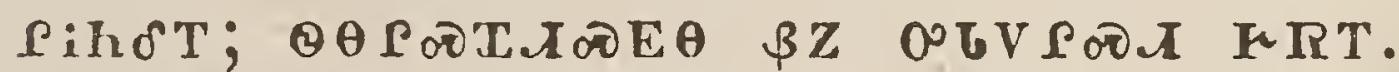

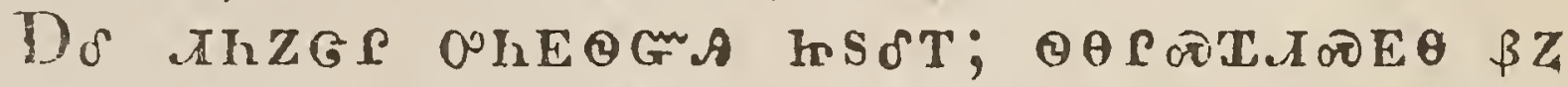

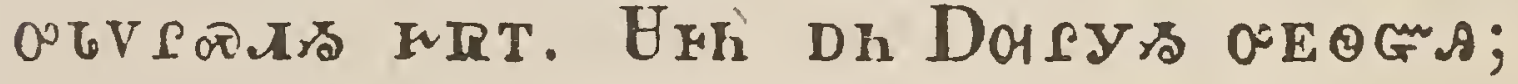




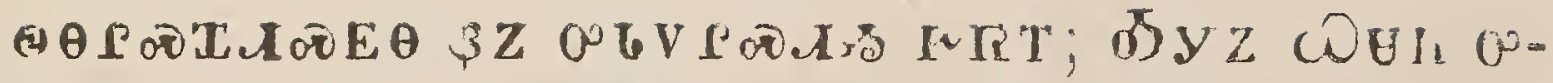

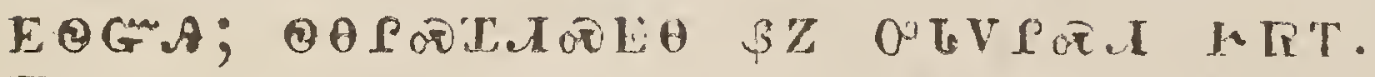

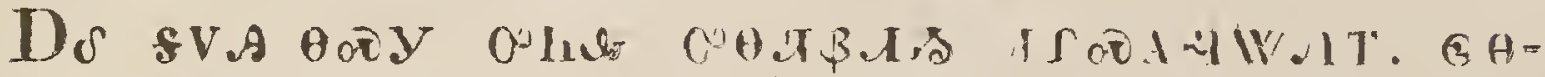

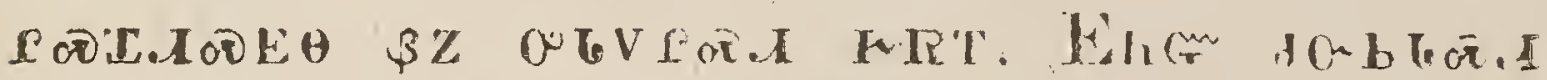

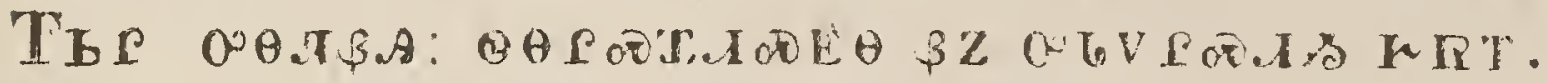

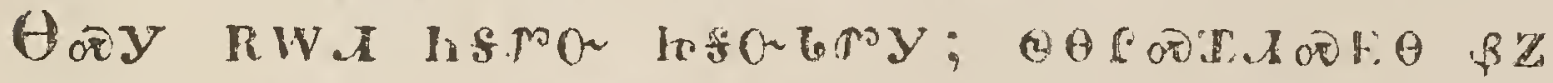

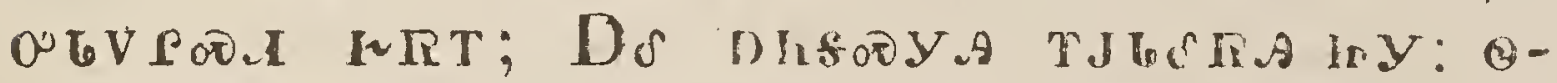

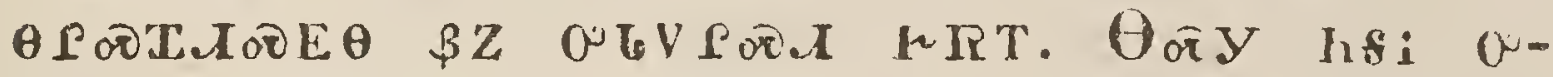

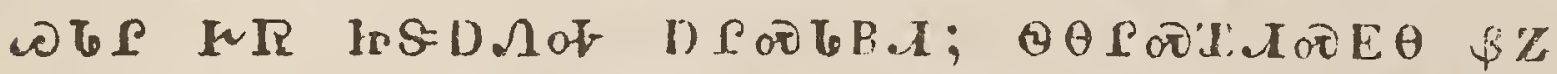

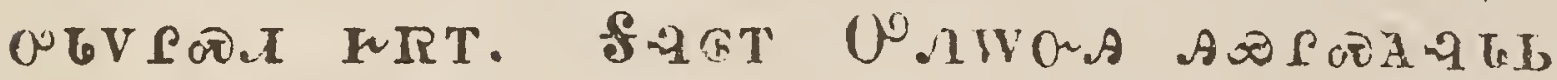

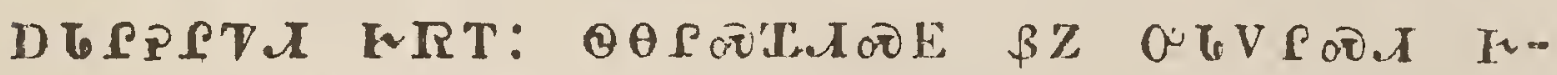

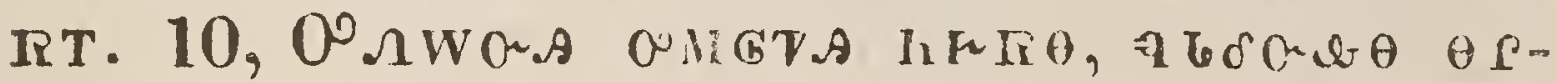

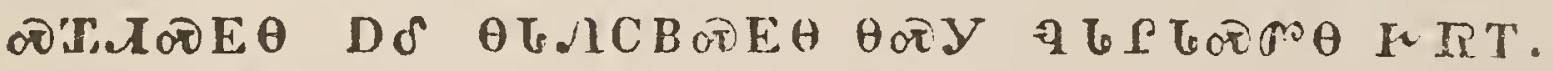

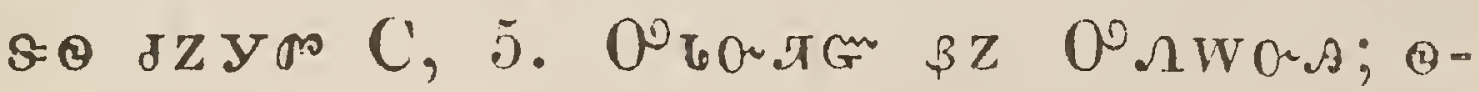

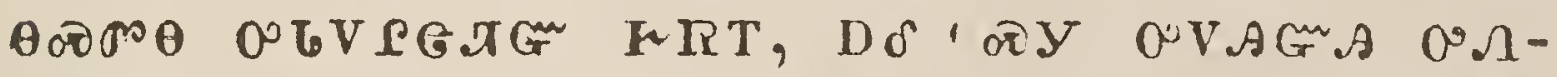

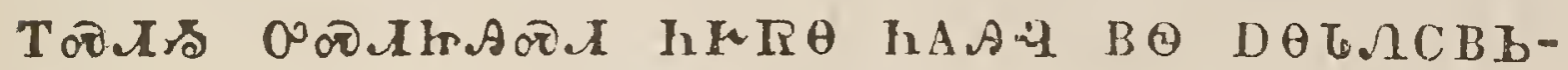
RT. Drogr, $V$.

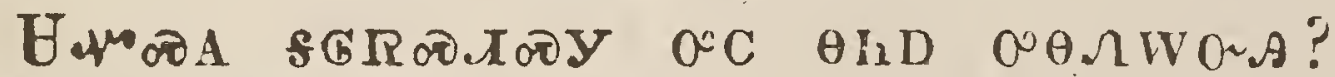

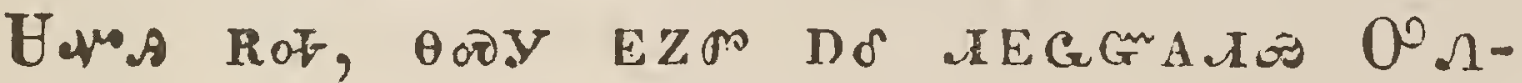
WOUA. A $\rho G^{a r} V A$.

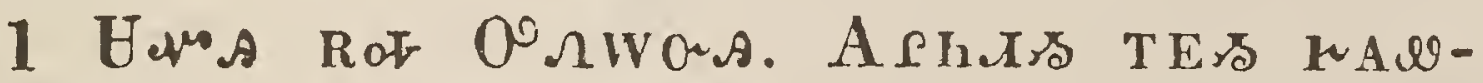

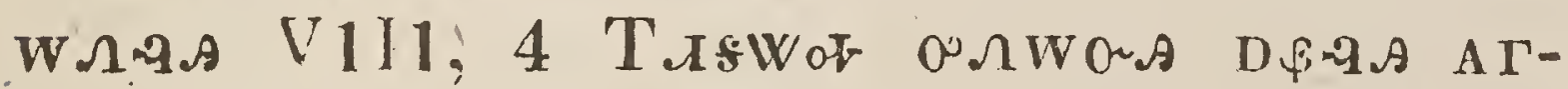

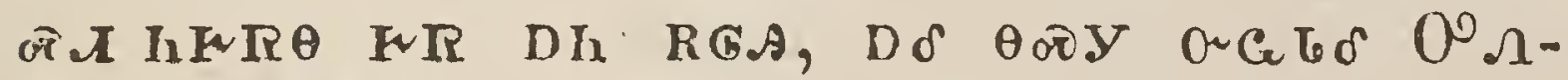

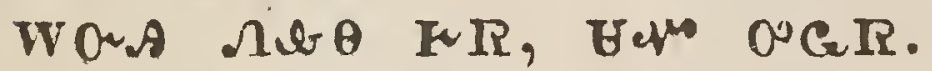

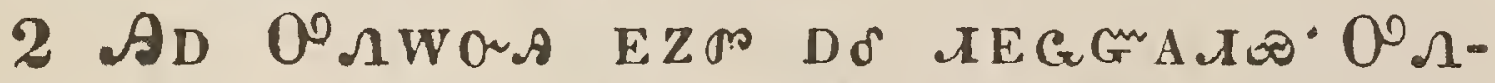

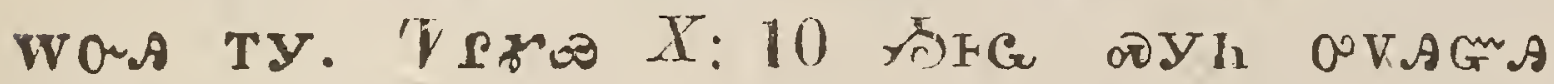

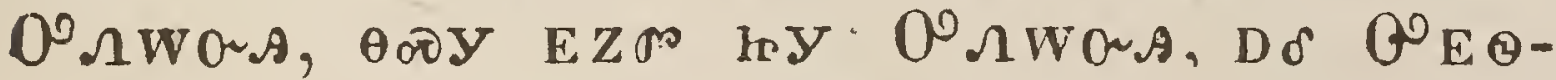
C $A \theta 000^{\circ} \theta: \tau G$ G

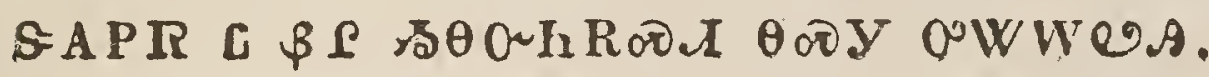




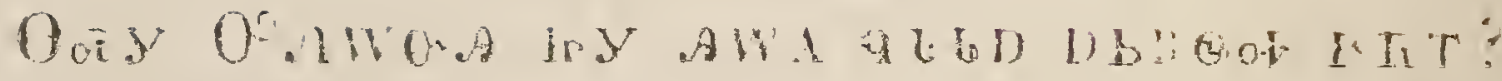

O. IWGA R R B A

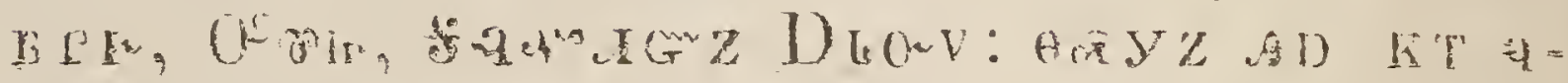

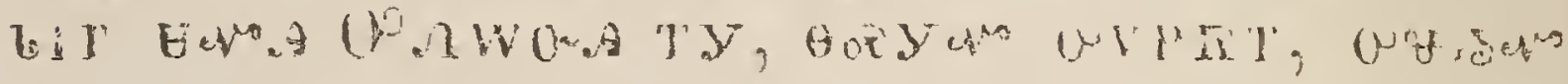

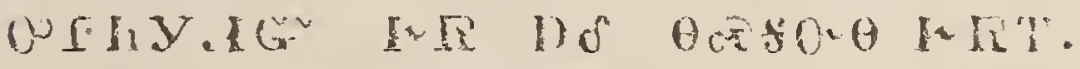

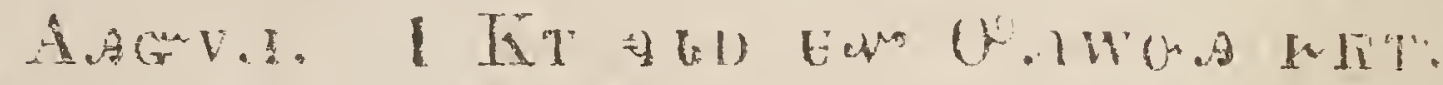

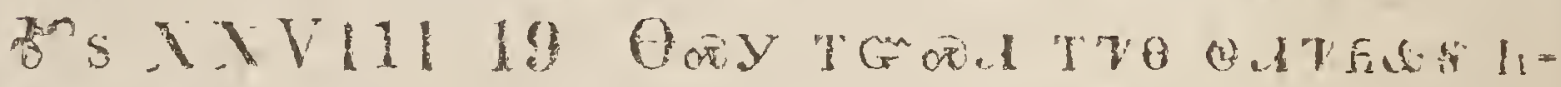

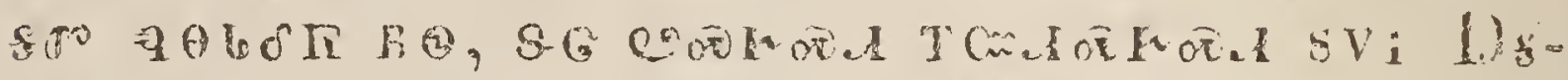

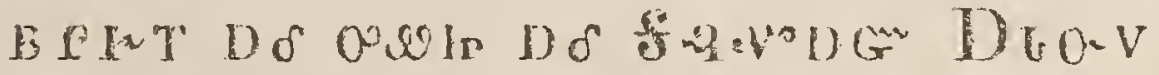

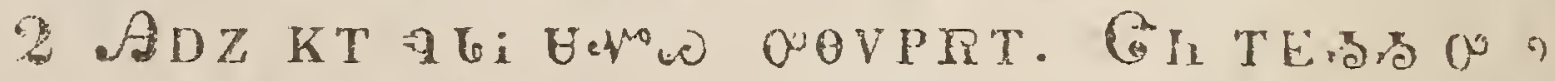

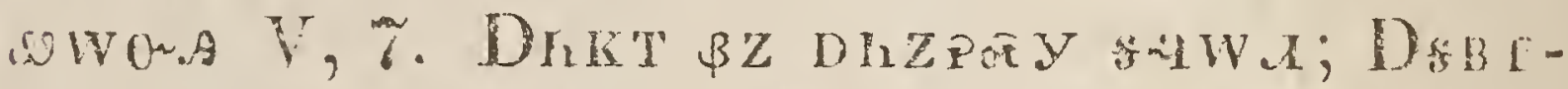

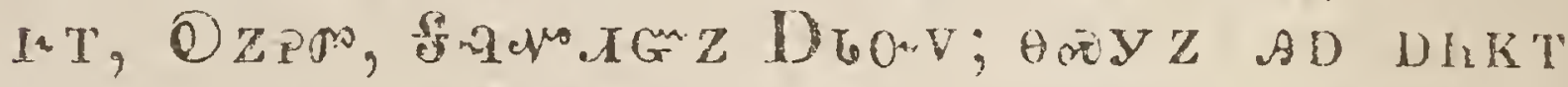
FT Eevers $\because A D Z$ KT च

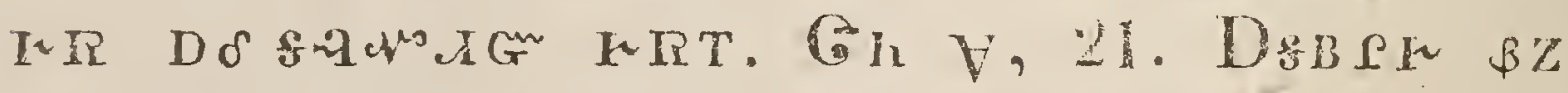

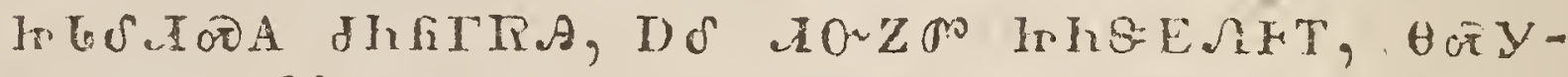

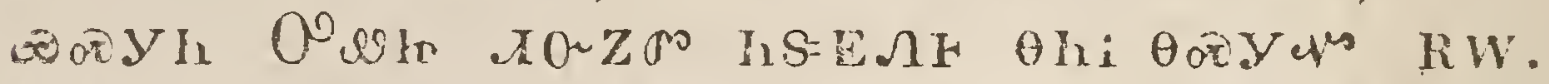

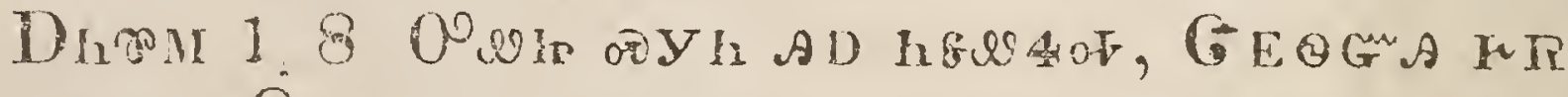
GOOYG OЛNOUA LAAA DO HAAA SGJA; SGA

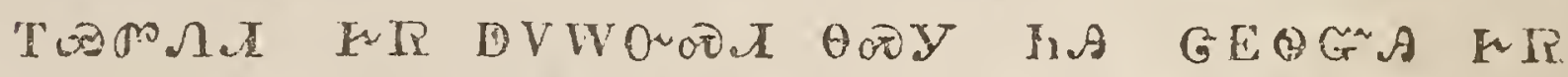

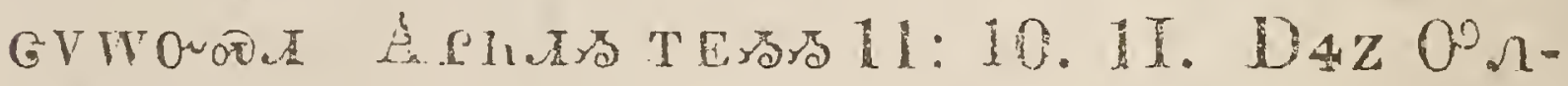

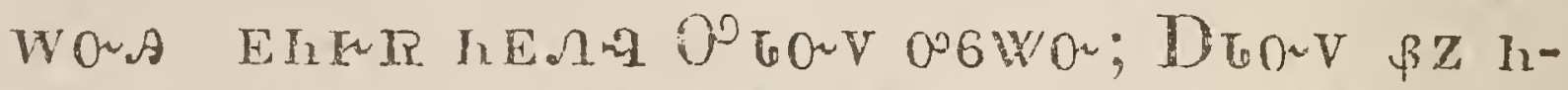

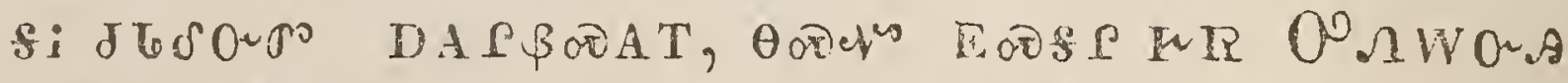

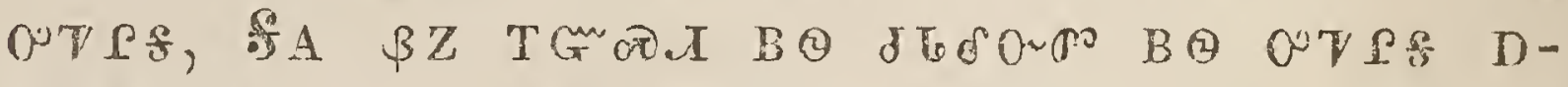

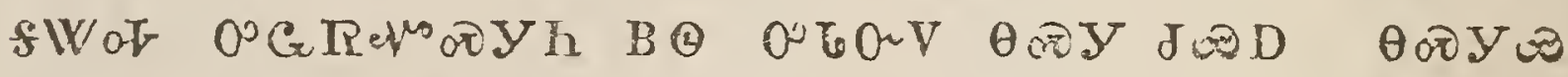

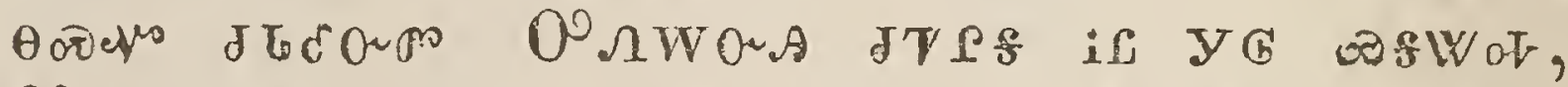
DAWOUA WUEV OCER. Do DB IL DGON REA

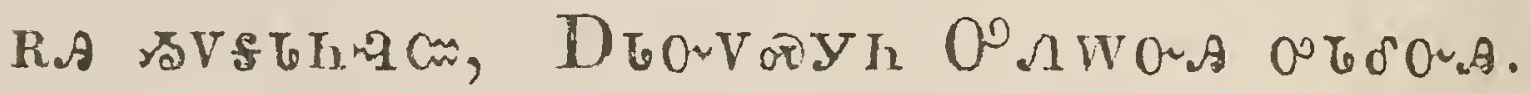




\section{7}

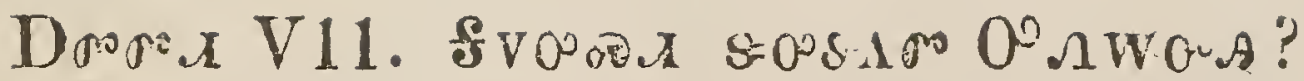

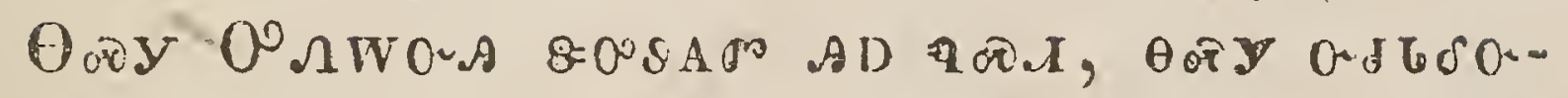

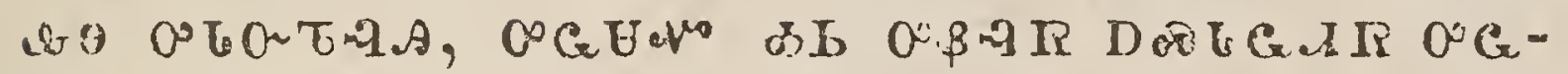

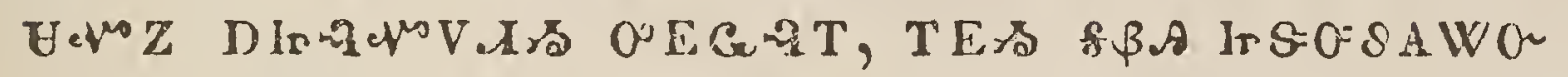

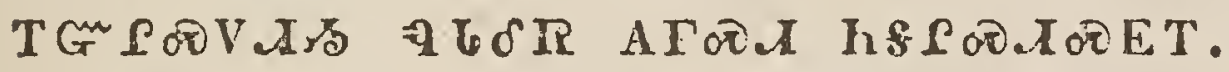

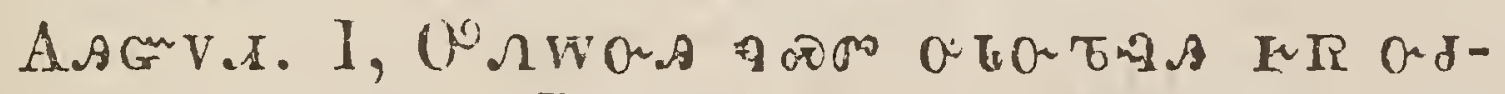

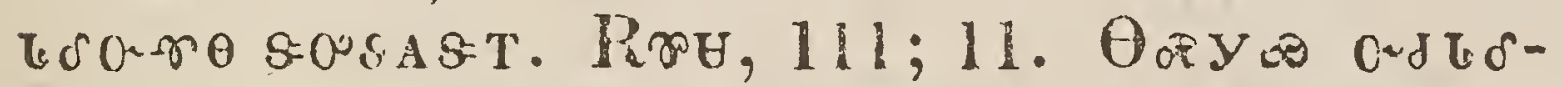

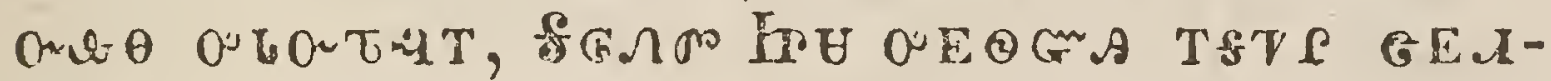

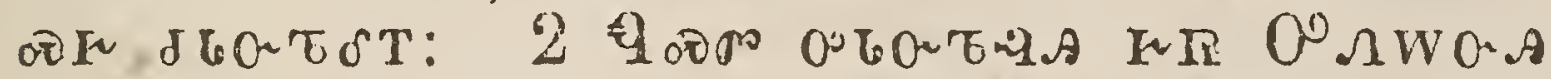
0 CUy бठ

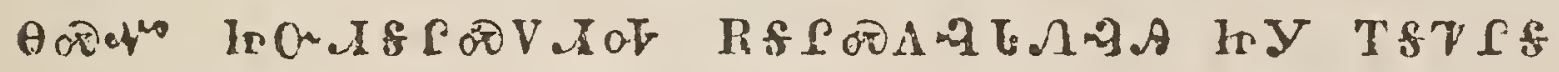

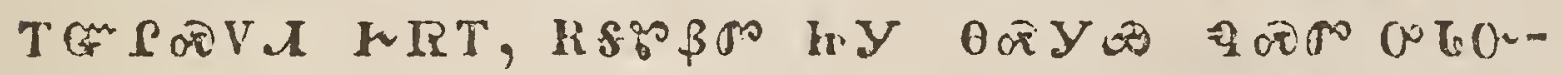

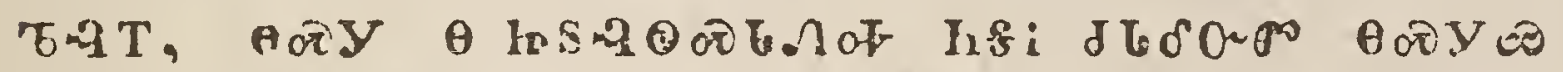

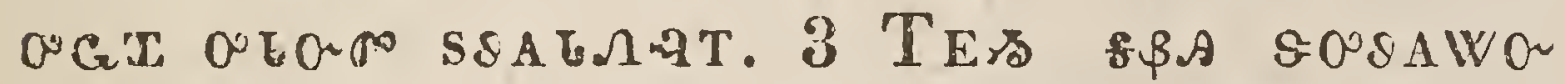

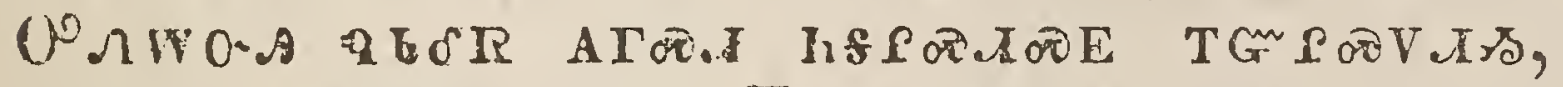

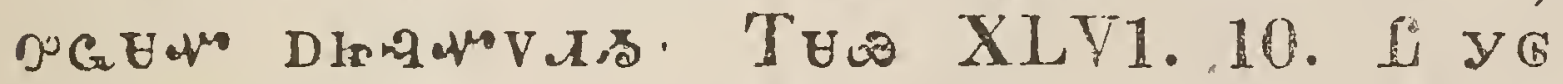

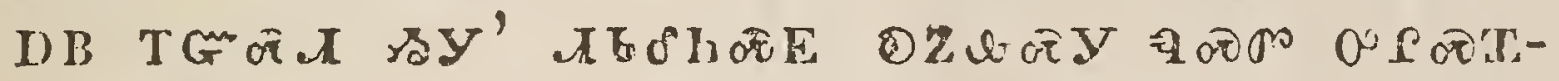

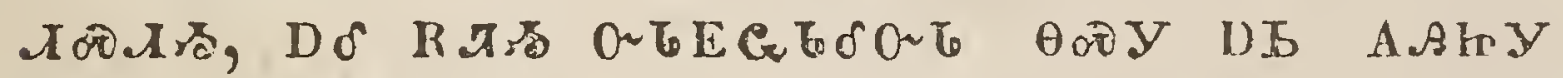

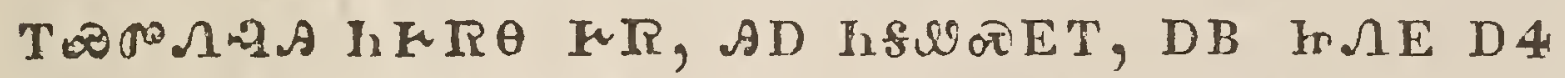

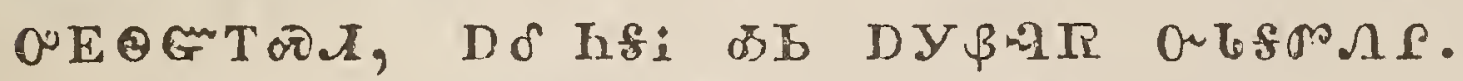

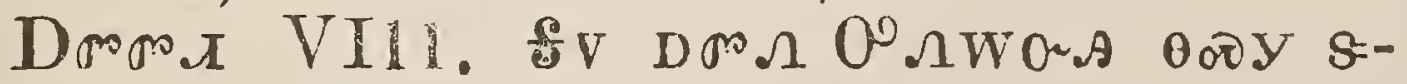

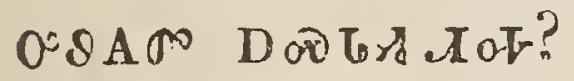

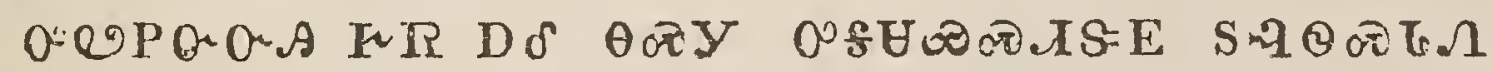

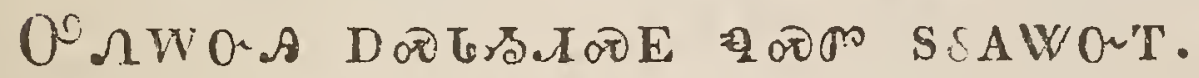

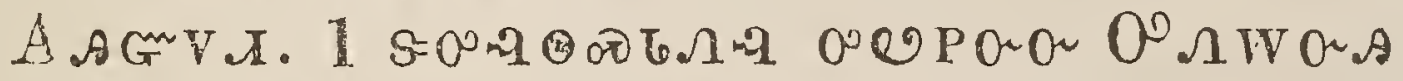
ก

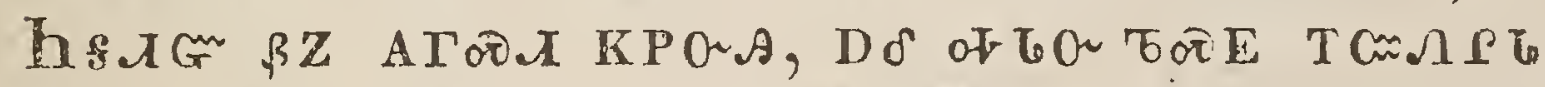
OT. D AWO ON IWO 
ET. SIR 1V: 3. Do DActs fur

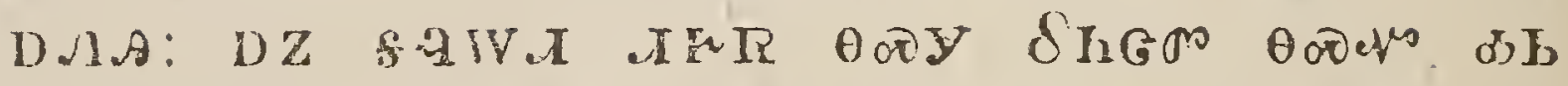

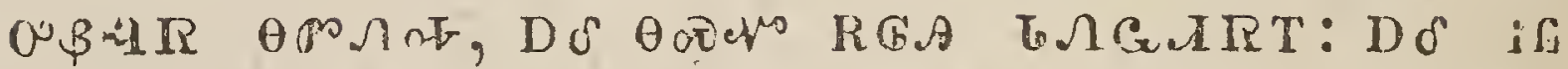
УGB AODY COSI COBAOE

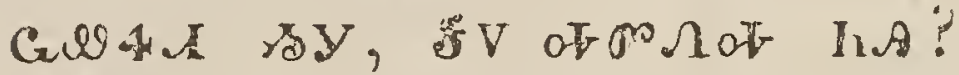

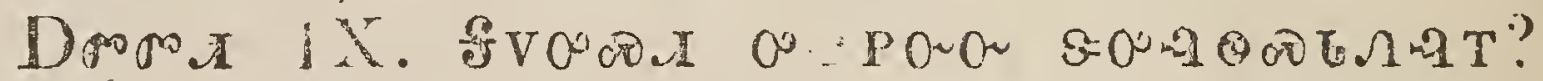

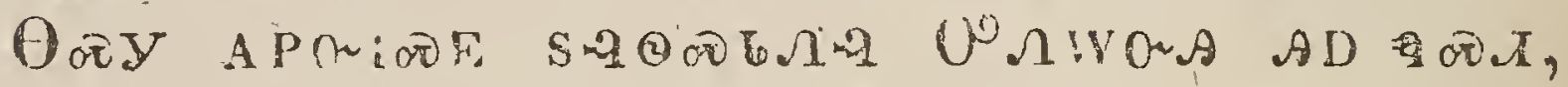

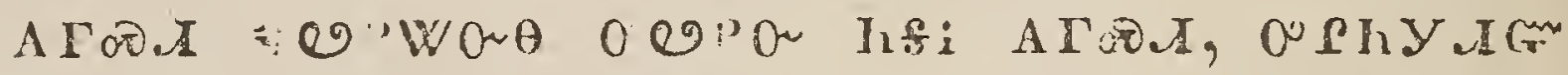

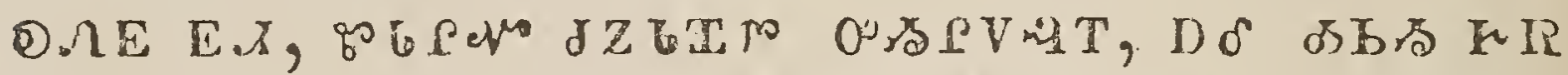

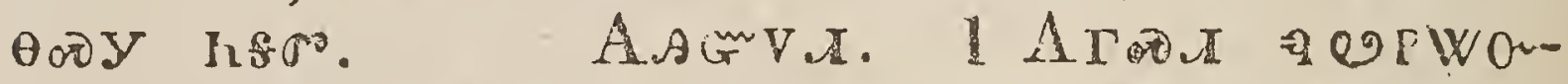

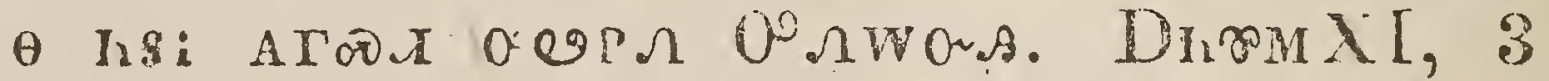
$A A G \Lambda$ IUR TPIOOE TVRS ONAWOA D.IE EW'-

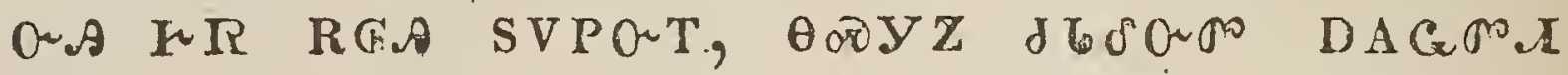

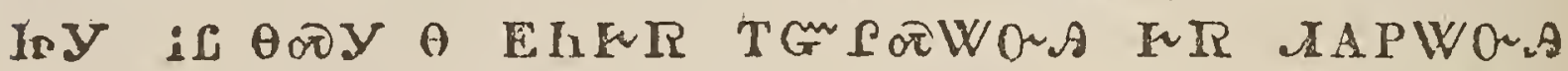

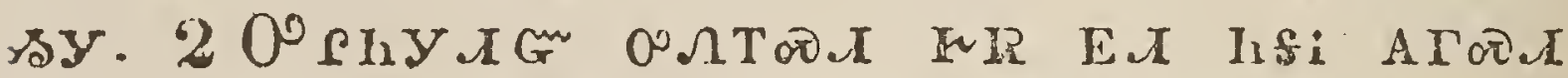

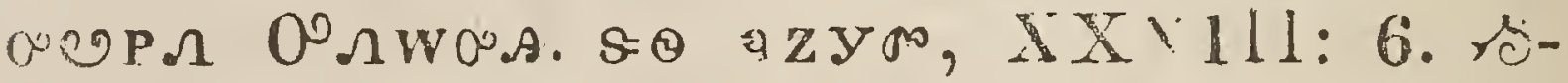
HE DЛE EA IAPOU च

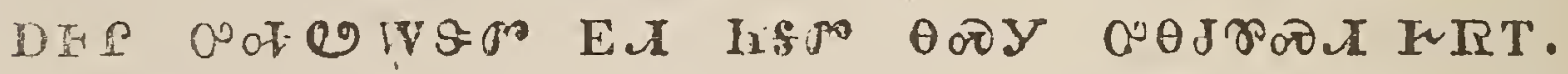
З

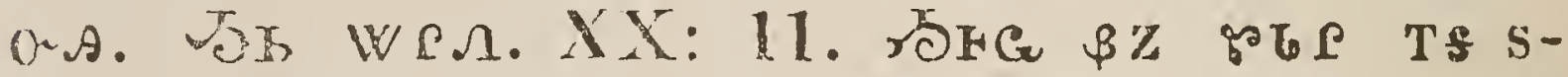

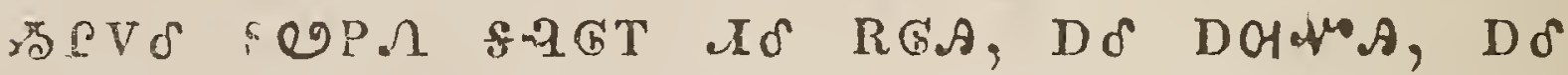

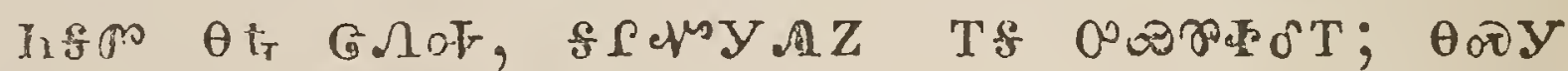
TG OD.

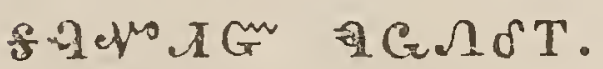

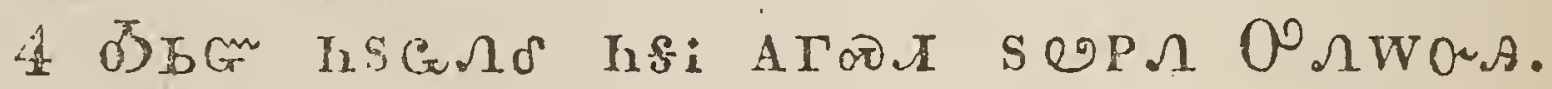

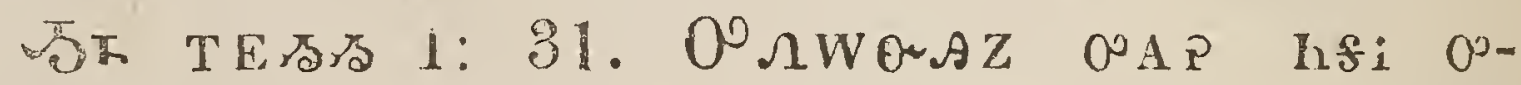

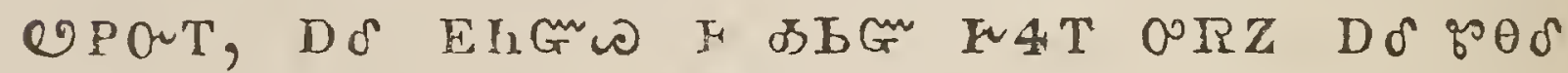

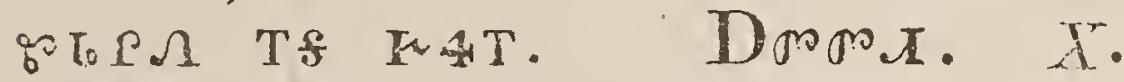

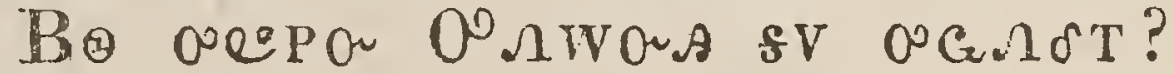




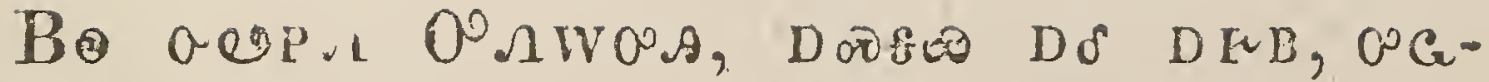

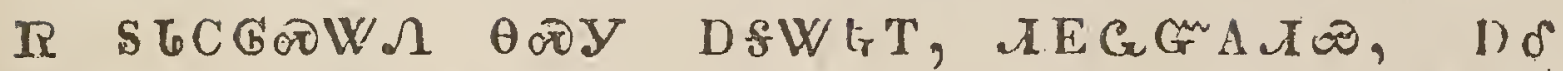

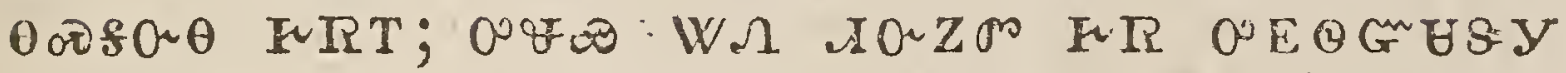

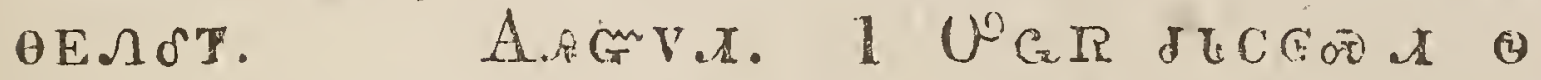

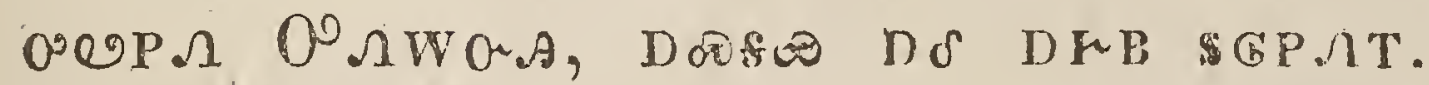

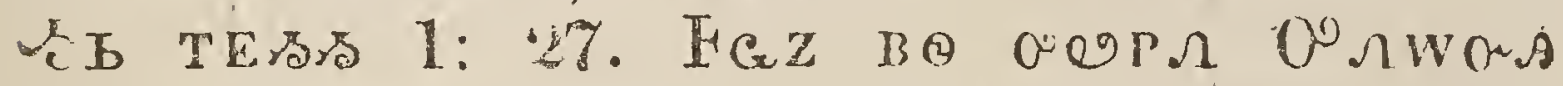

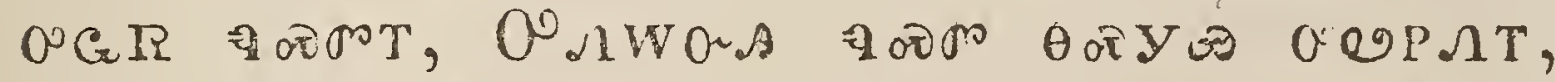
DOO\&̊ Do DI B

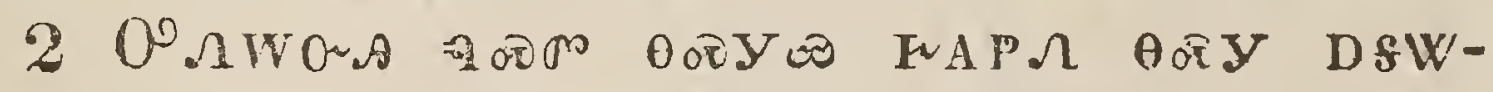

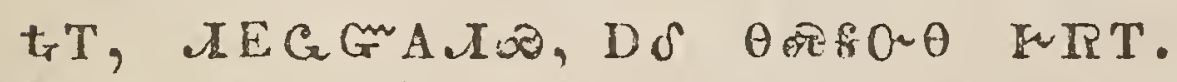

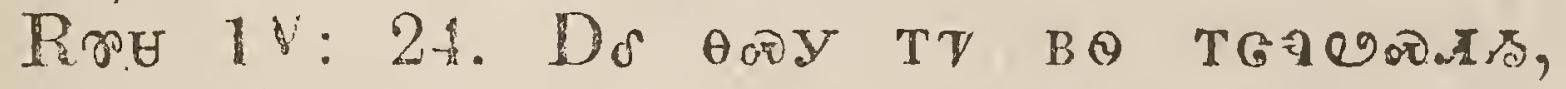

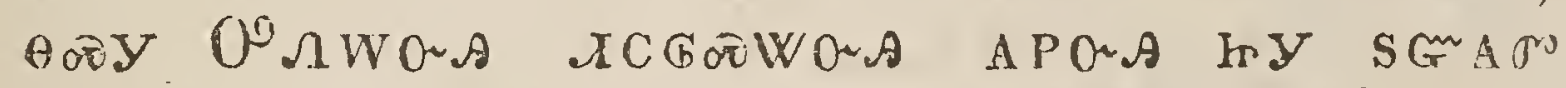

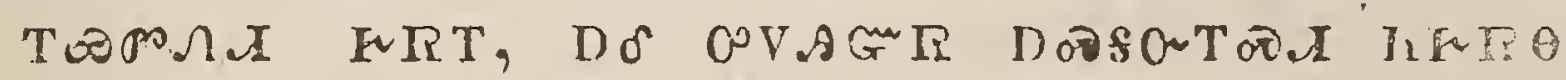

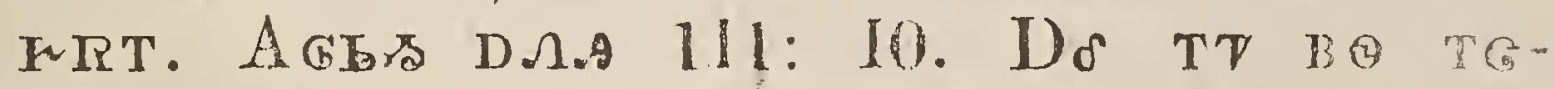

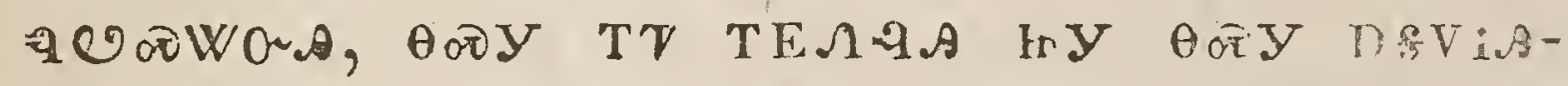

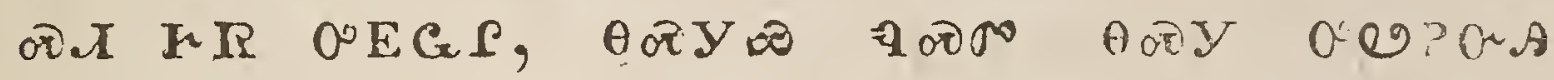

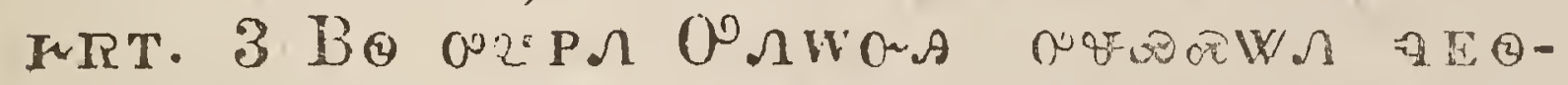

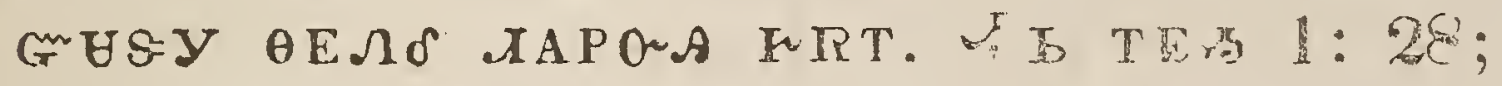

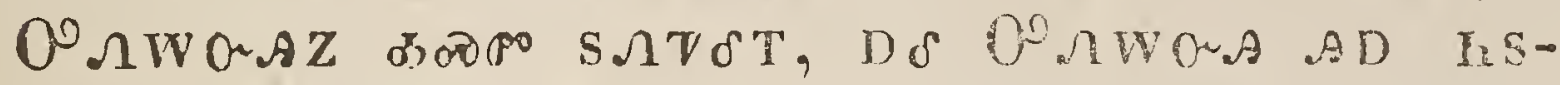

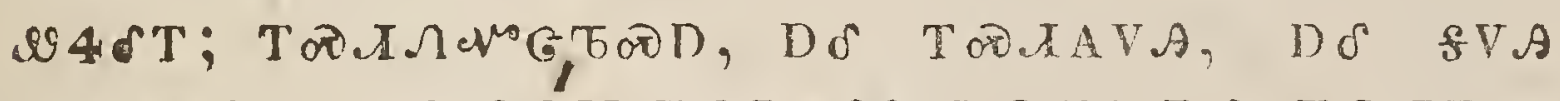

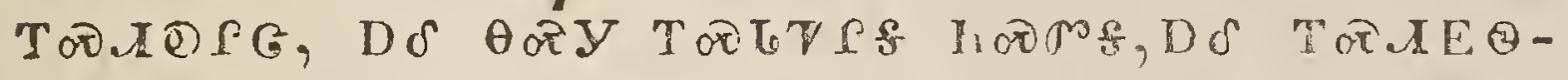

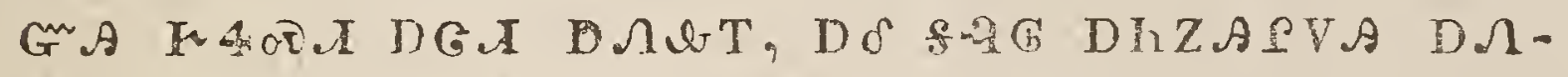

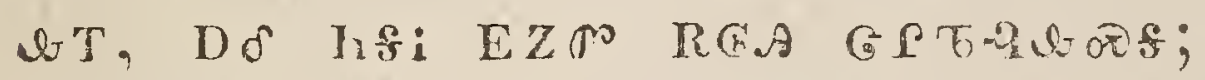

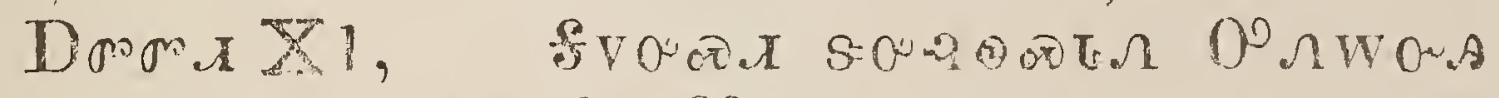

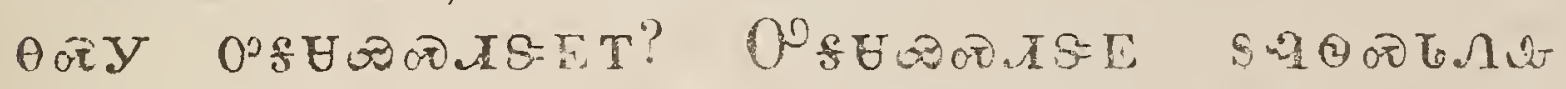

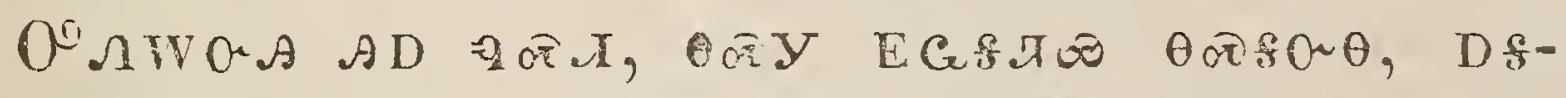

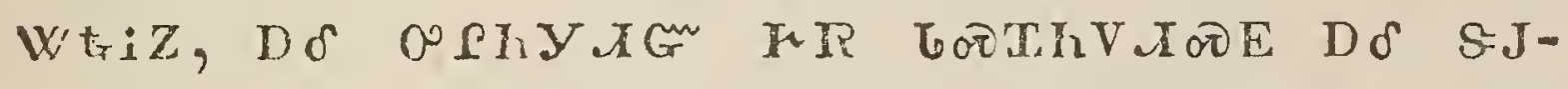

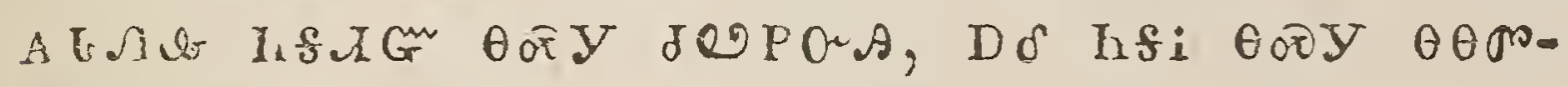
Ati; 


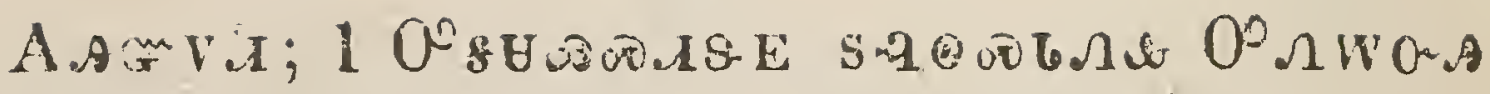

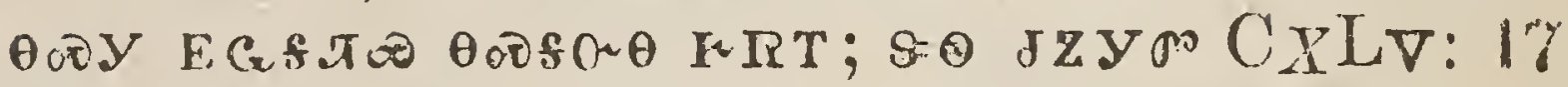

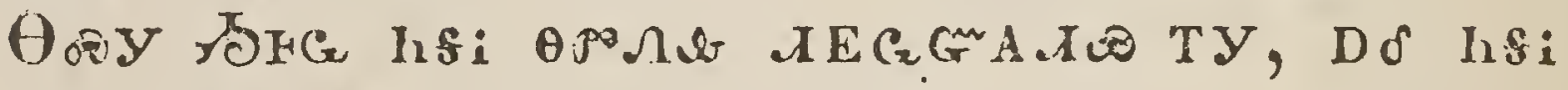

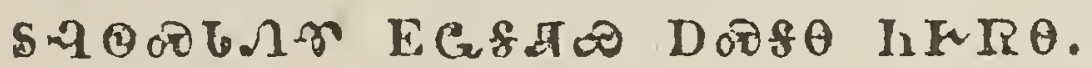

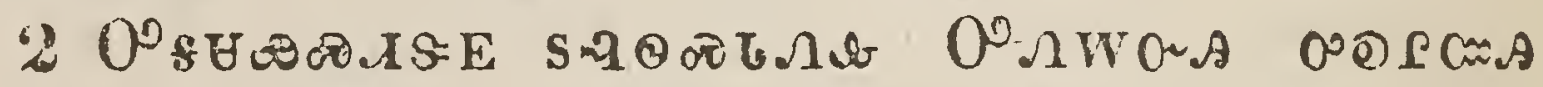

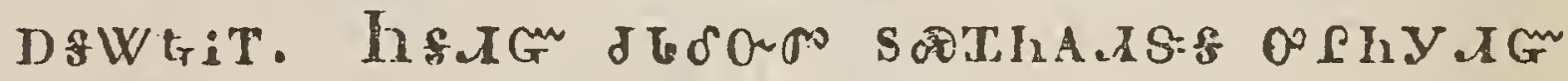

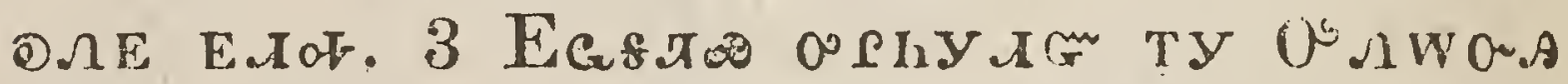

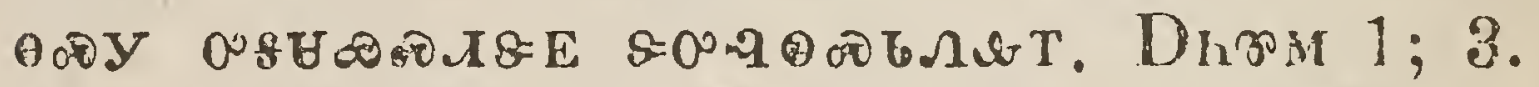
hFIG d

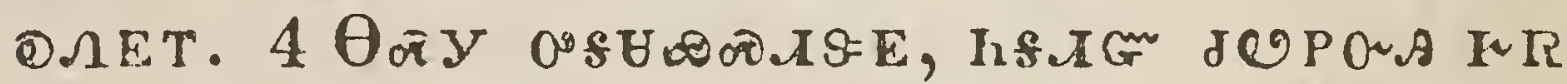

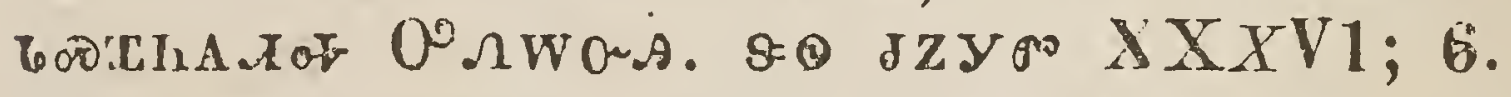

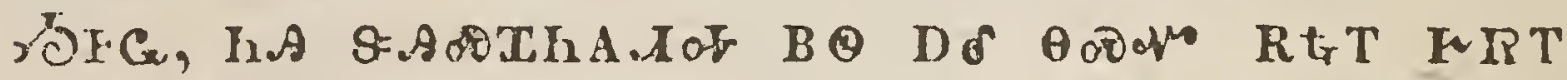

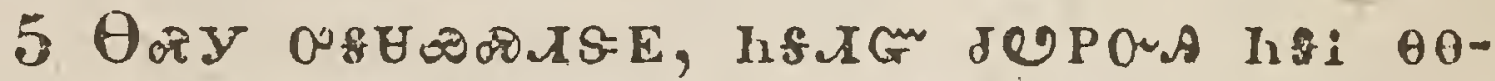
PonG \&JA B.

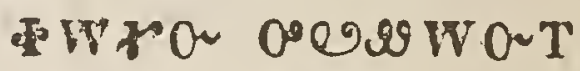

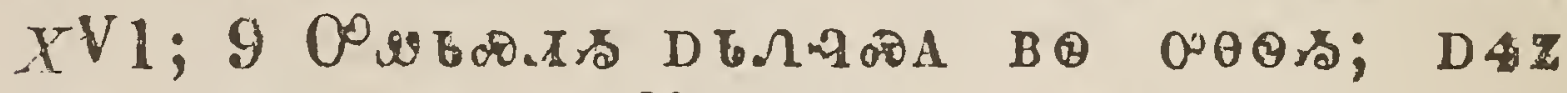

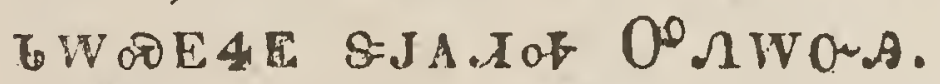

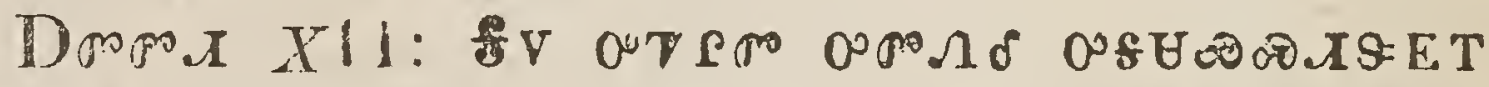

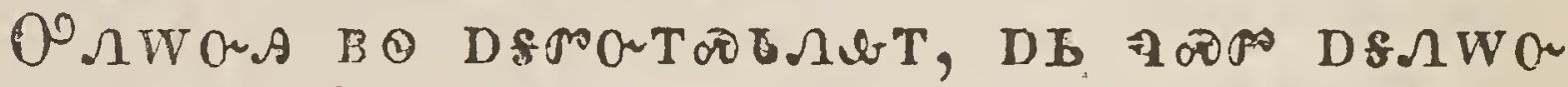
Iroucurat?

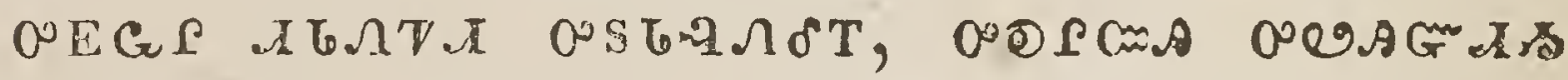

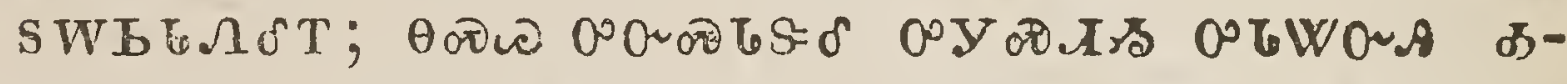

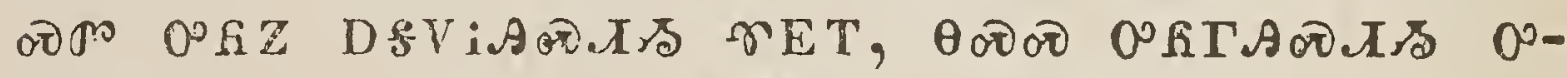

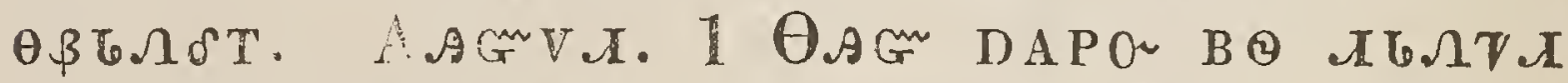

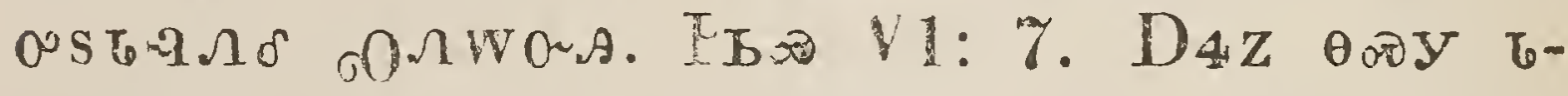

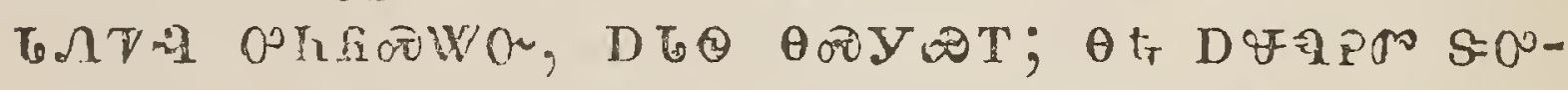

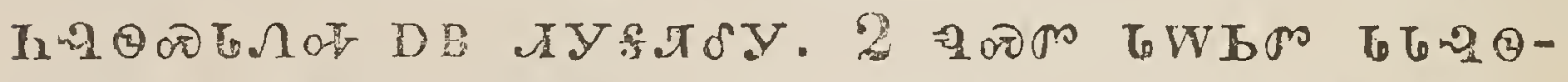

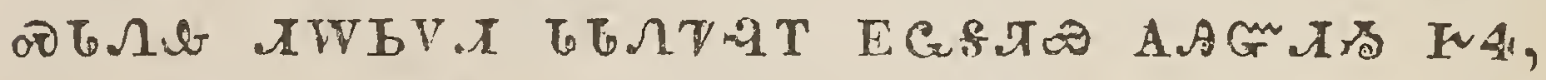

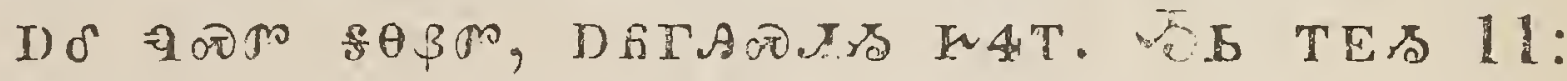

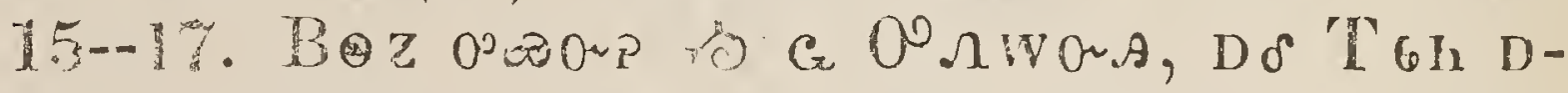

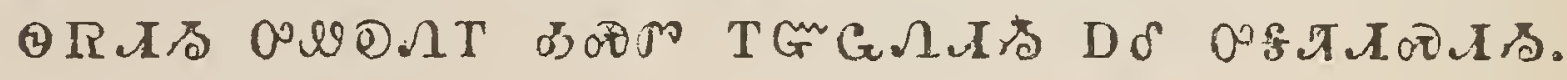




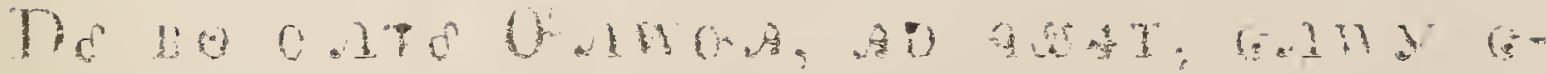

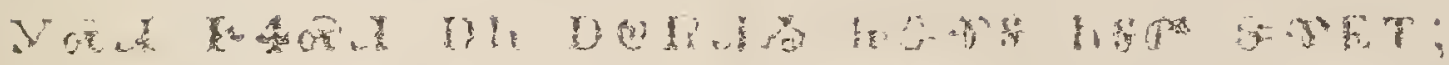

A d

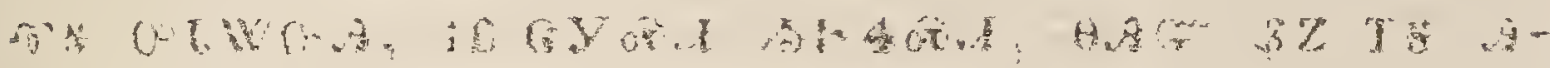

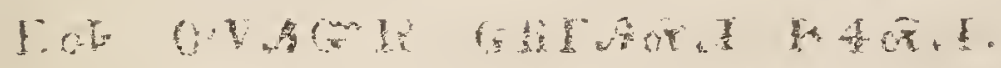

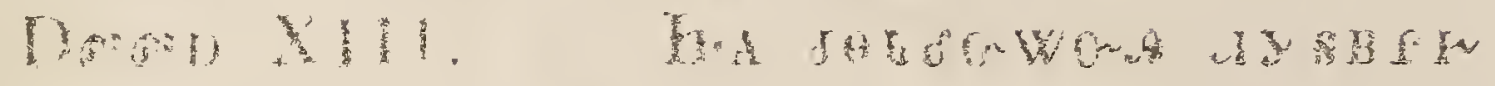

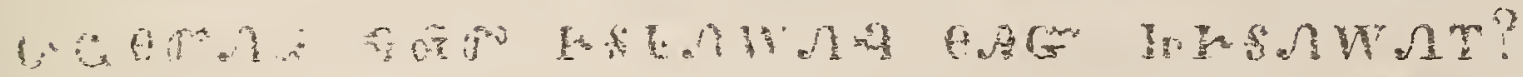

If

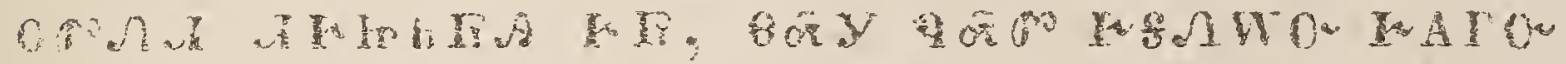

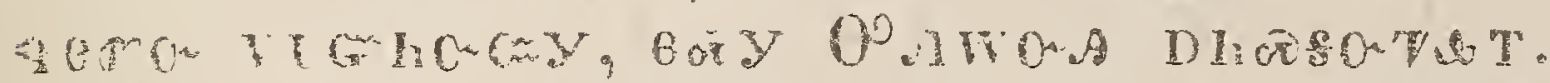

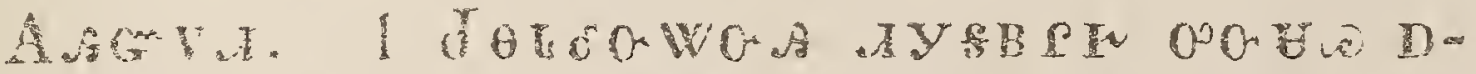

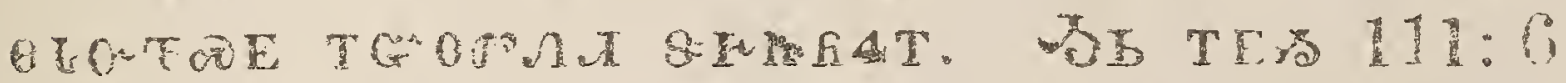

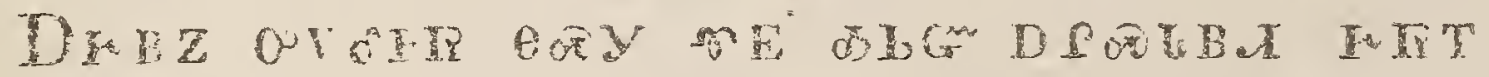
110 OCF A

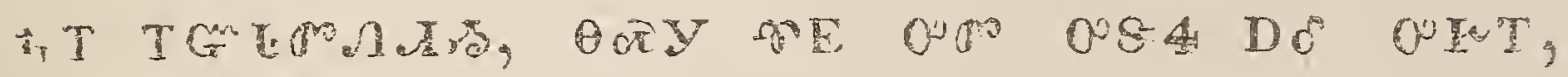

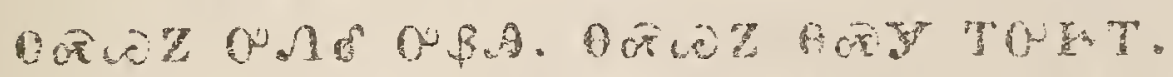

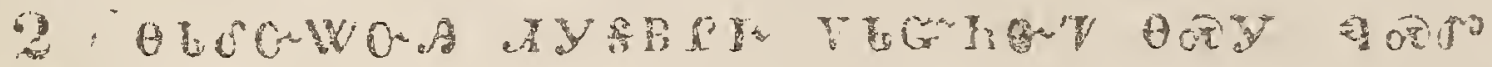

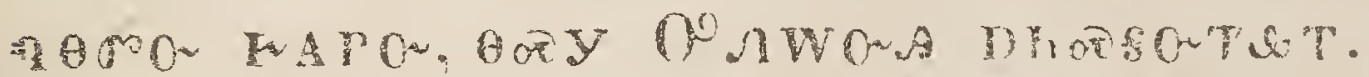

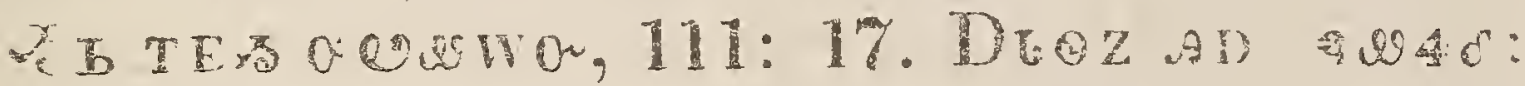

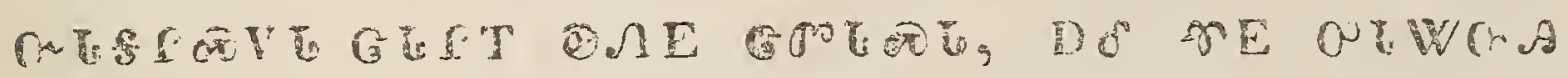

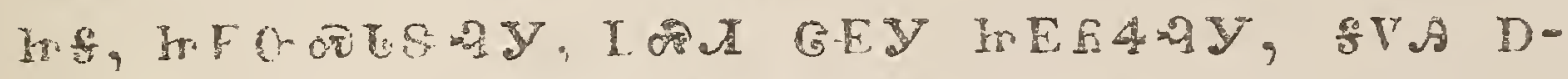
Oरी AY OA

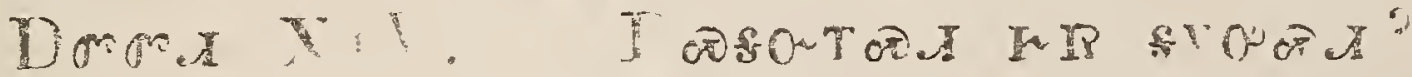

Do

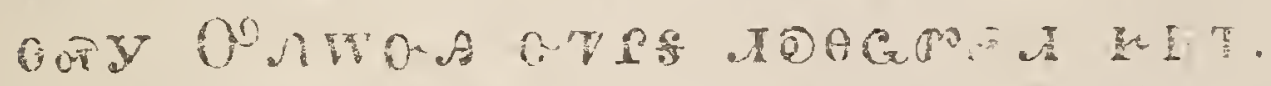

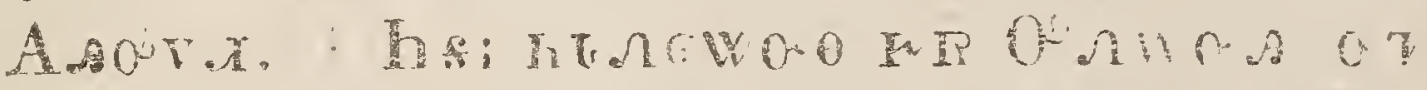

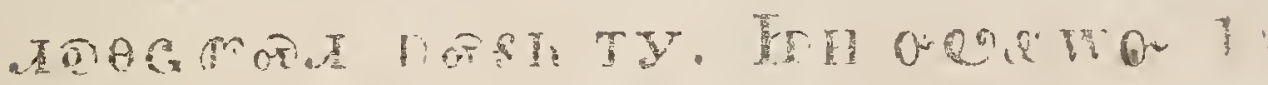

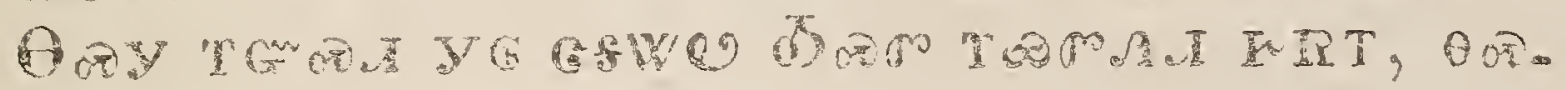


YZ

方量直

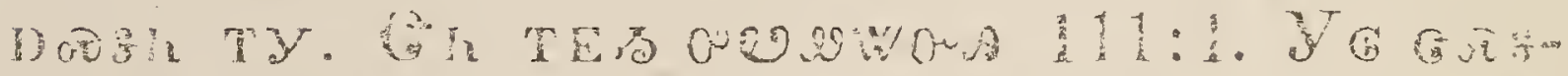

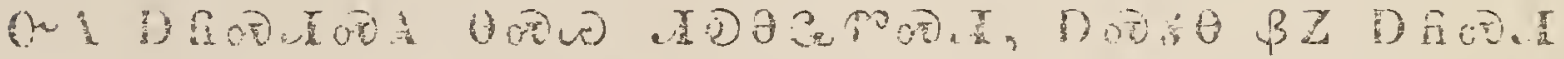

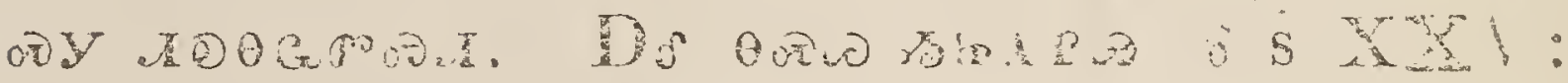

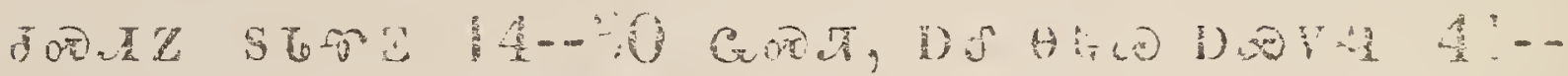

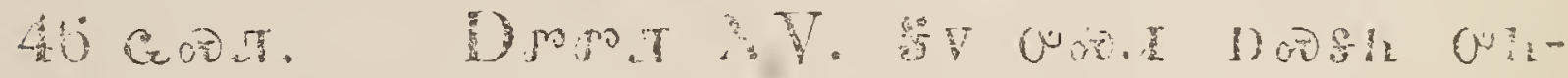

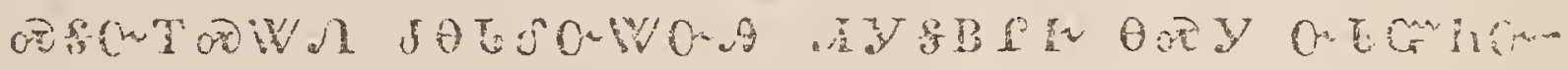

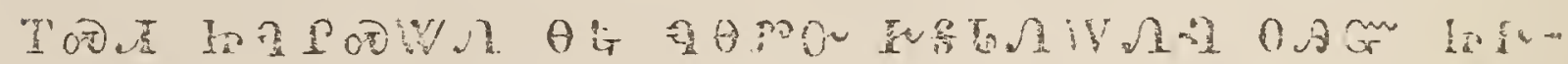

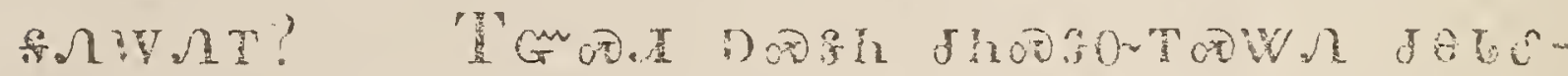

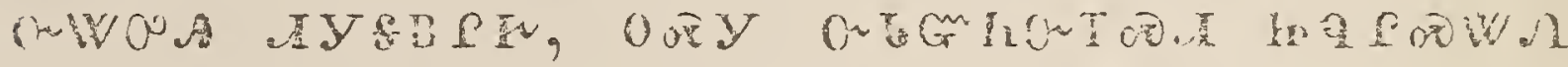
ot t

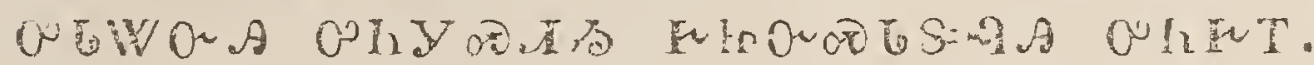

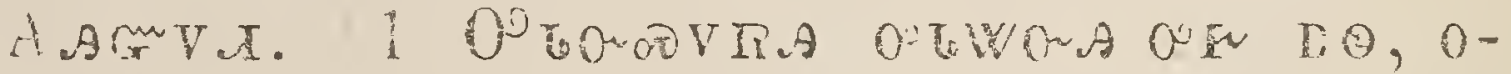

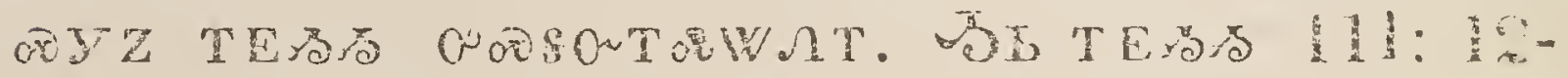

W

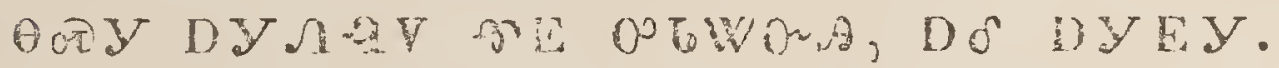

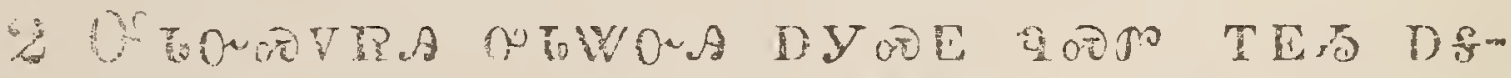
A TGO

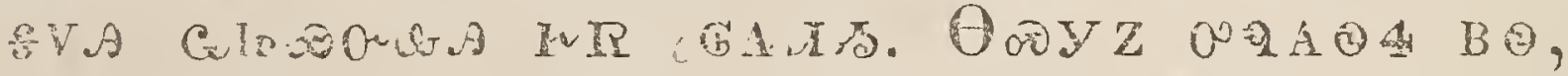

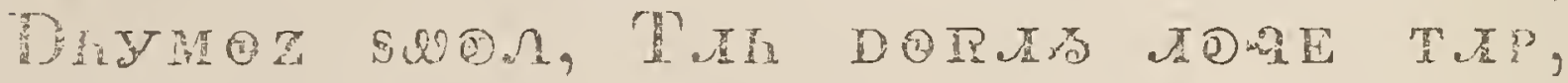
DS OSEM DEWPOEY OF'

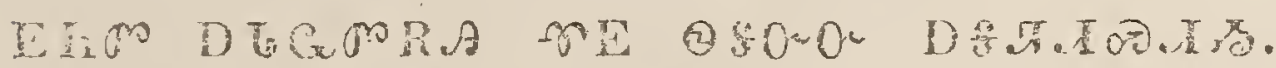

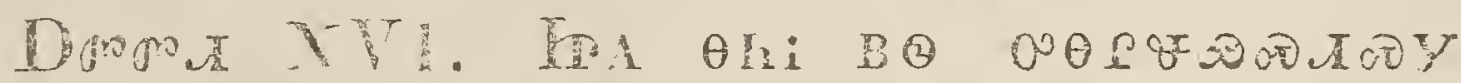

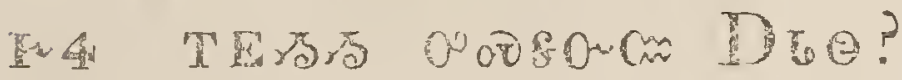

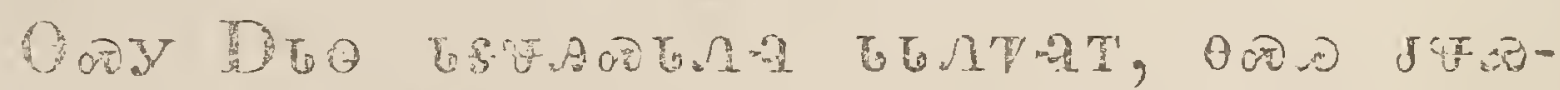

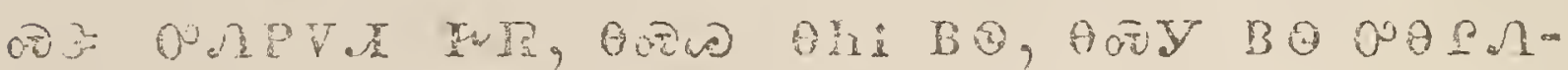

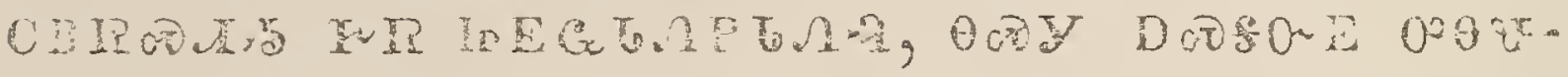




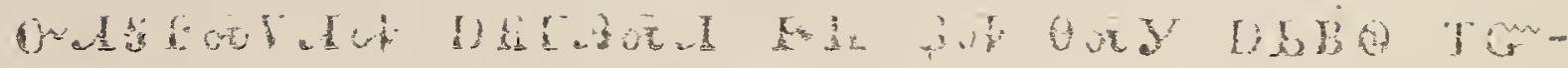

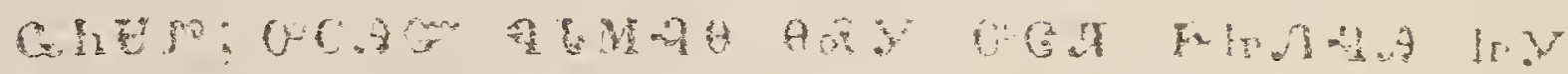

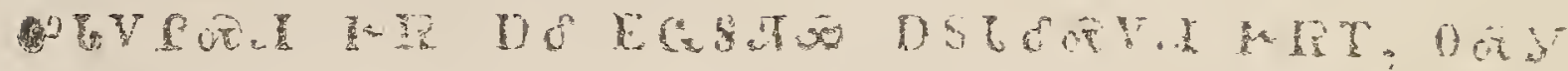

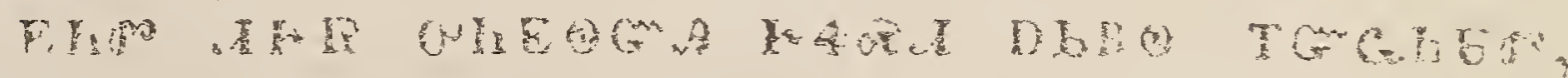

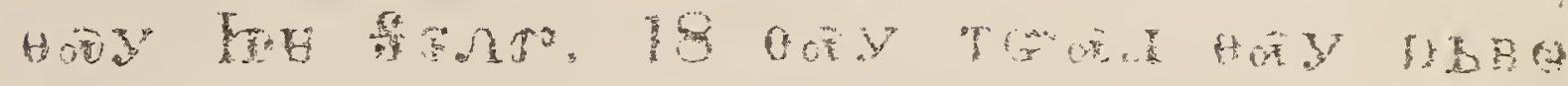

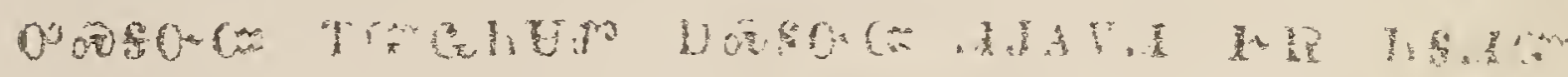

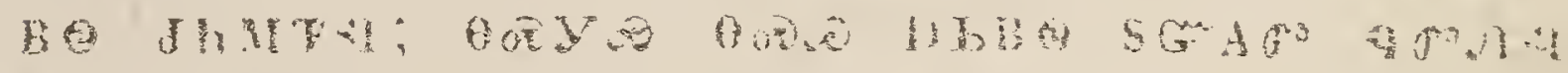

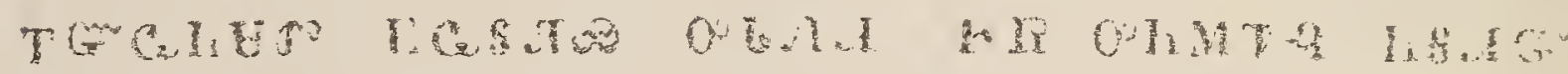

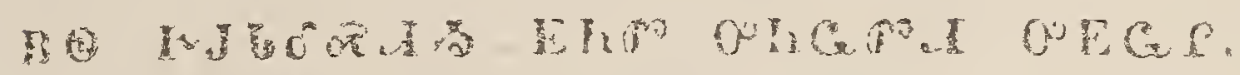

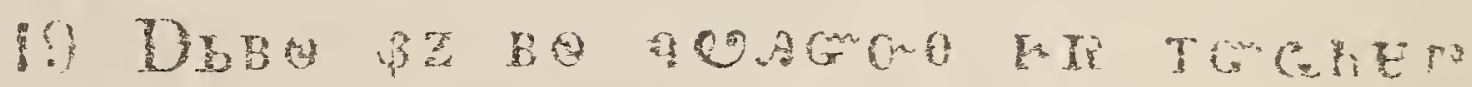

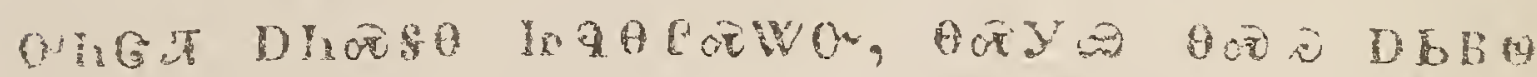

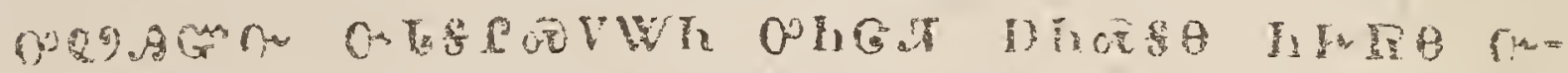

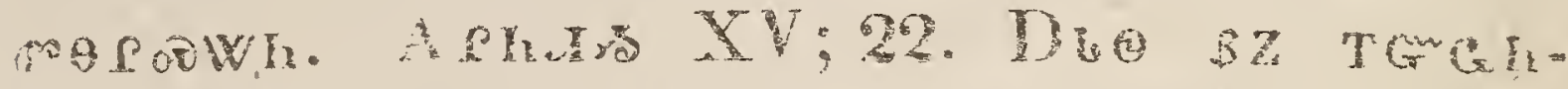

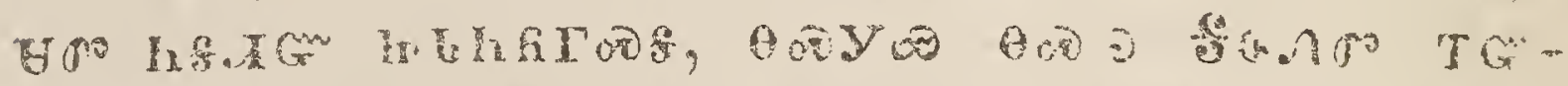

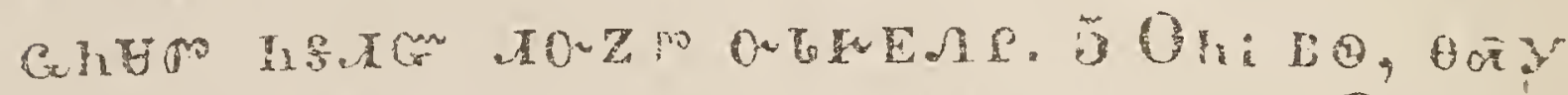

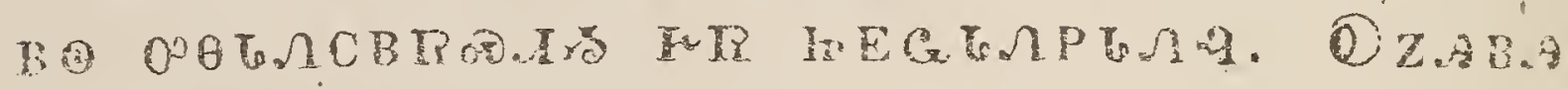

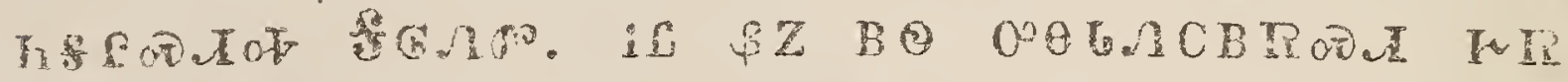

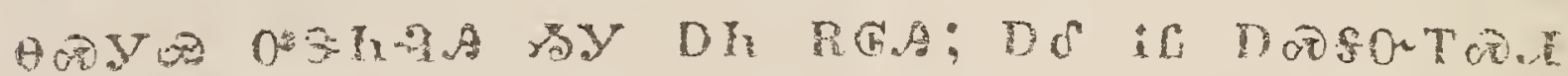

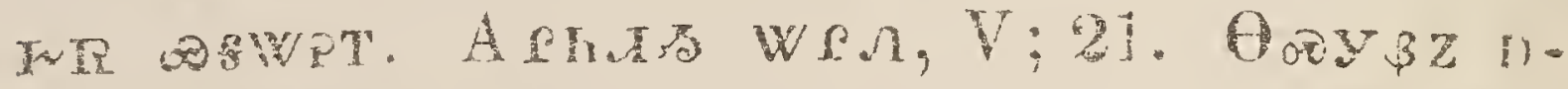

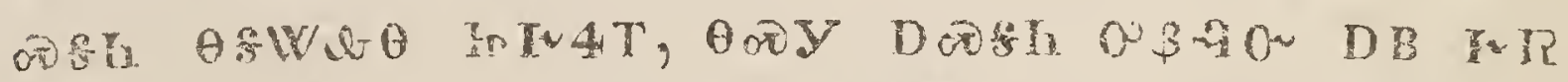

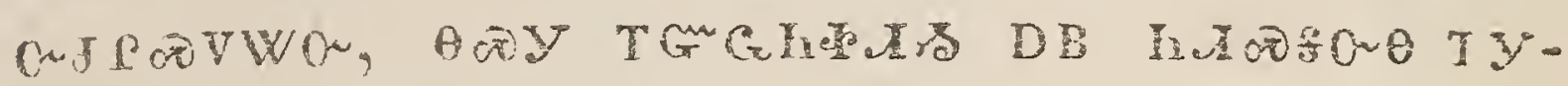

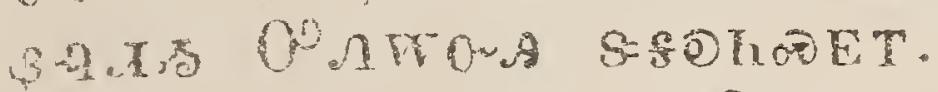

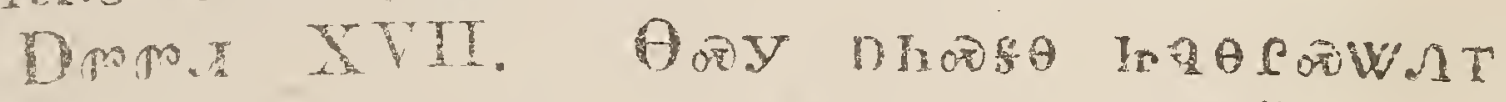

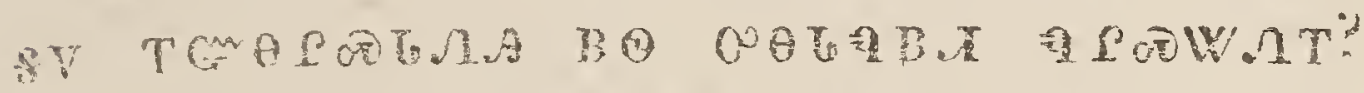

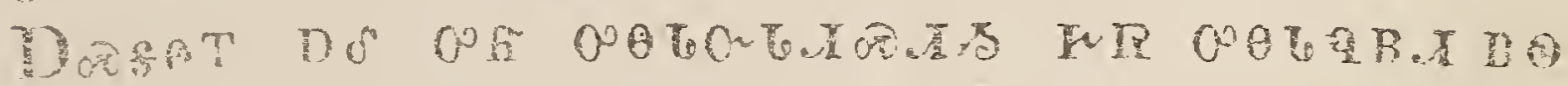

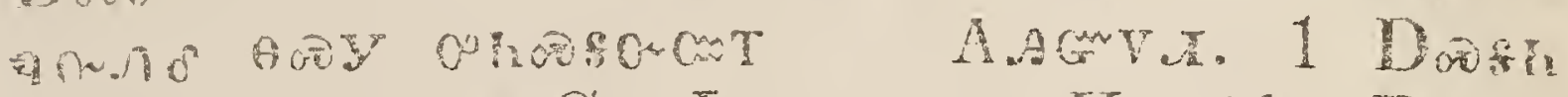

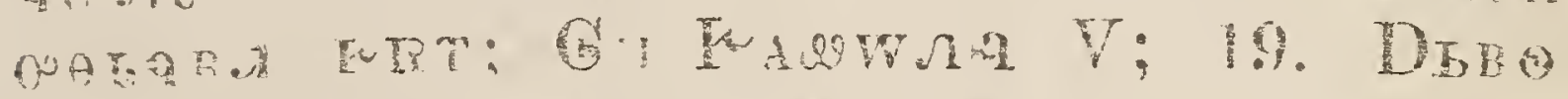

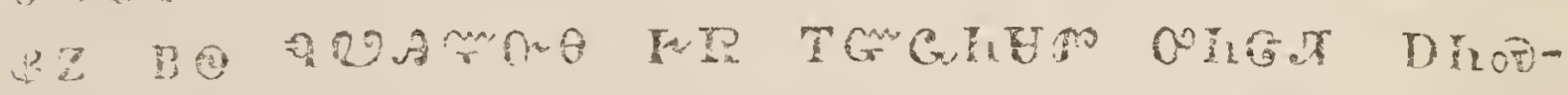

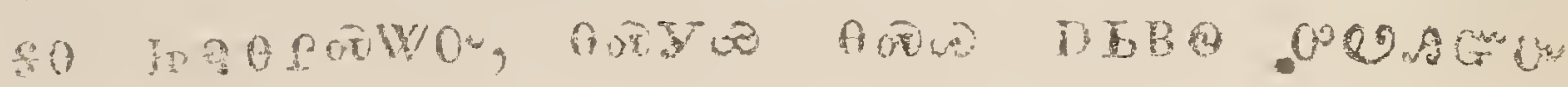




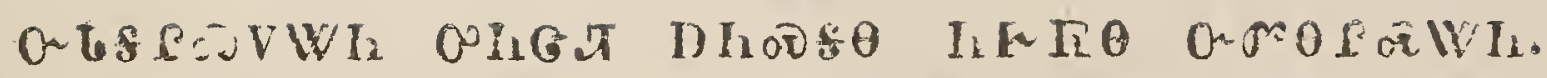

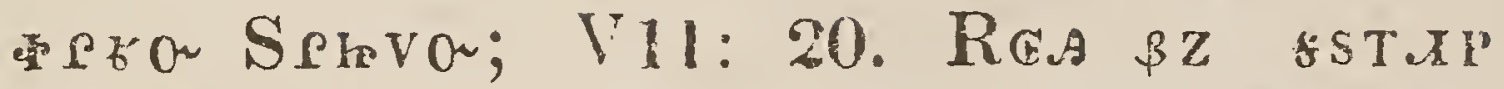

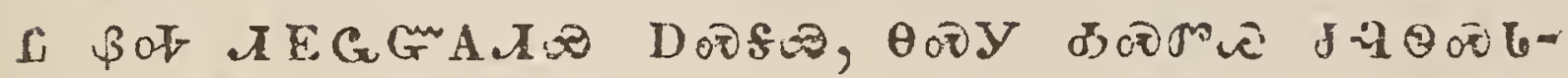

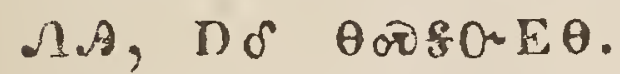

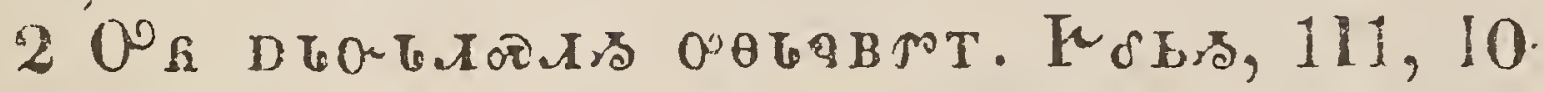

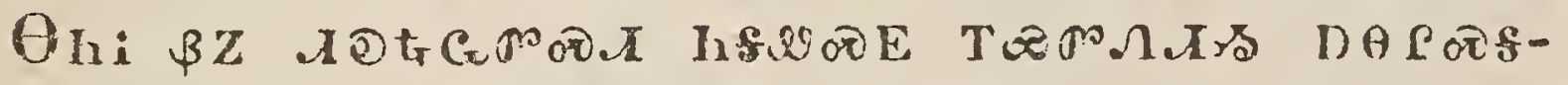

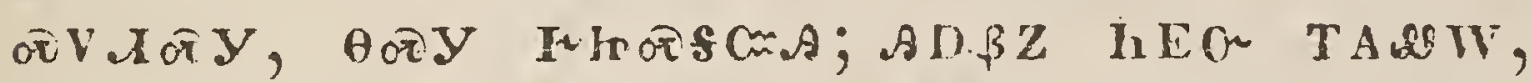

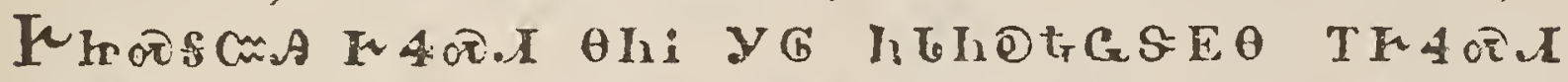

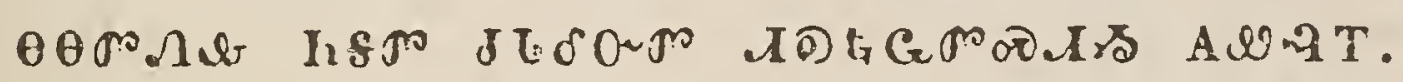

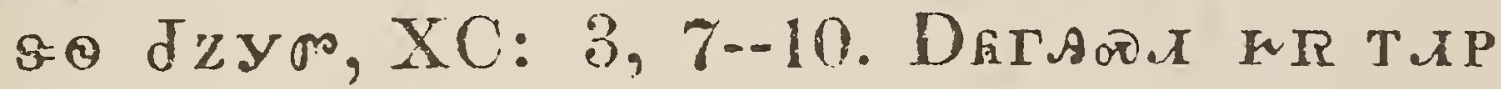

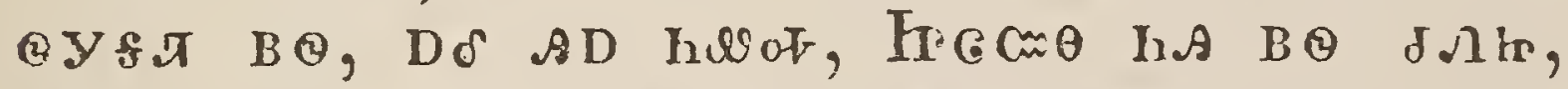
HAभIR $\beta Z$ कY

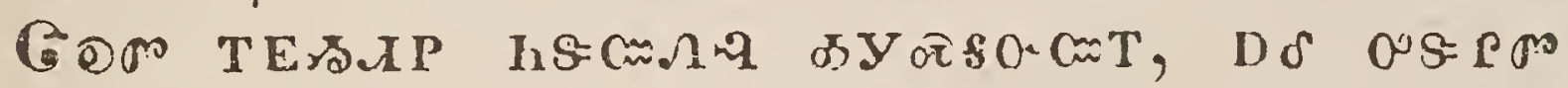

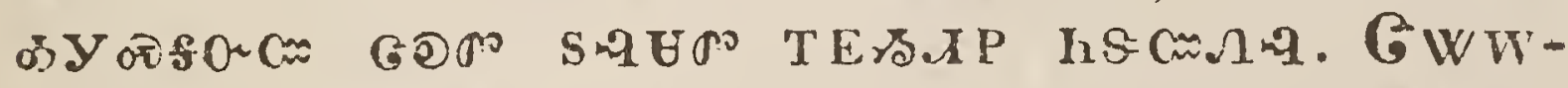

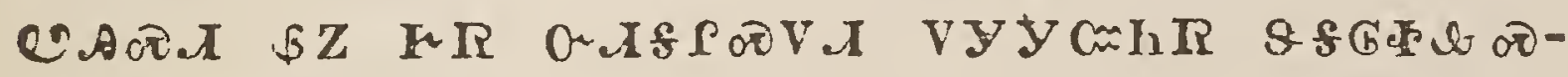
AT; VSS

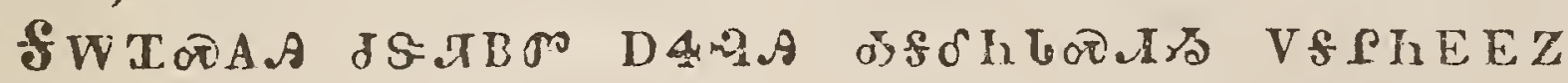

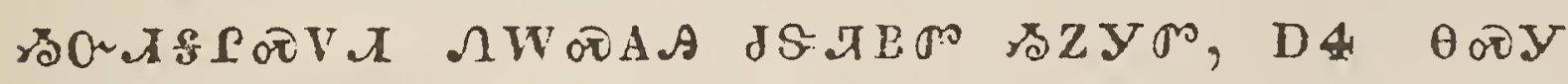

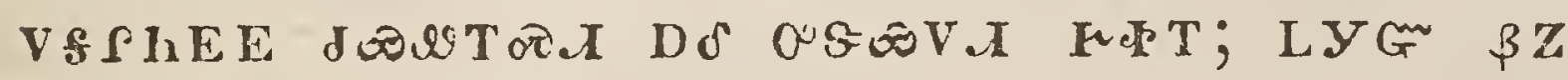

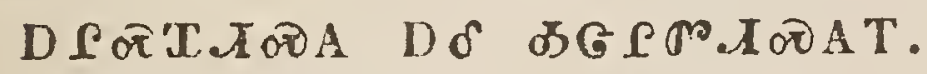

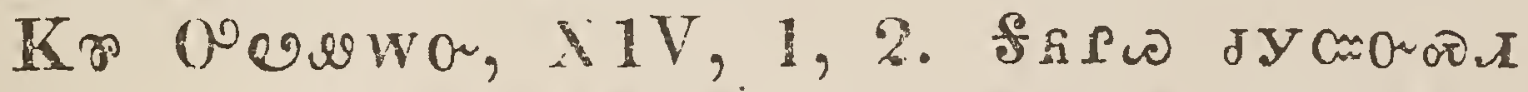

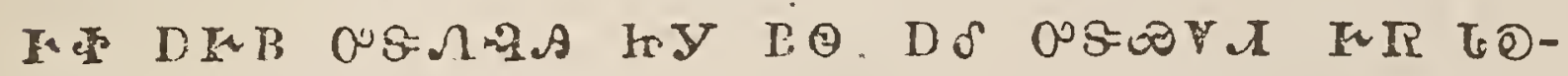

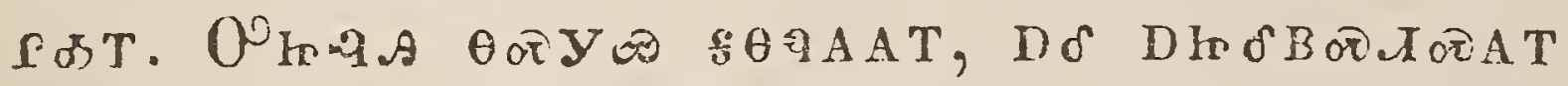
OU GW

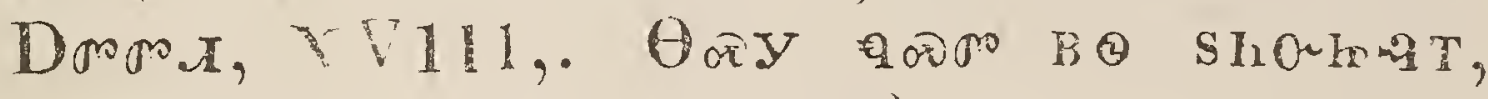

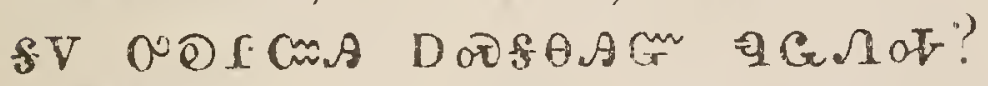

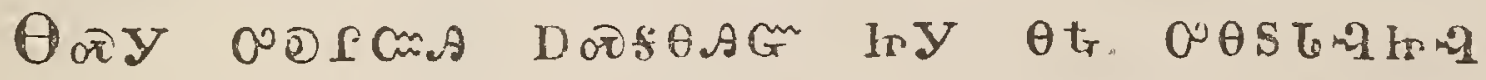

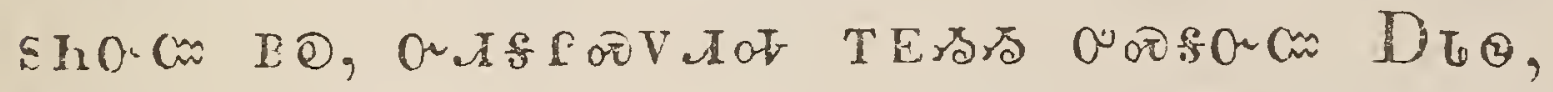
ECCOS S S A 


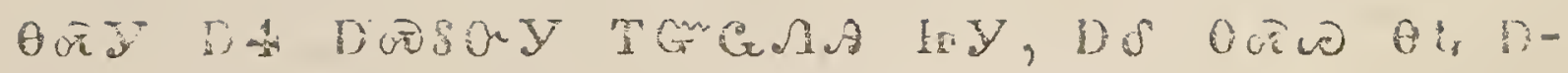

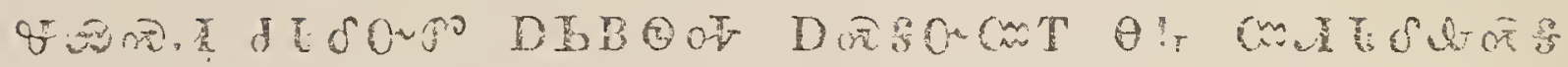
As

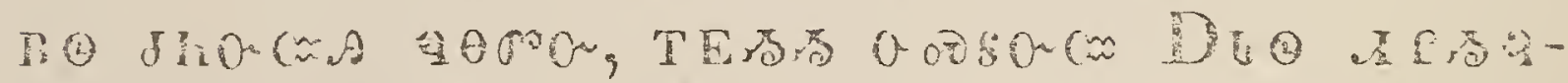

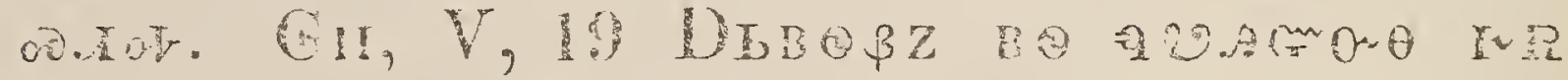

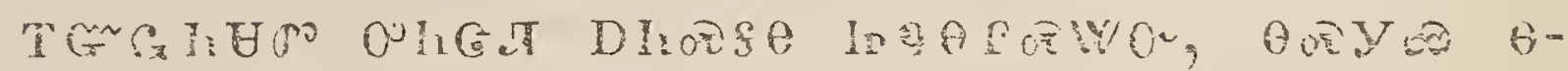

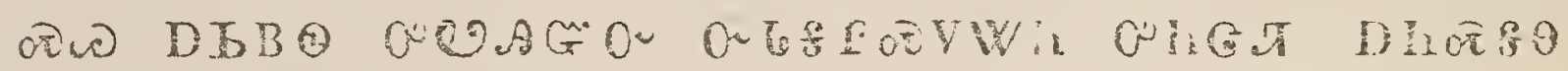

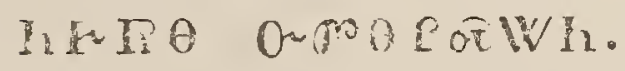

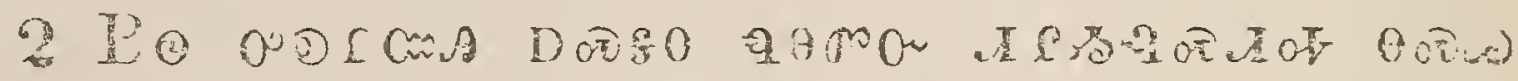

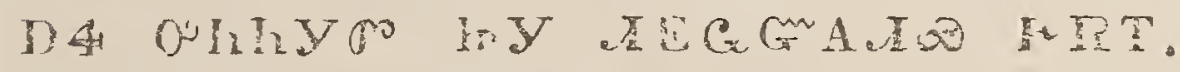

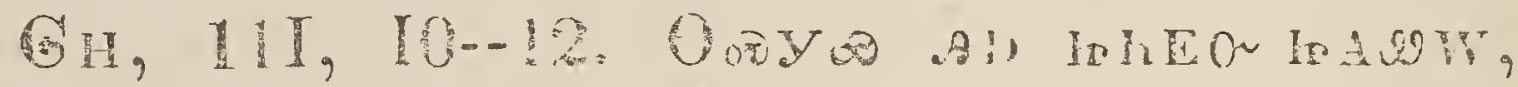

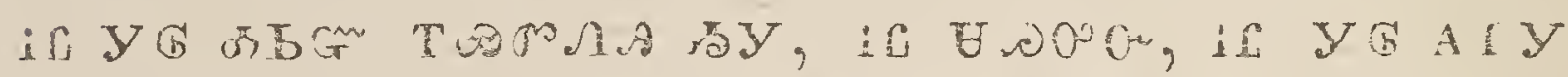

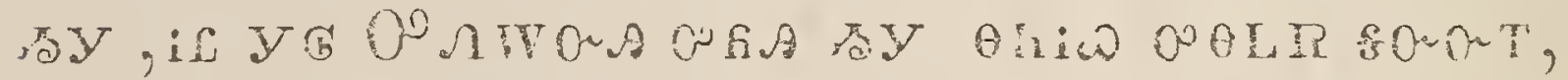

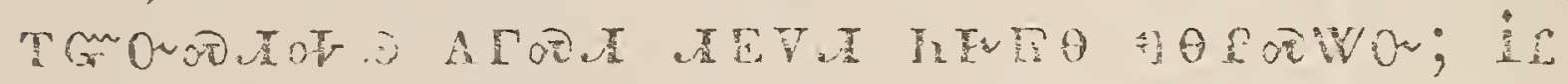
YG

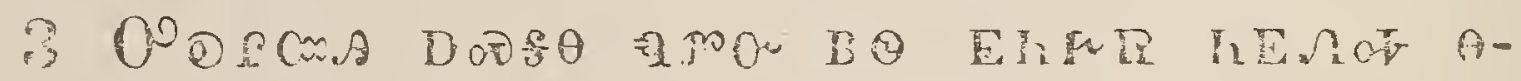

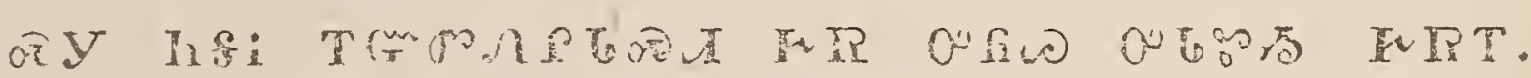

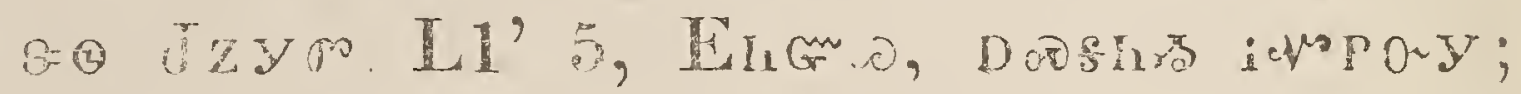

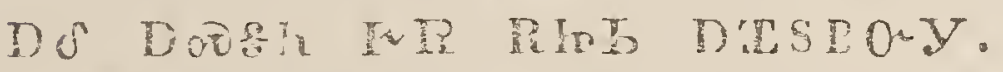

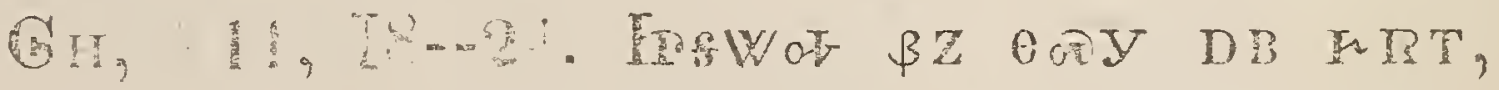

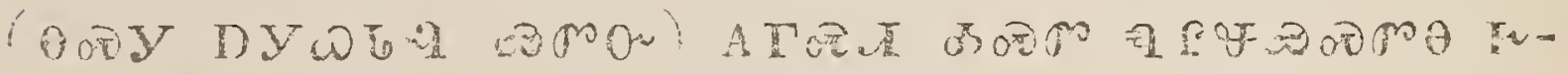

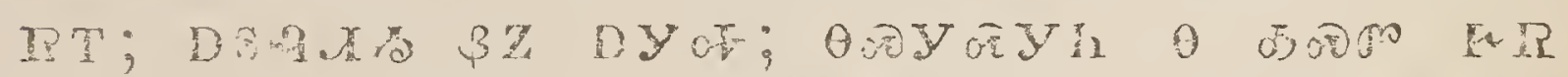

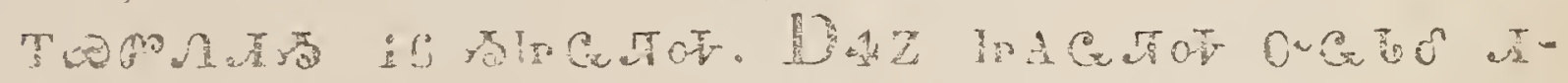

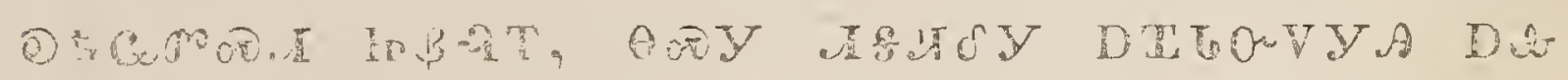

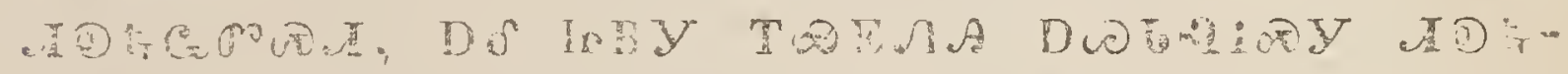

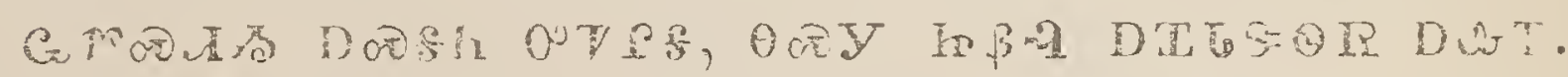

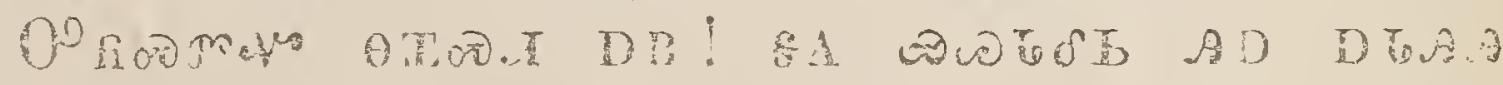

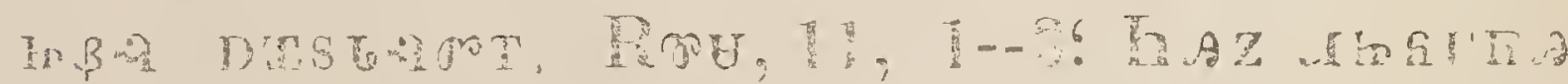

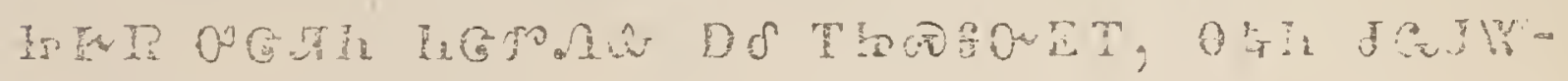




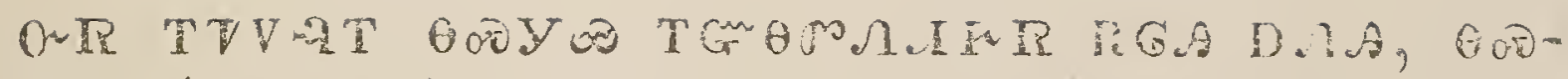
Y

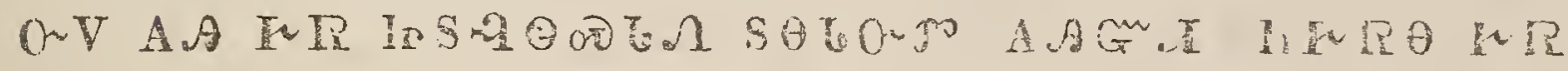

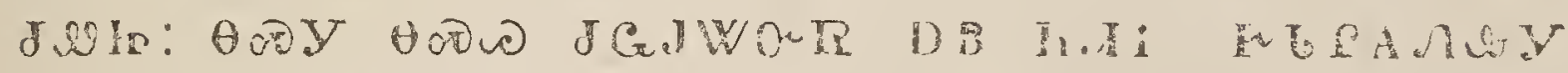

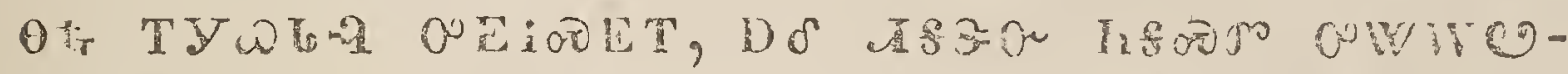

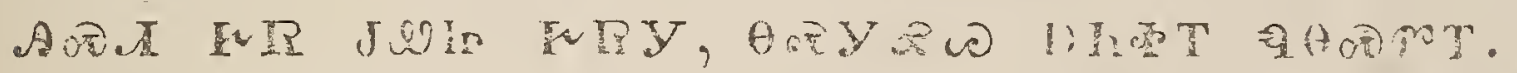

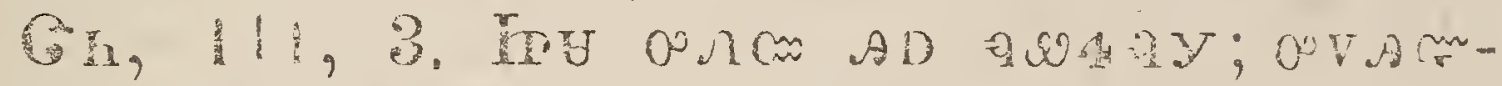

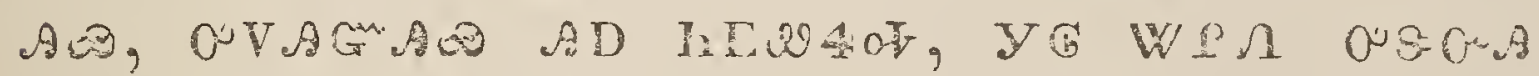

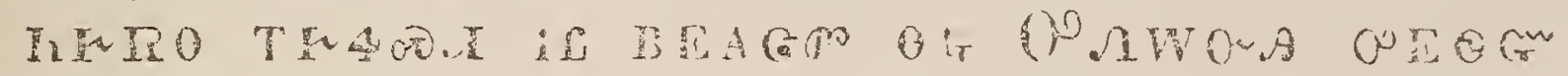
A E ITT. $\quad$ TE.

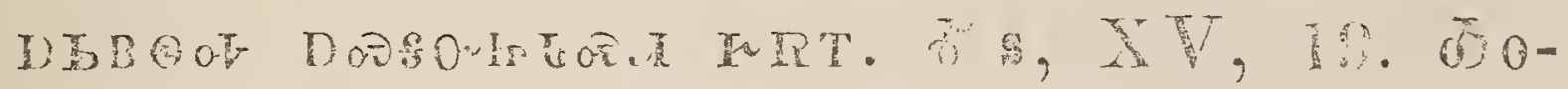

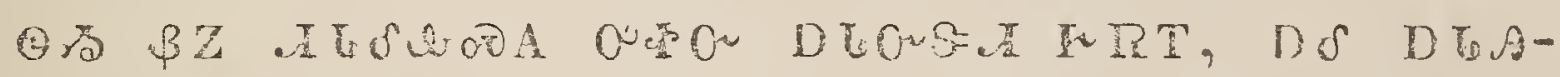

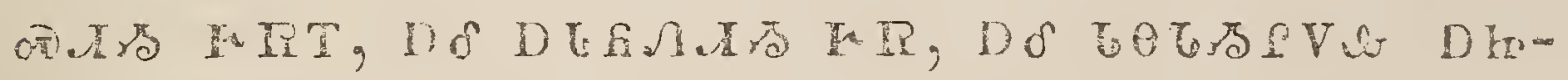

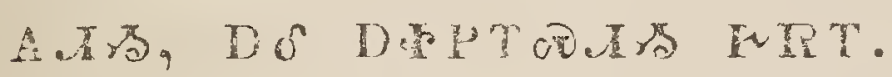

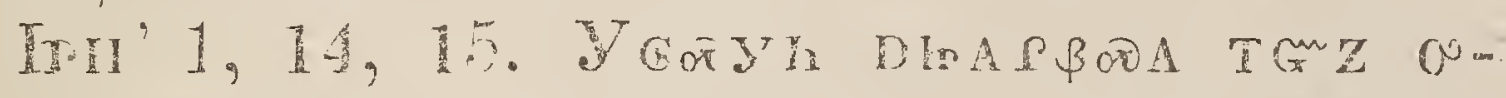

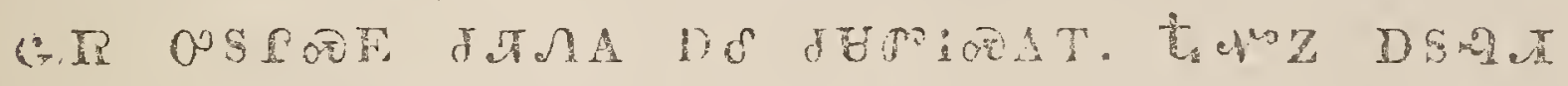

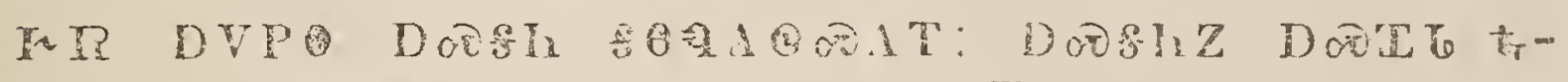

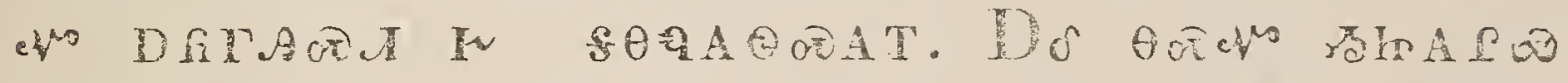

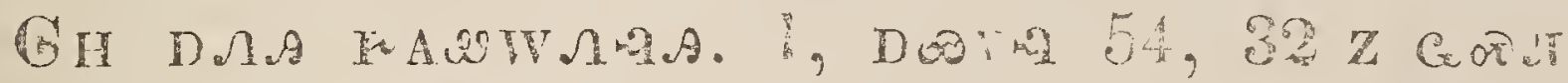

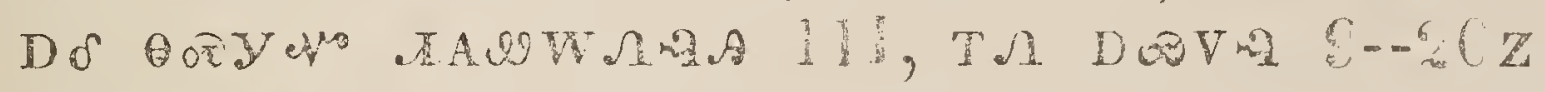

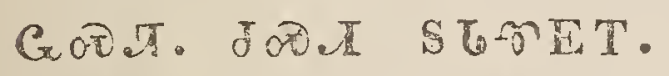

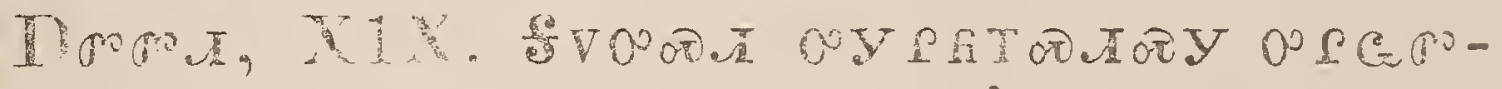

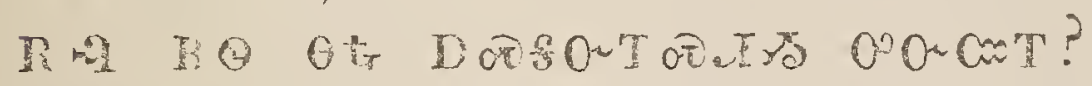

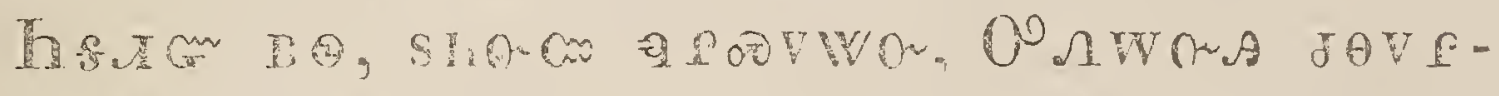

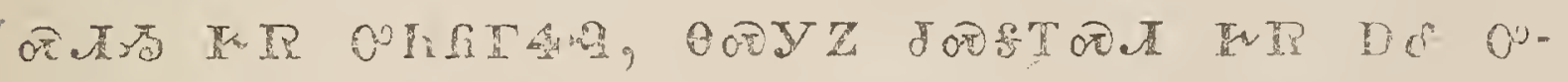

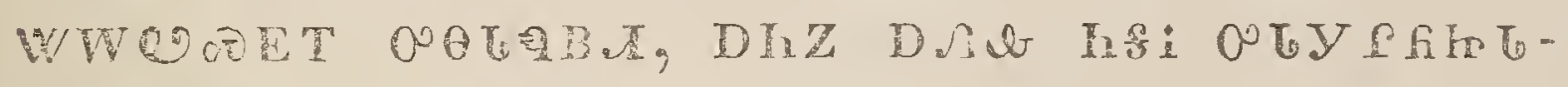

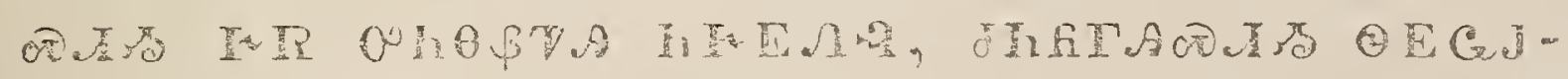

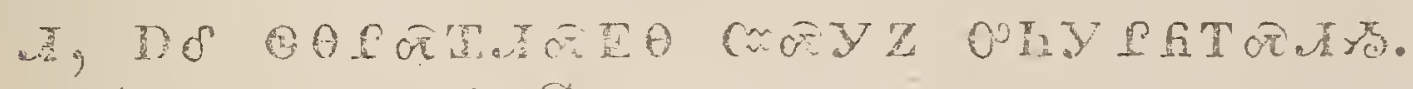

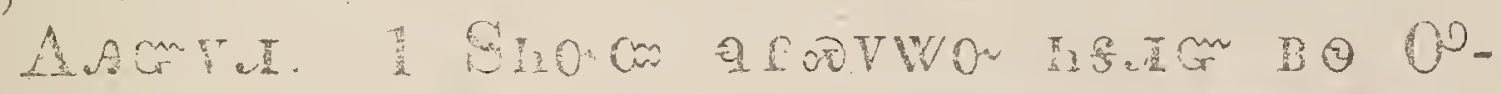

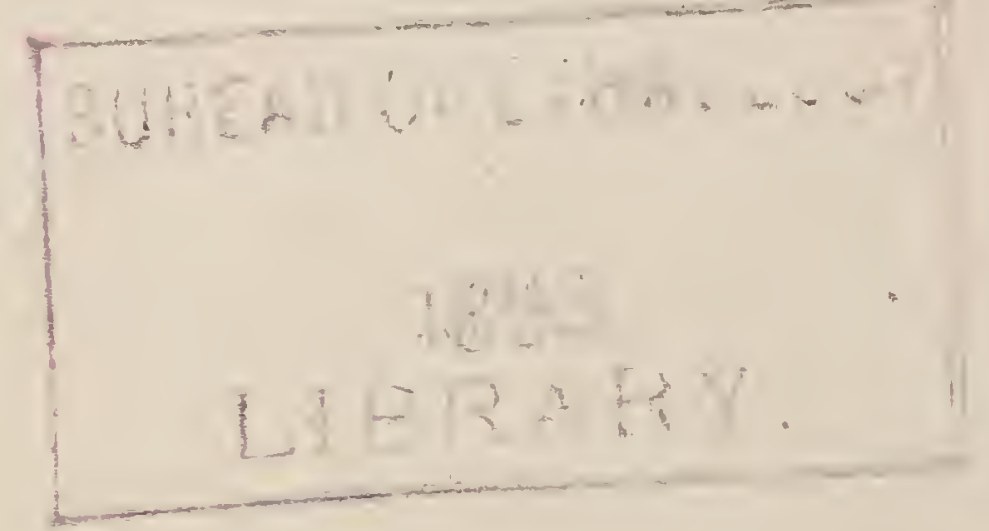




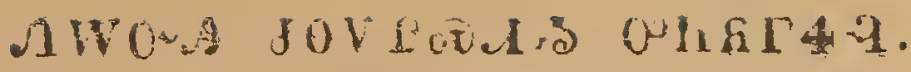

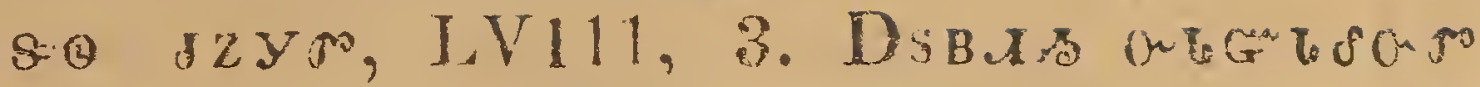

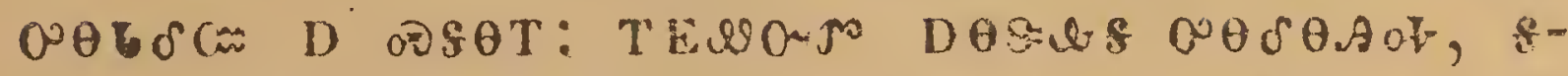

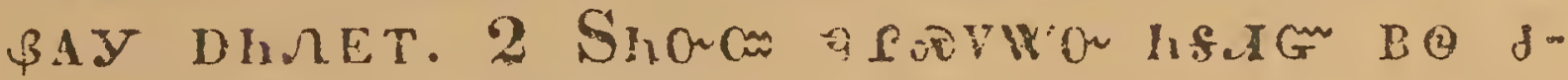

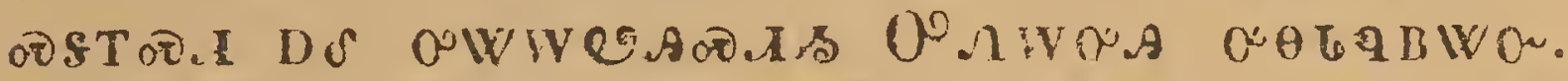

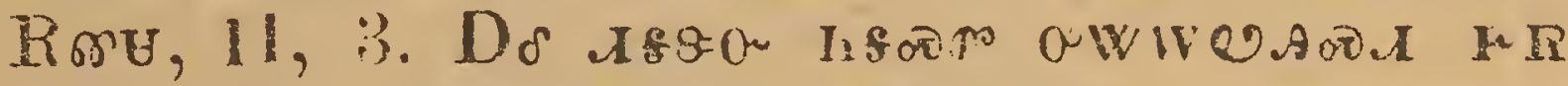
doir RY,

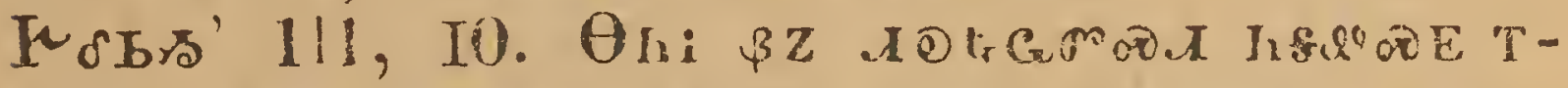

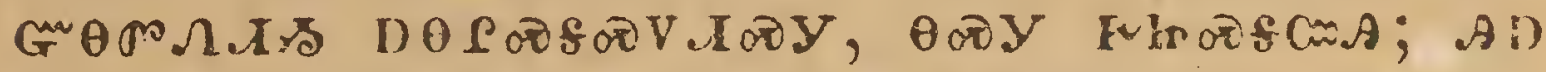

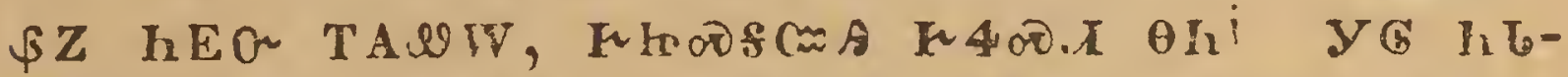
hอtcese TH

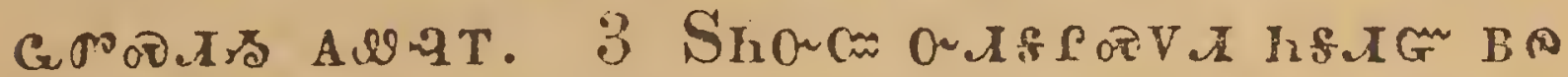

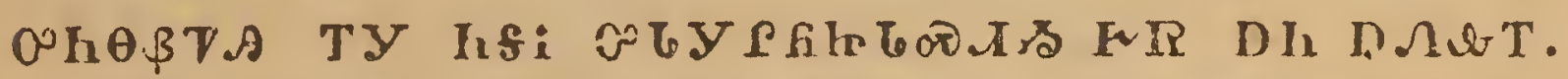

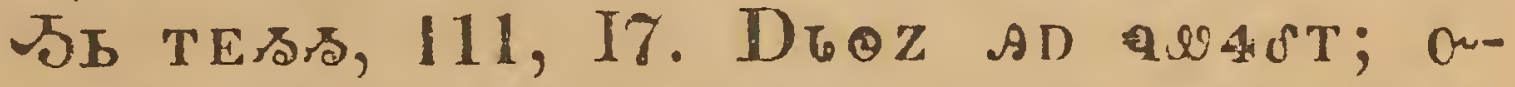

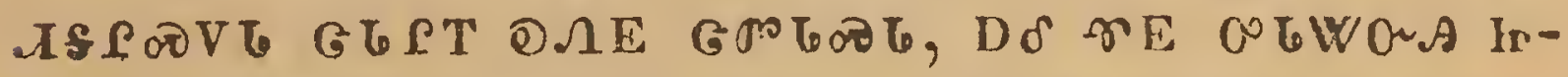
8, hE0

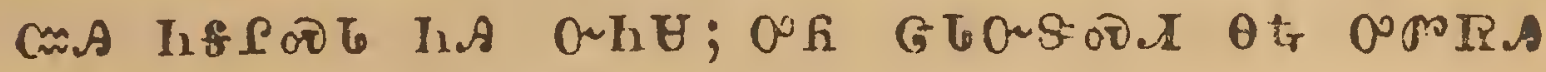
AY OO $\sim$ OOD IAAA bO T.

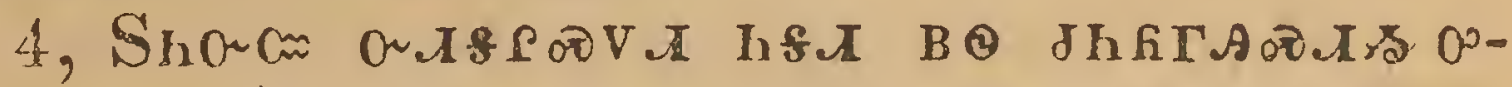

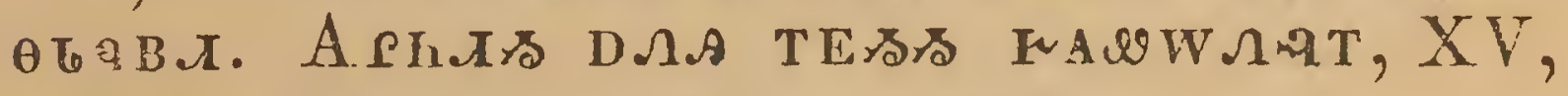
$\mathrm{D} \circlearrowright \mathrm{VM}, 22,00 . \pi$ \%

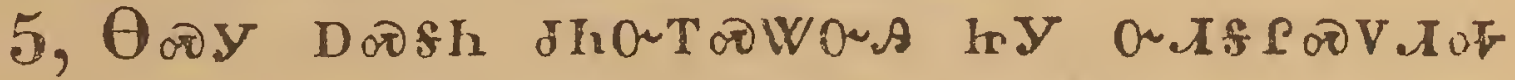

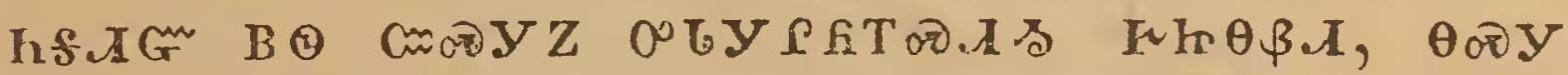
(3) $\theta$ PODTA

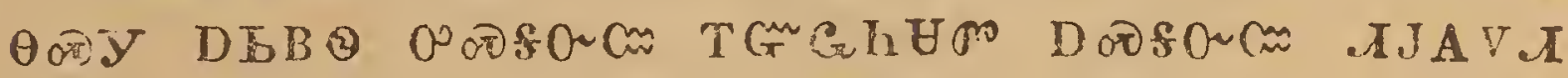

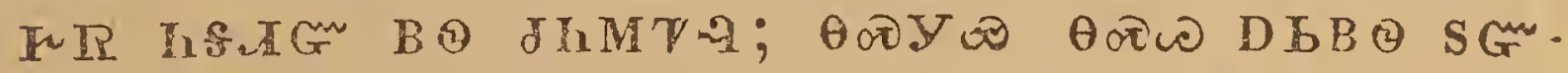

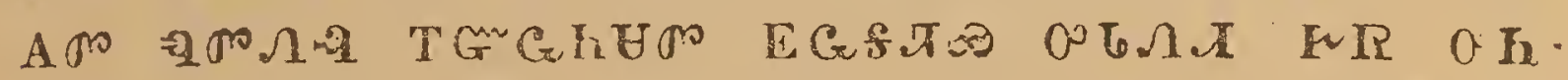

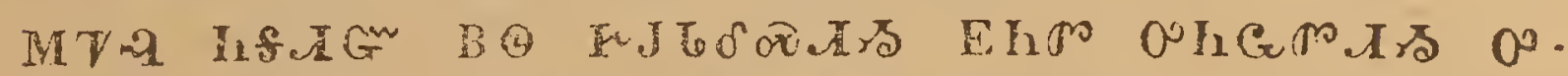

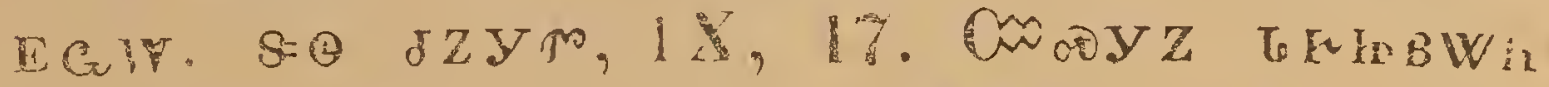

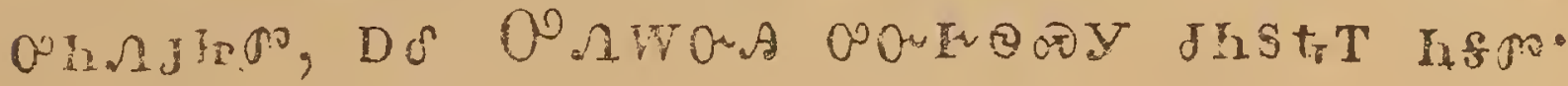




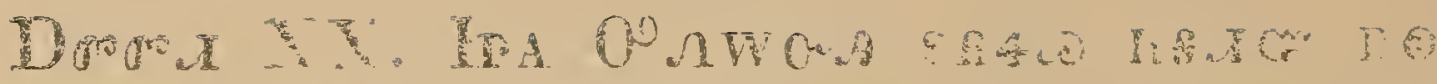

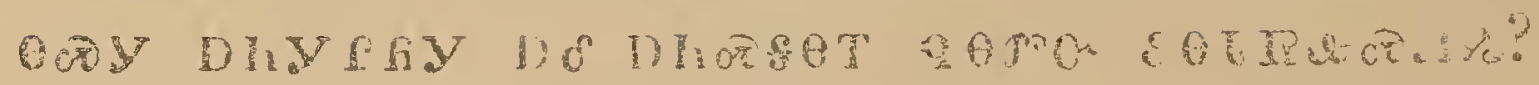

OC CR

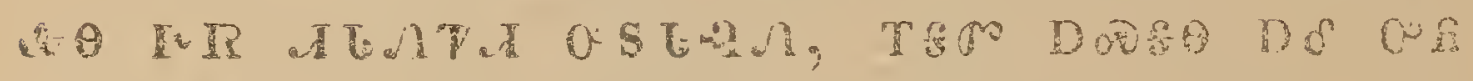

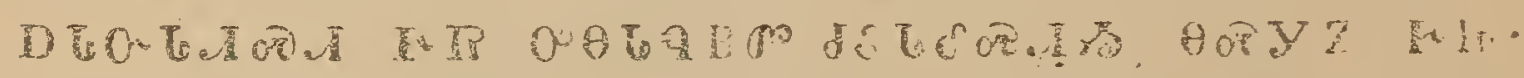

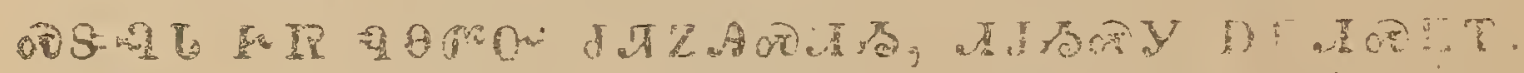

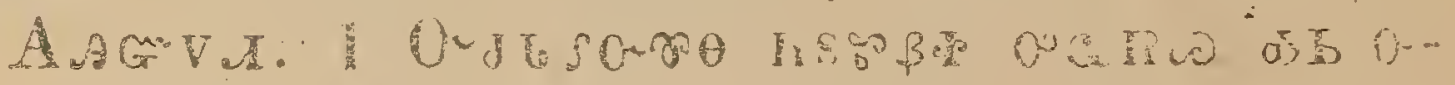

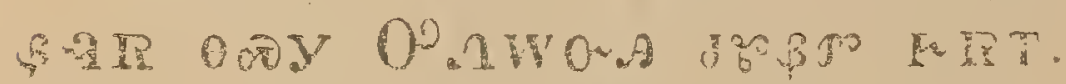

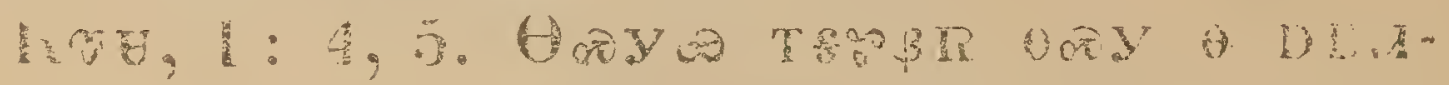

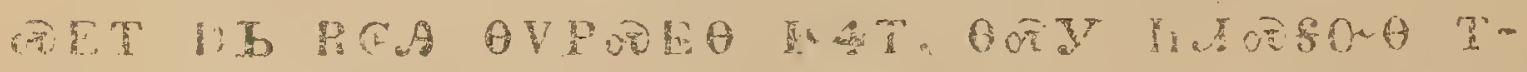

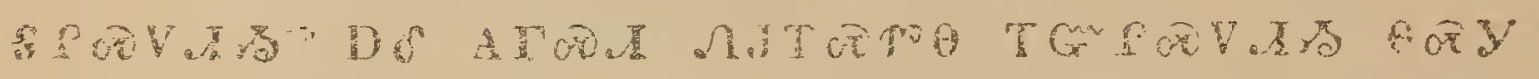

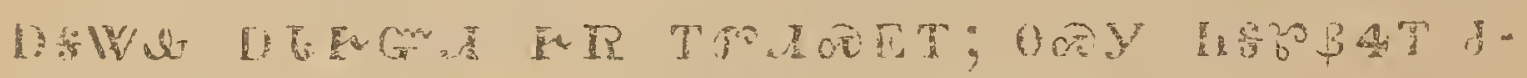

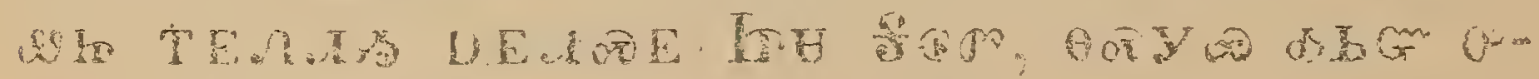

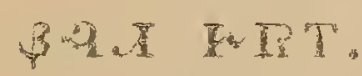

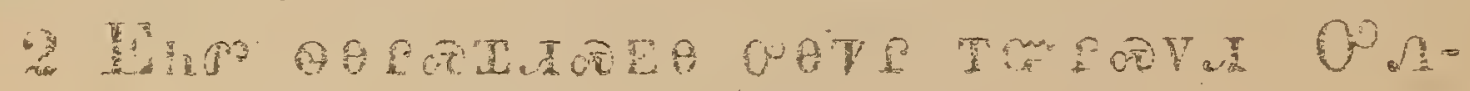

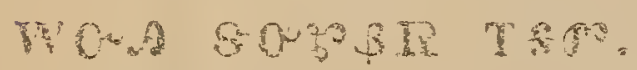

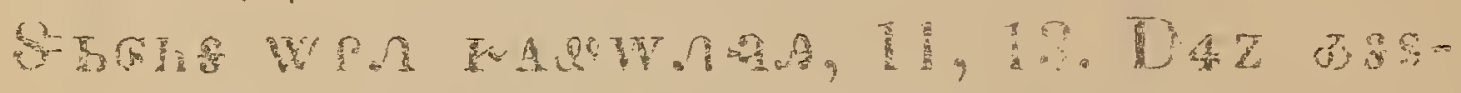

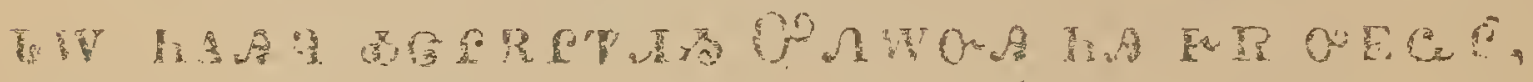

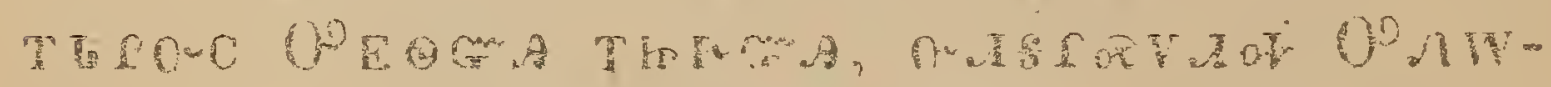

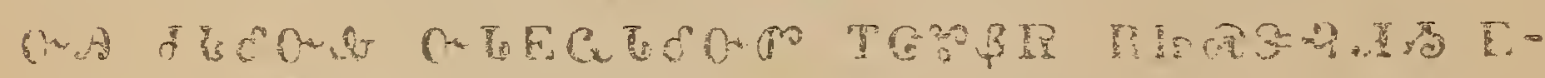

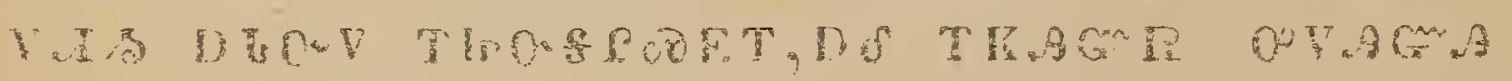

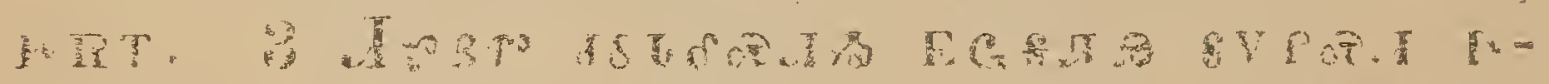
T. 更A

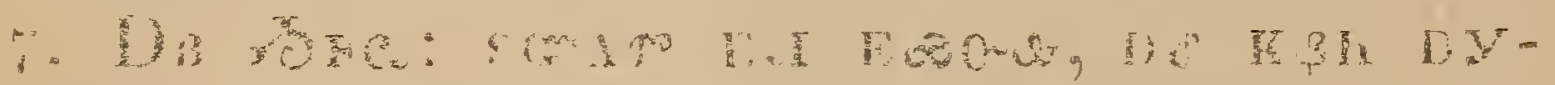

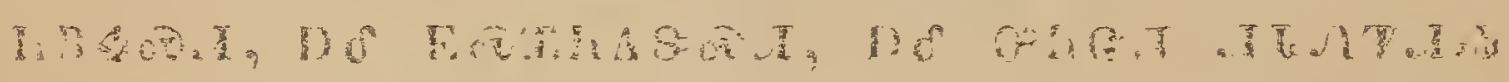

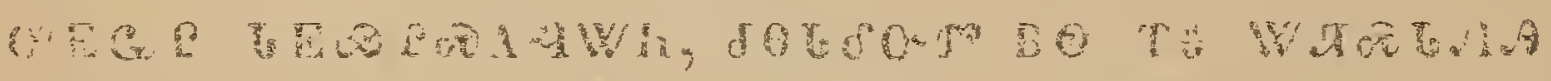

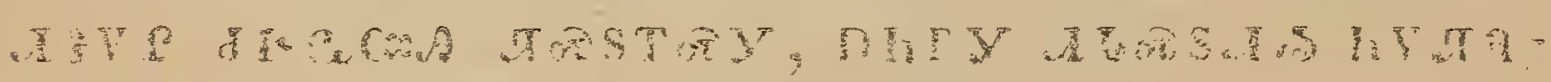

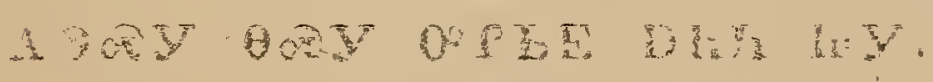

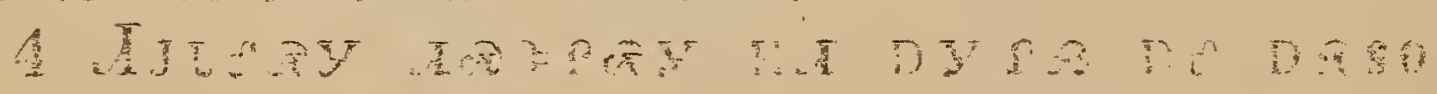




\section{ats}

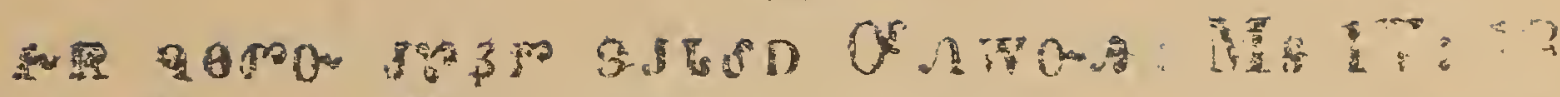

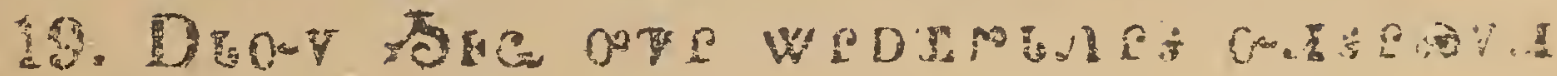

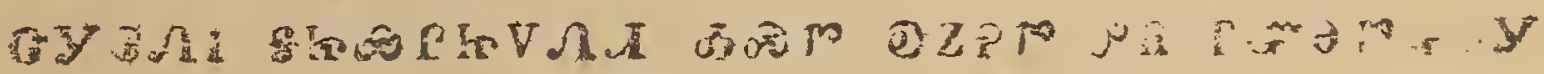

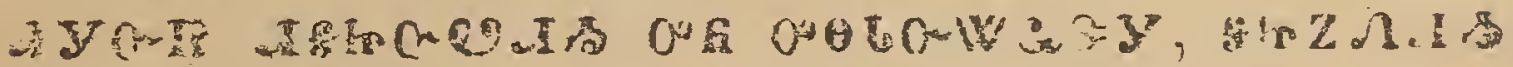

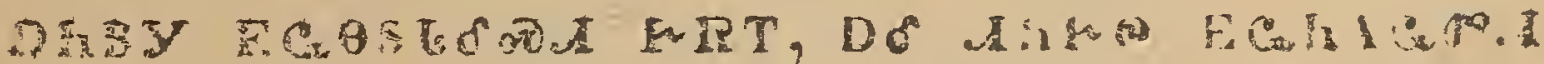

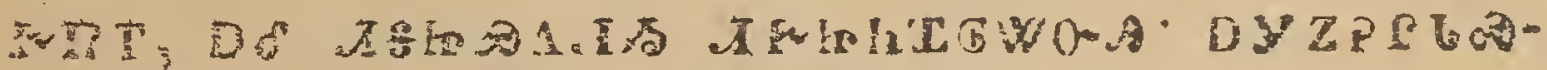

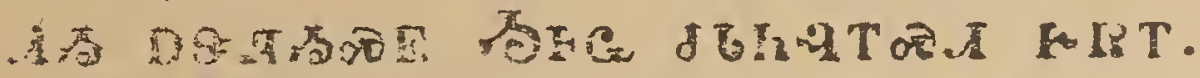

F.

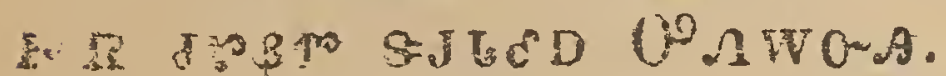

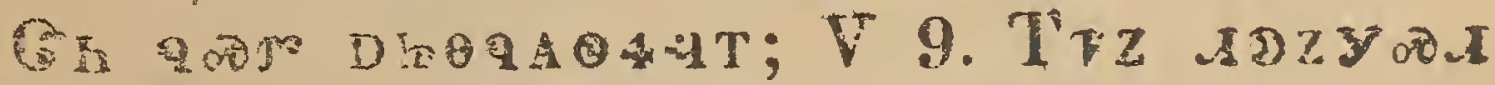

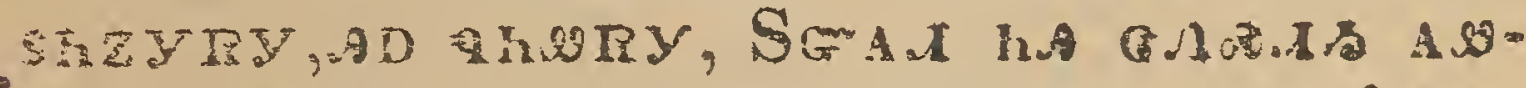
is O. S P

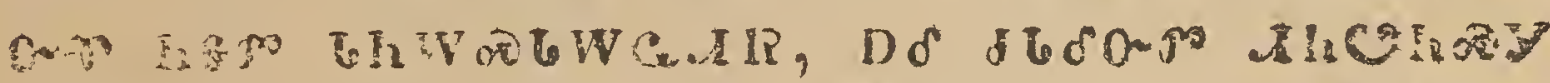

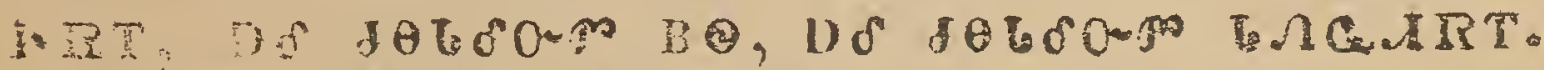

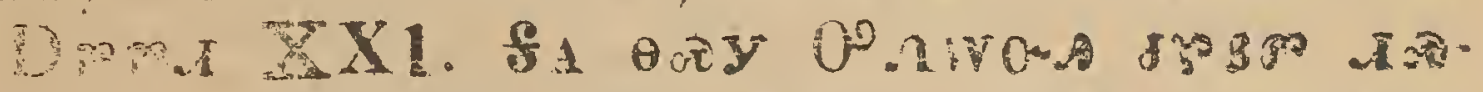

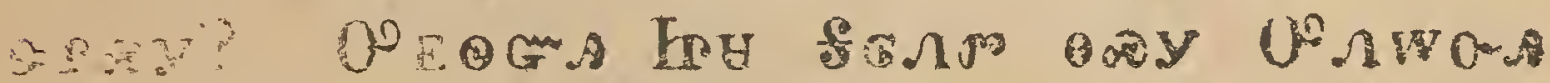

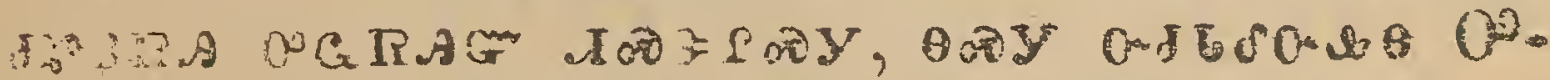

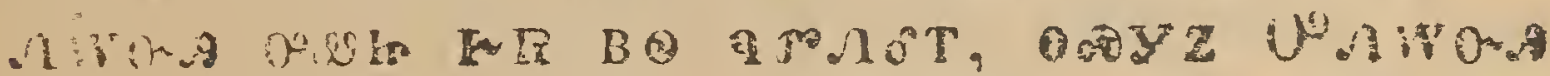

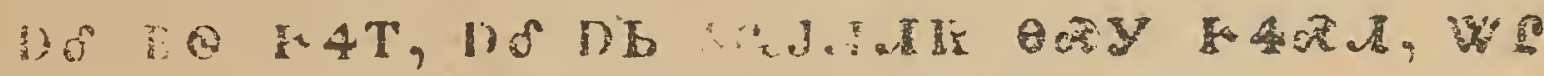
J

A A

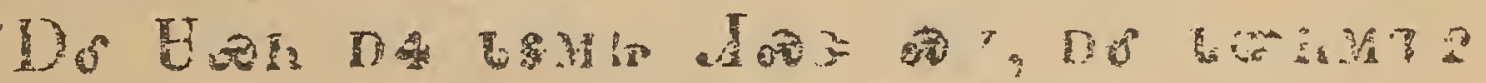

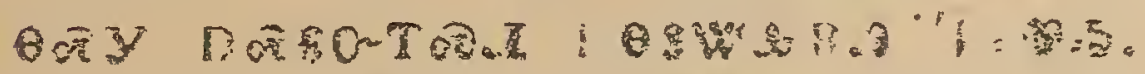

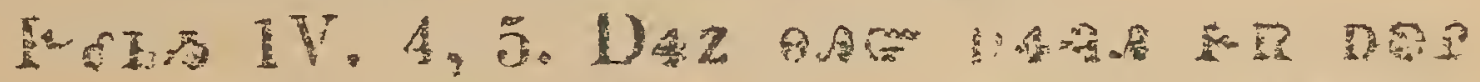

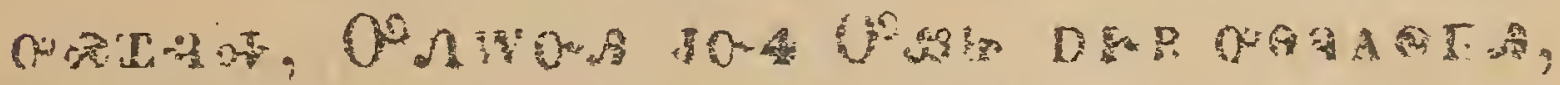

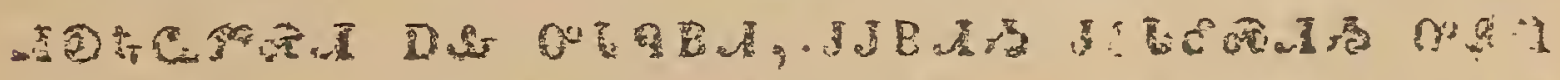
4 OOX O'E

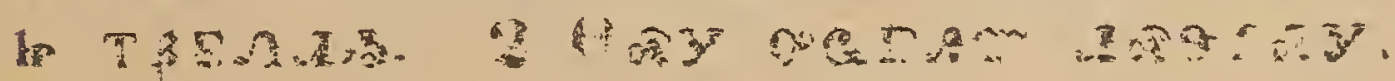


$\vdots \frac{i}{2}$

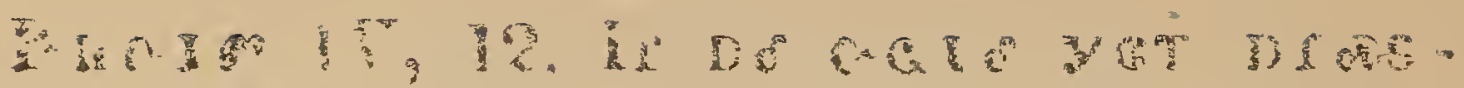

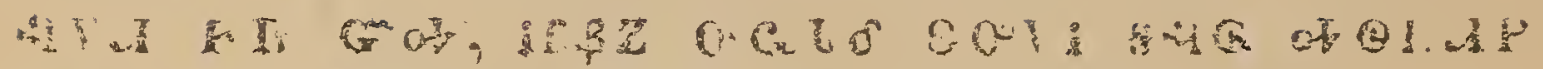

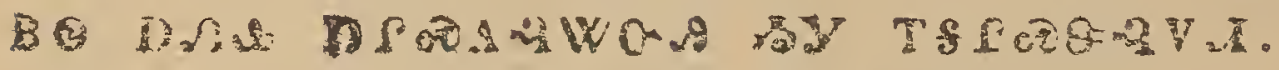

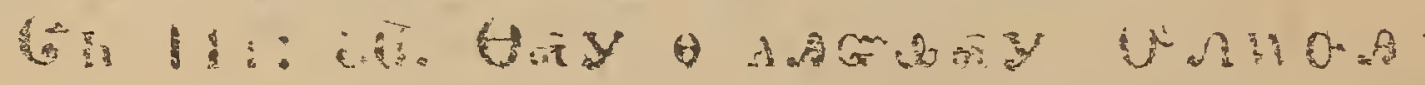
U,

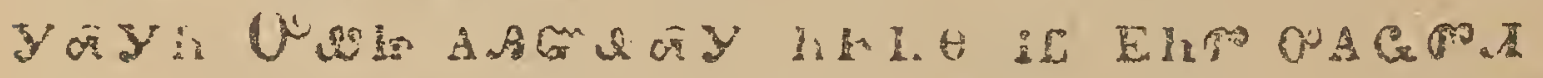

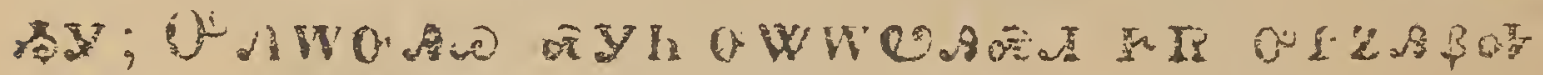

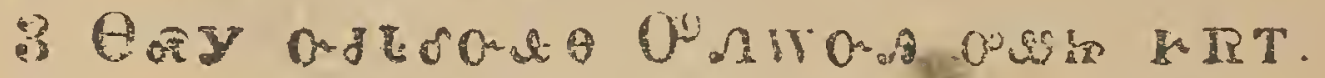

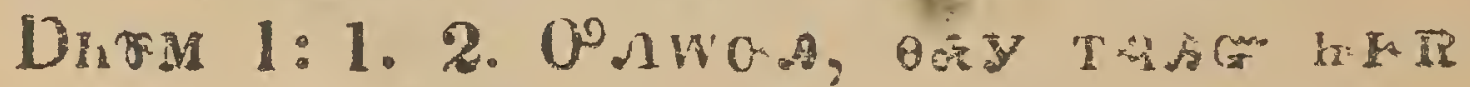

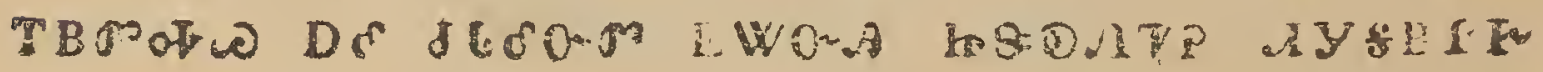

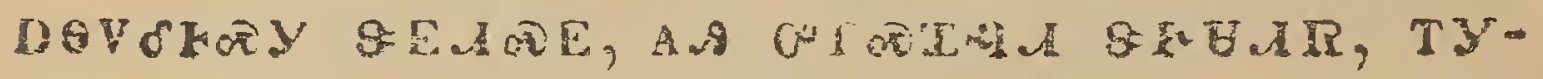

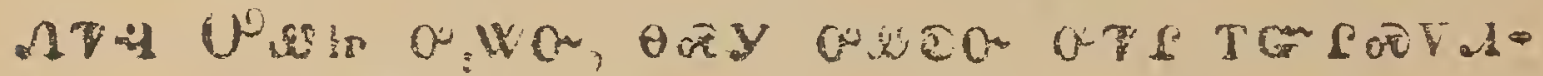

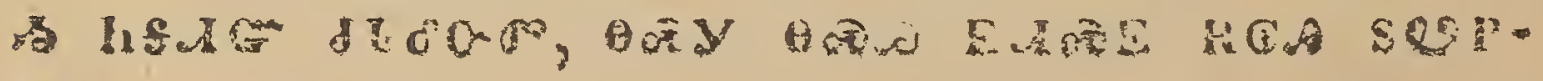
AT.

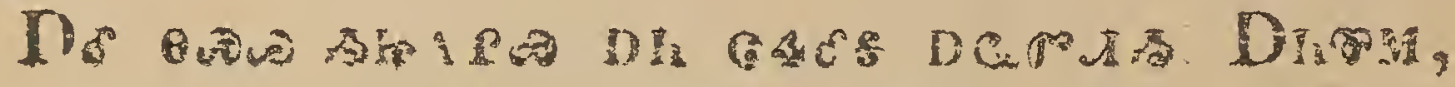

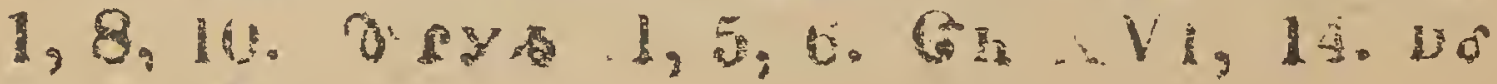
$6 \mathrm{x}+11 ; 5$

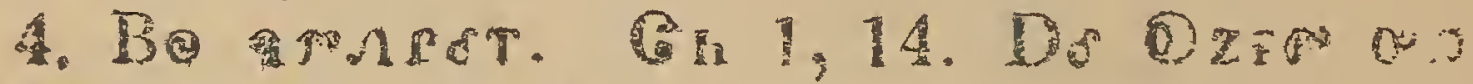

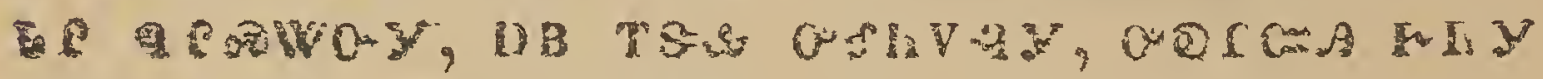

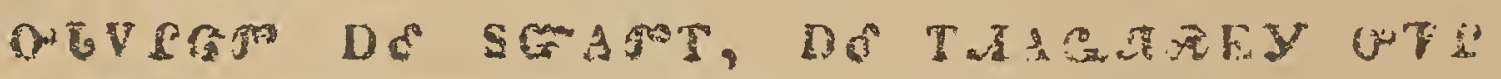

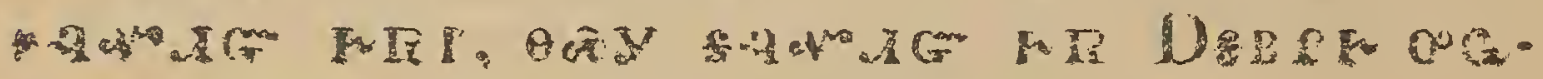

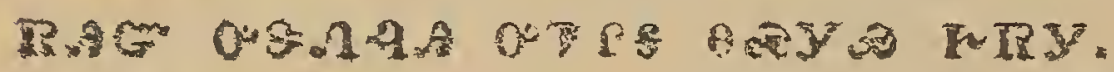

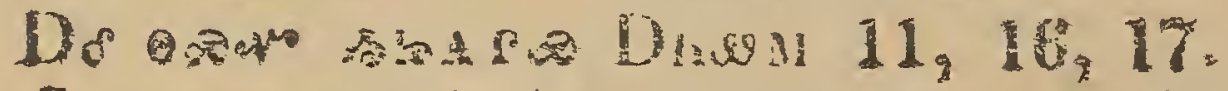

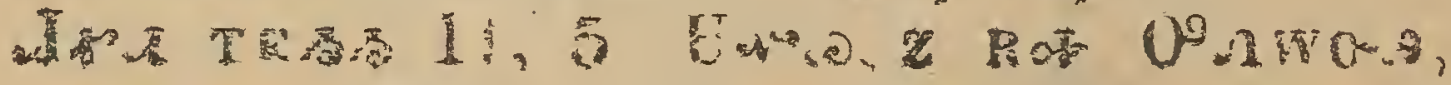

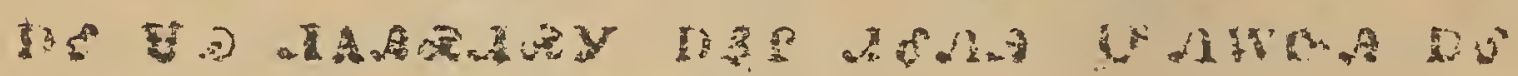

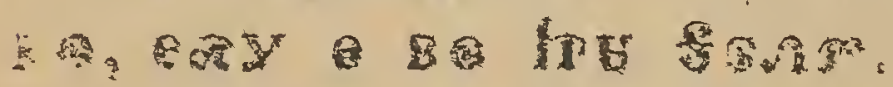

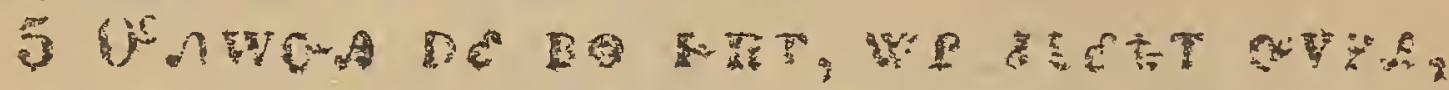

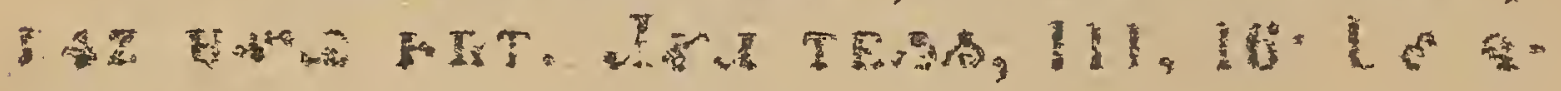

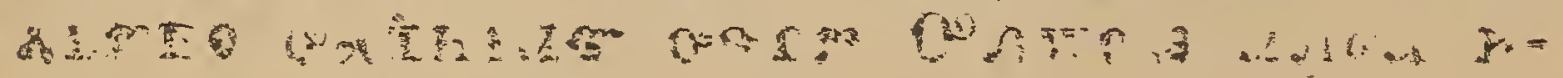




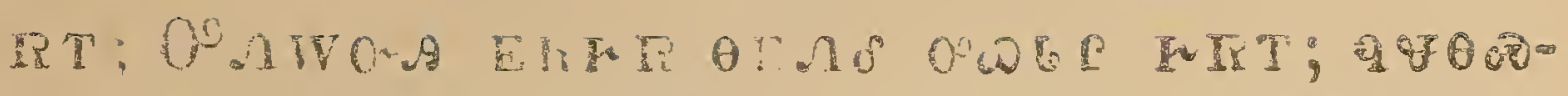
$0^{3} \theta$ Eh

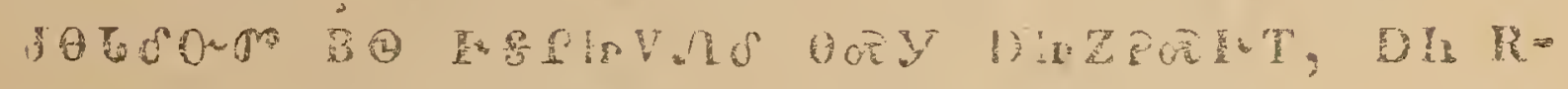

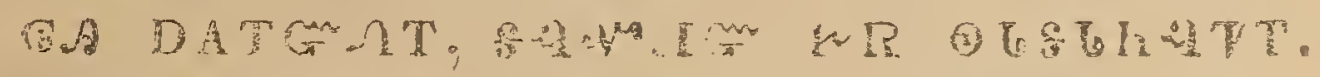

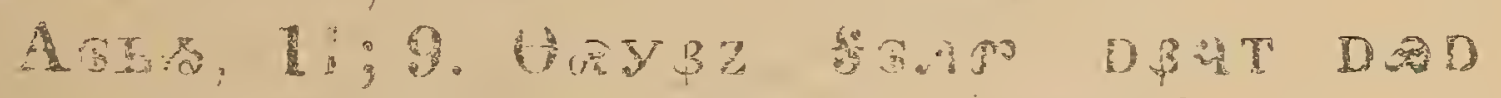

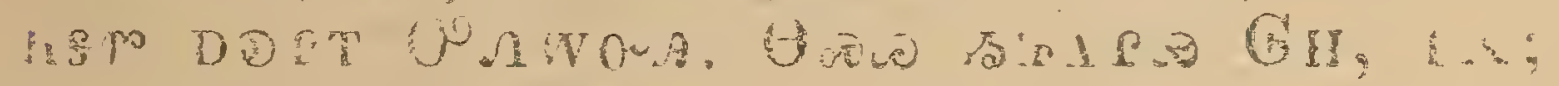

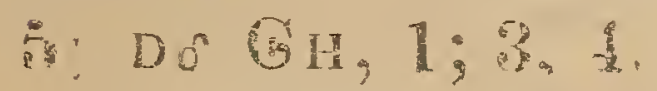

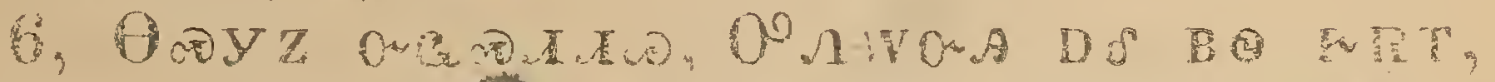

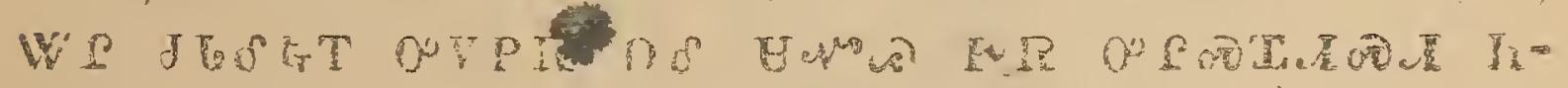

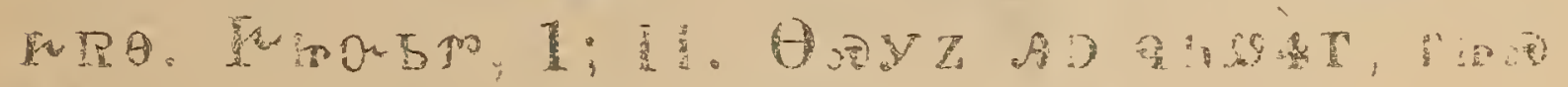

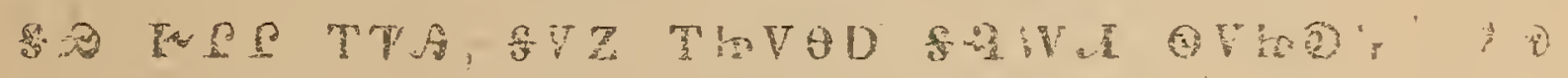

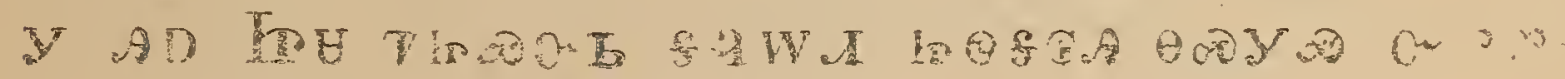

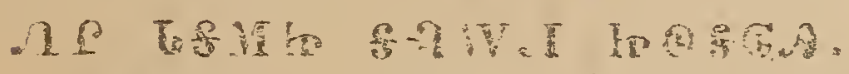

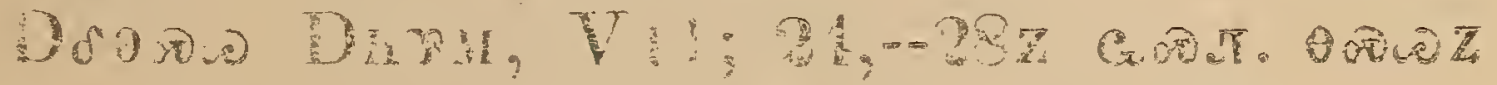

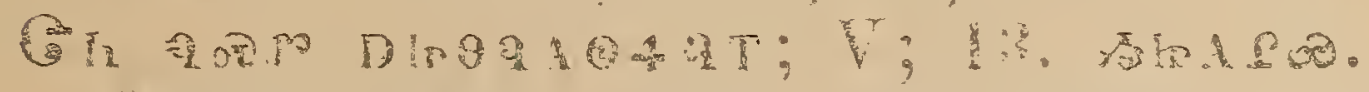

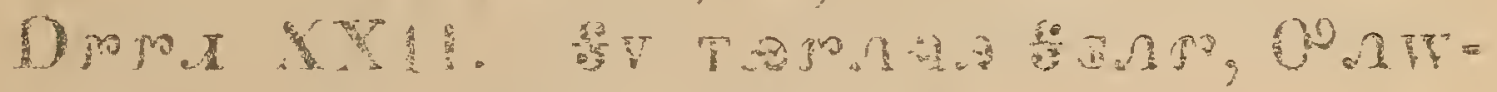

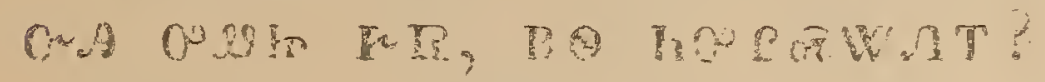

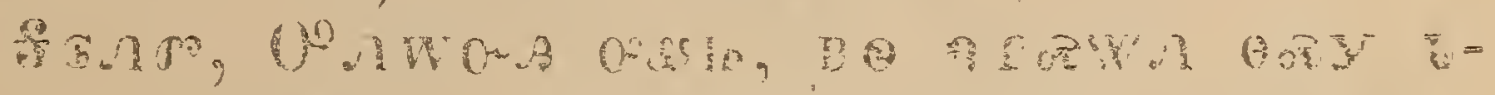

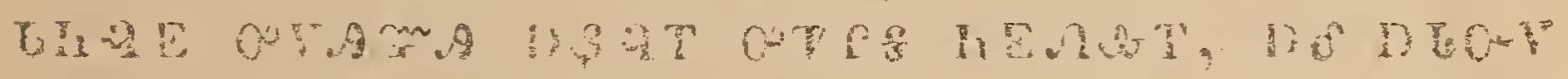
6.

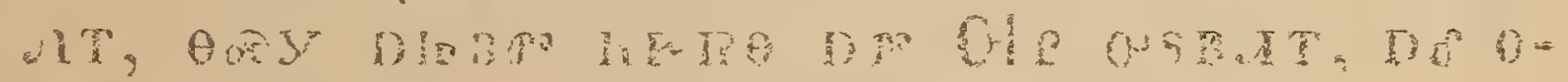

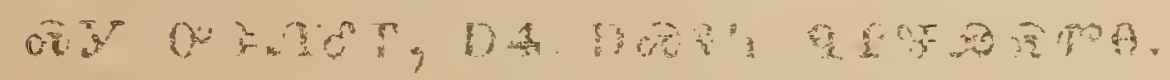

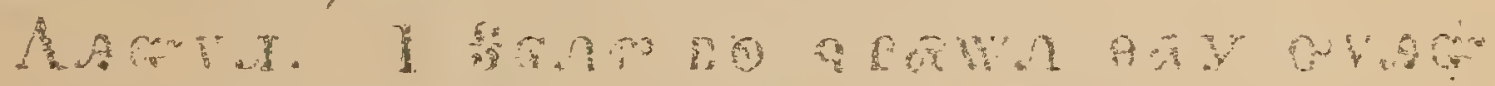

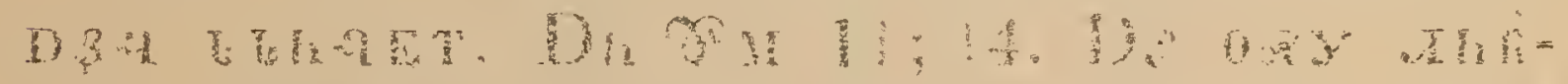

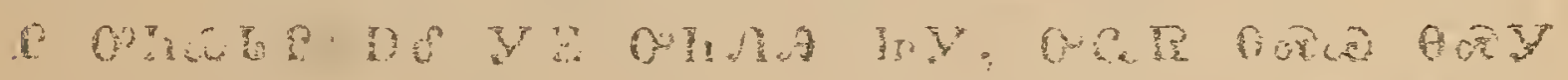

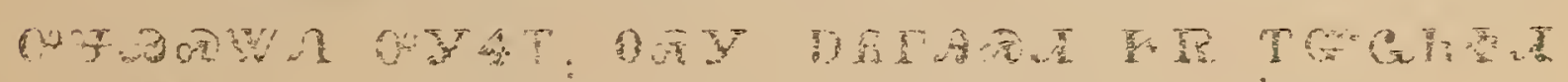

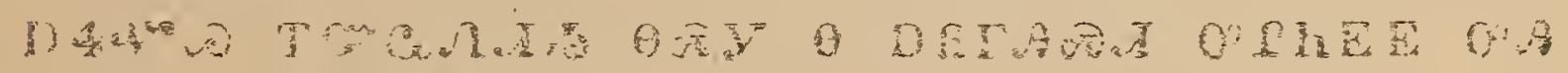

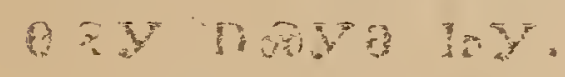

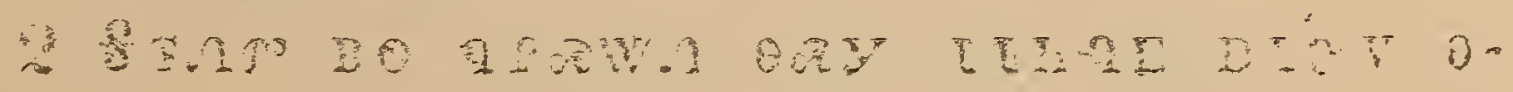




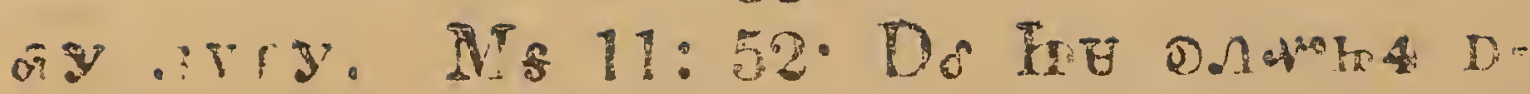

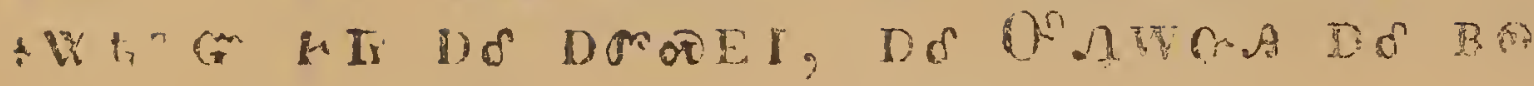

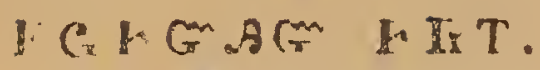

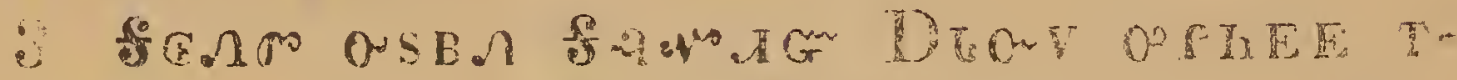

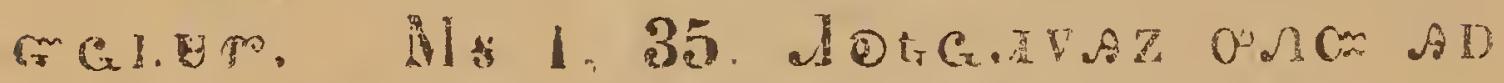

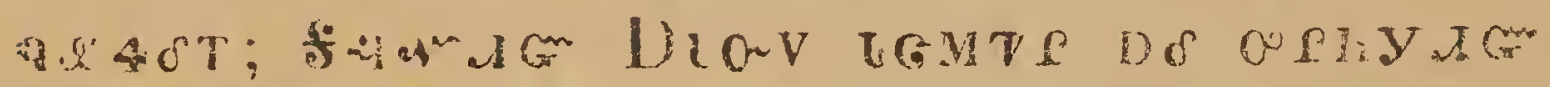

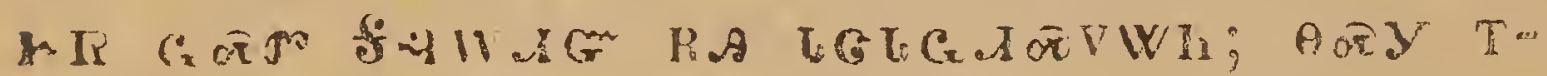
(m) O.xitr DA4 PिOAd.

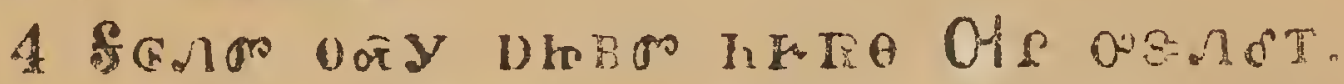

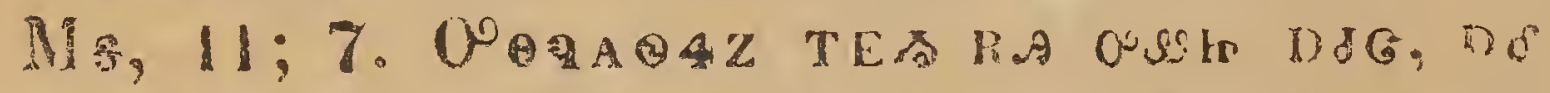
Q中.

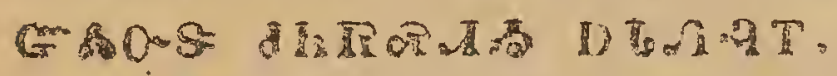

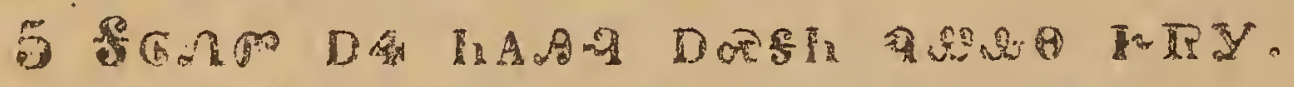

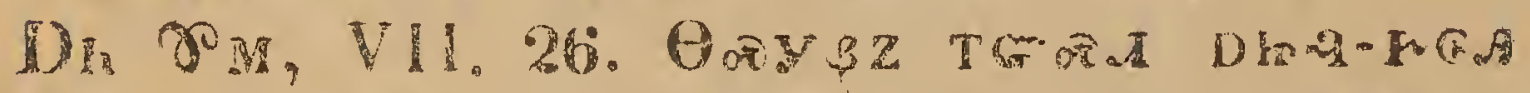

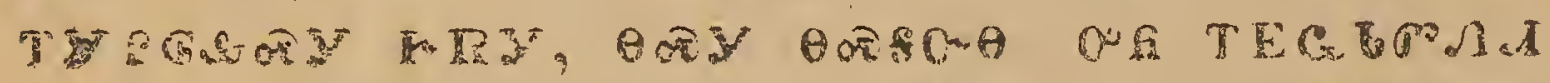

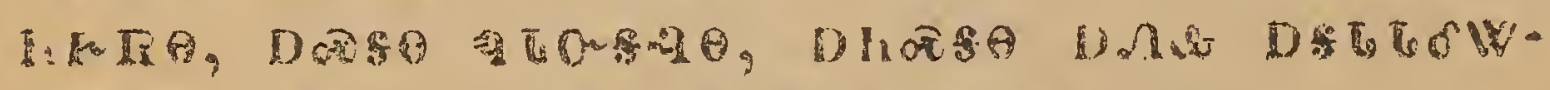

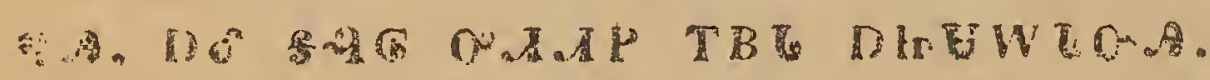

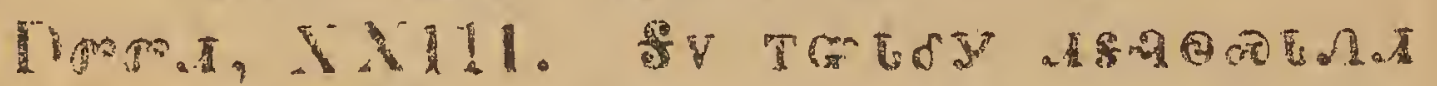
80 -

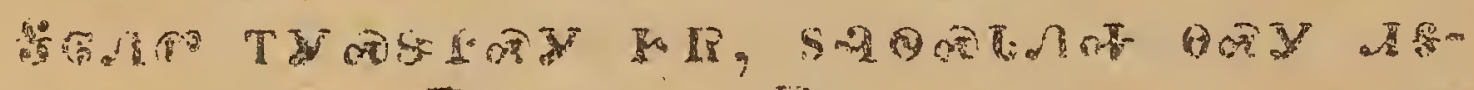

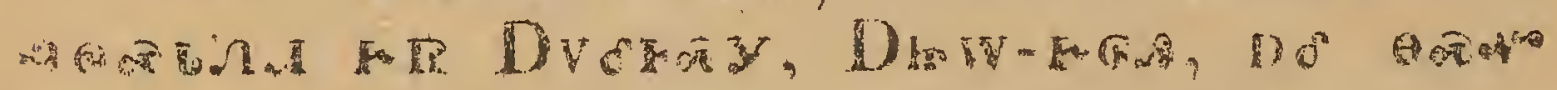

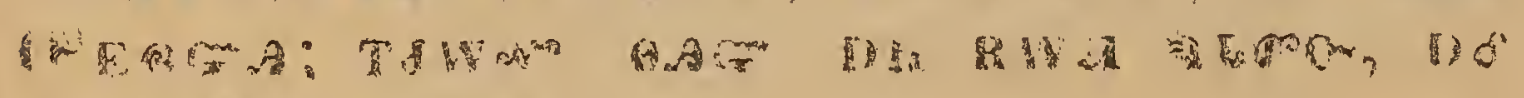
(1)

A, A

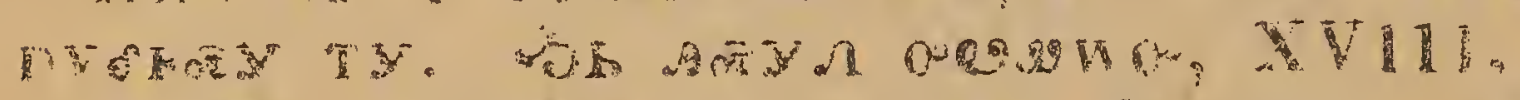

1

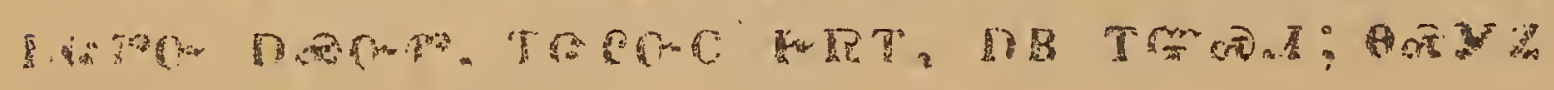

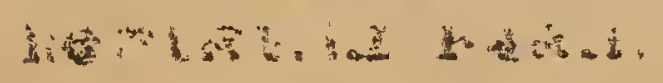




\section{结兵}

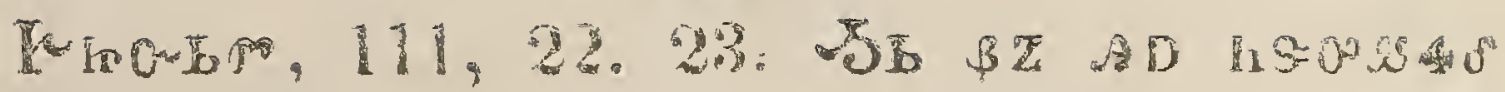
IVVG; "T6

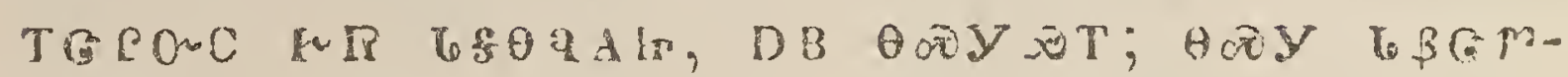
ToOU

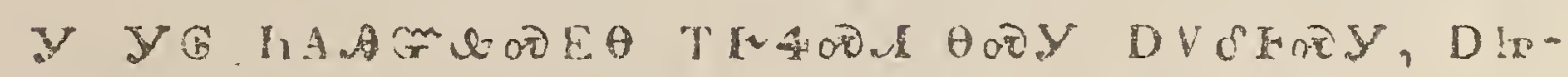

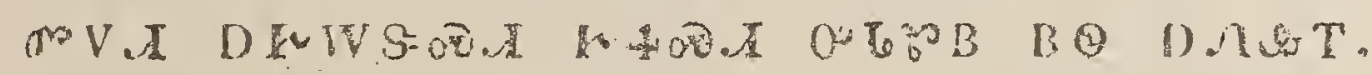

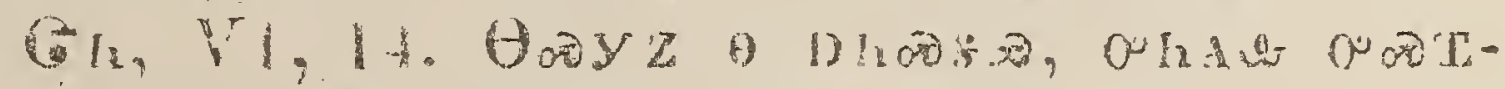

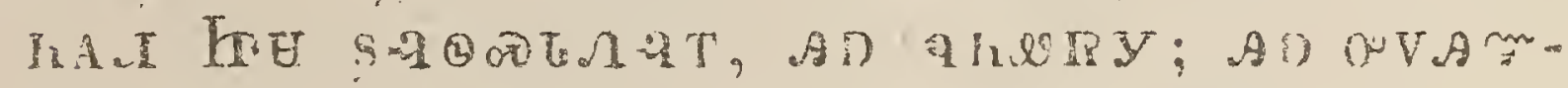

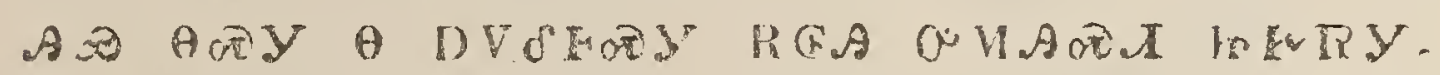

2 T.

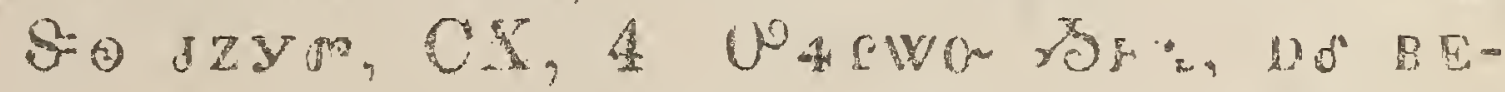

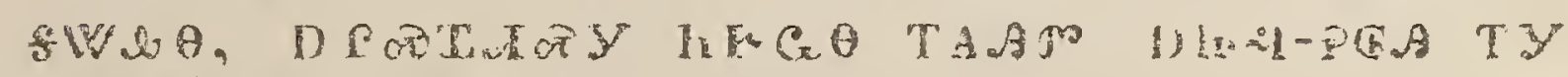

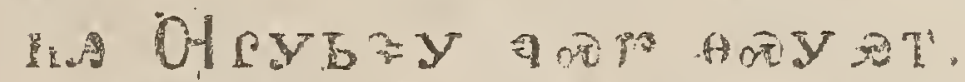

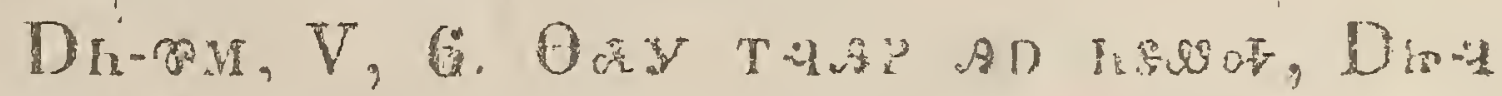

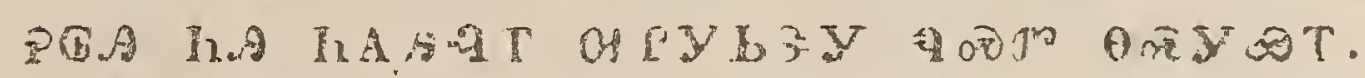

3 ТУ,

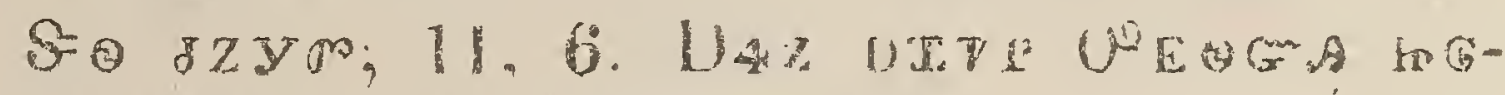

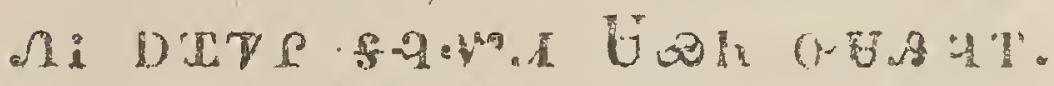

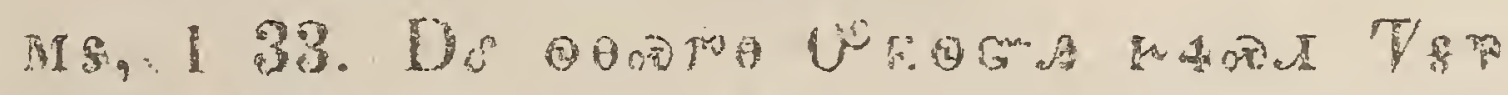

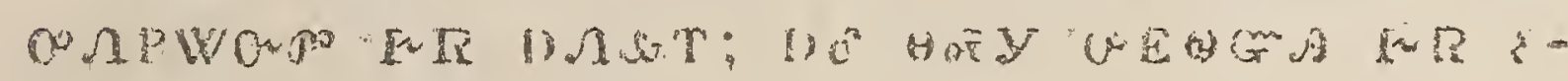

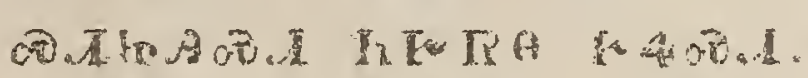

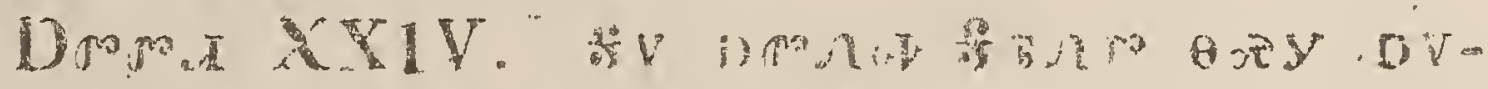

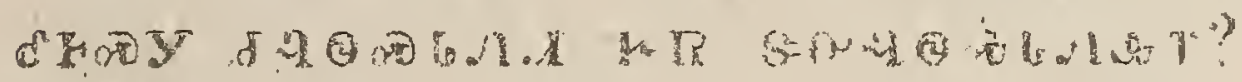

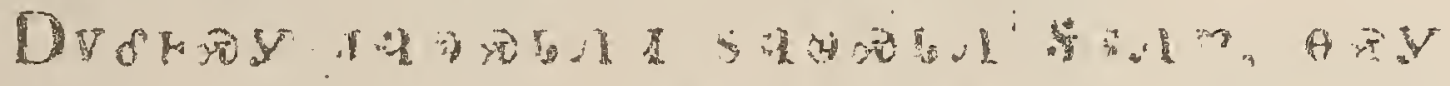

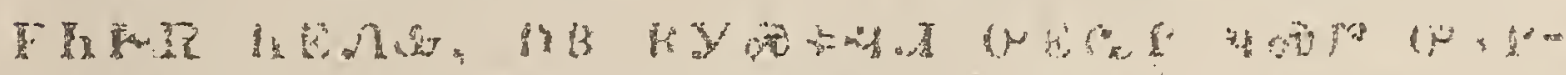

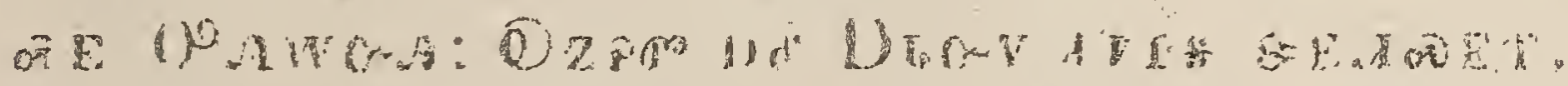

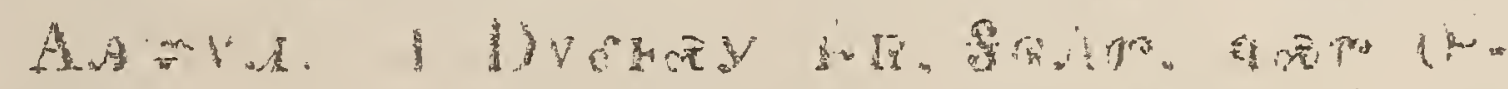
AWO

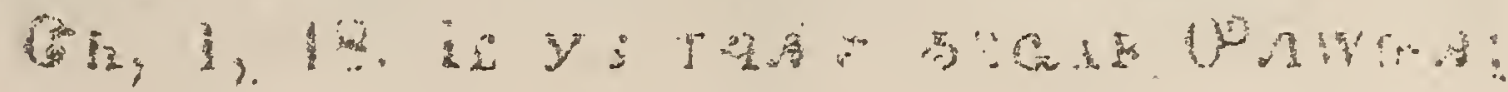




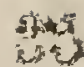

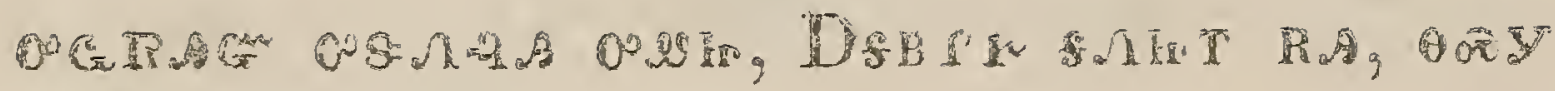

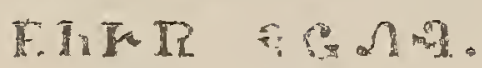

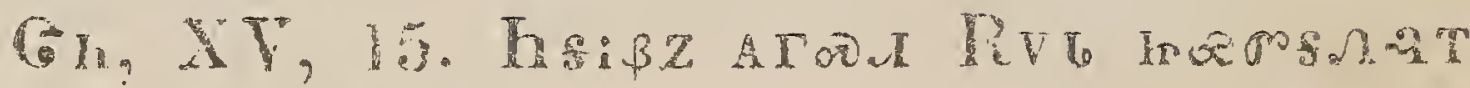

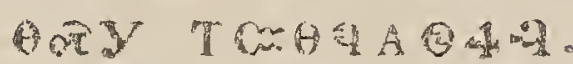

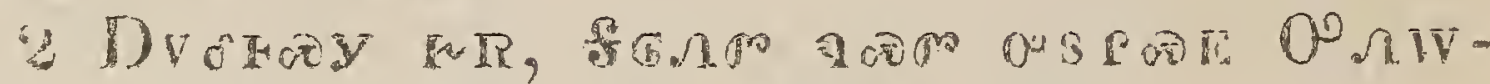

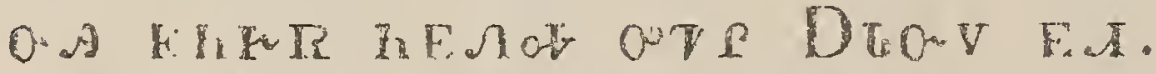

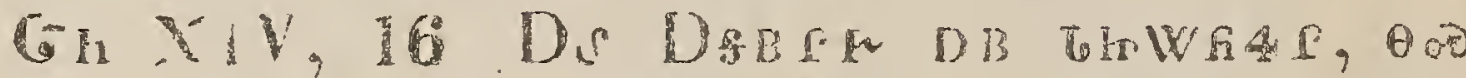
YZ. UGPOAn

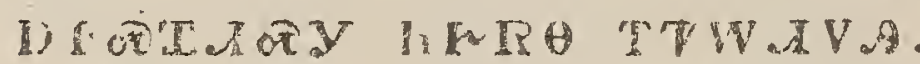

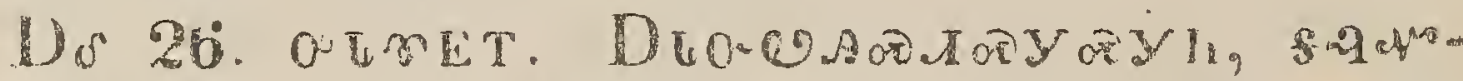

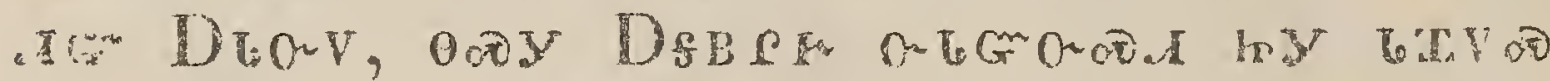
H,

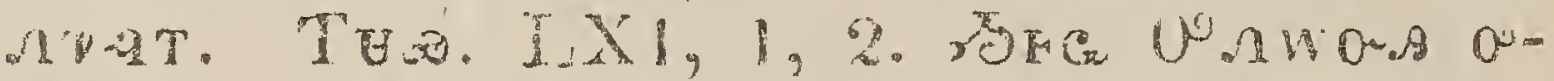
TI DEOH WE-DT,

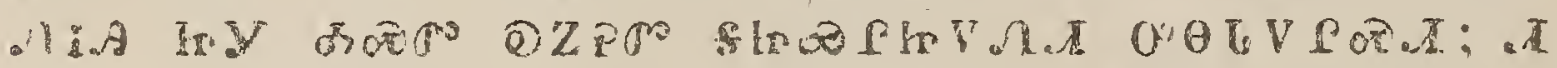
YOW I I I

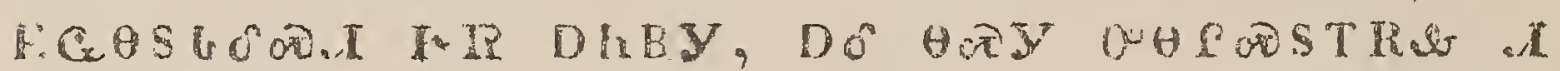

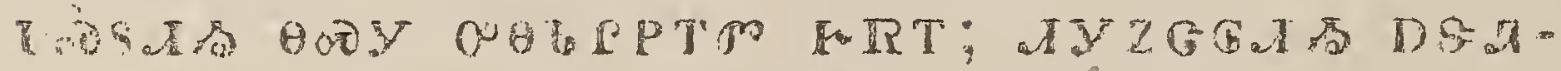

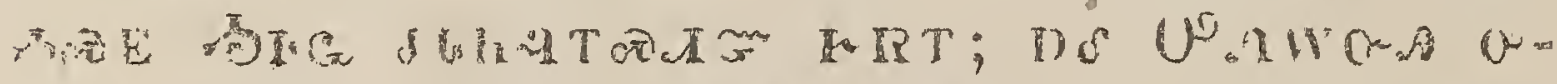
B

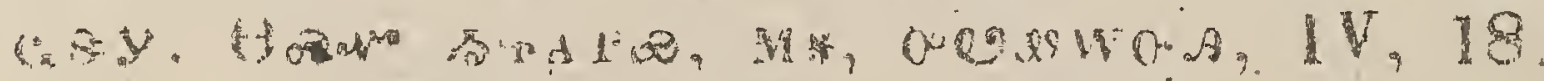

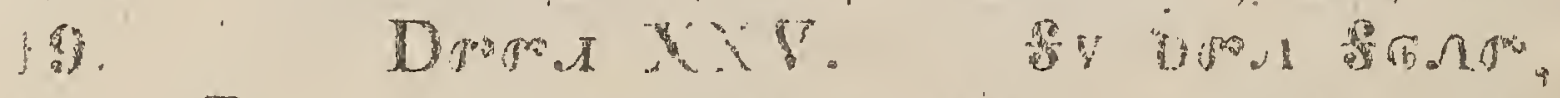
4. 1)

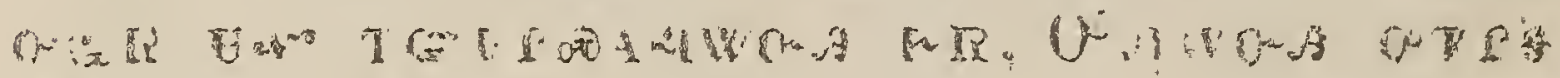

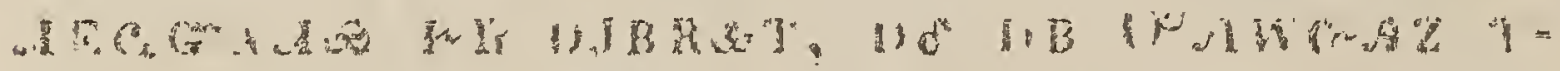

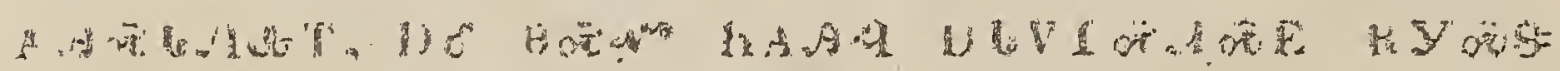

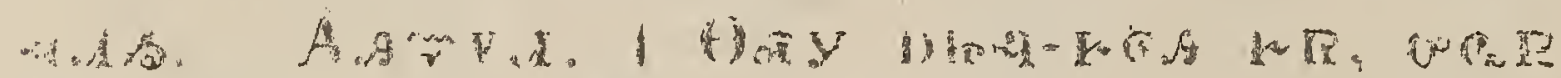

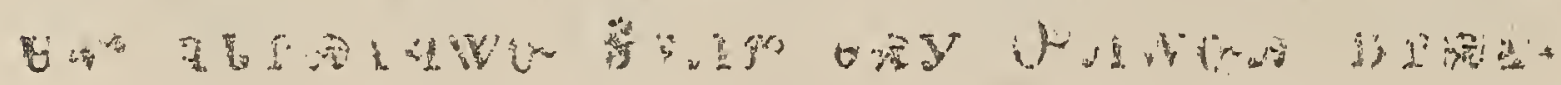




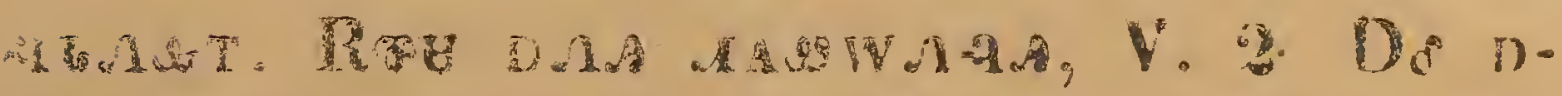

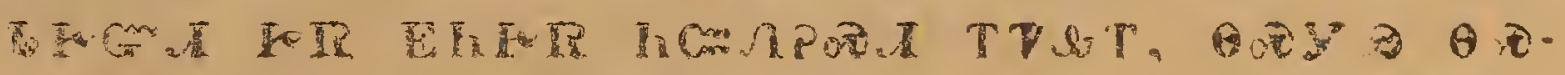
4t

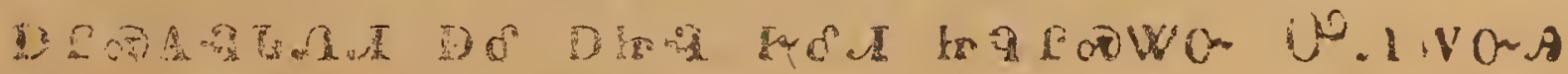

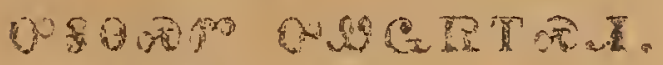

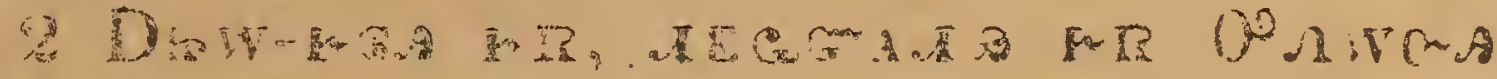

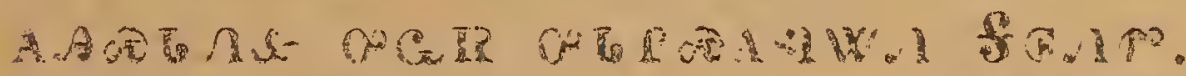

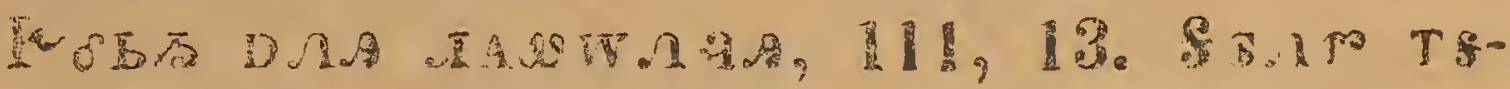

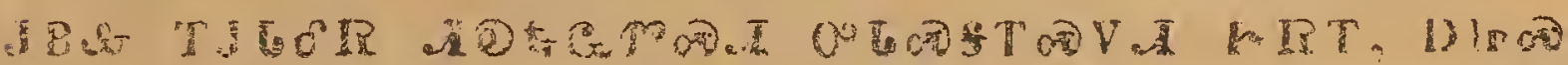

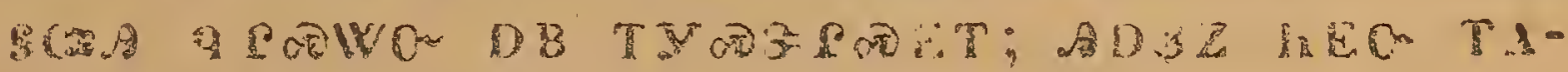

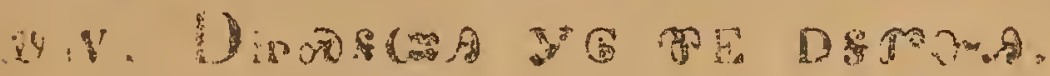

当)

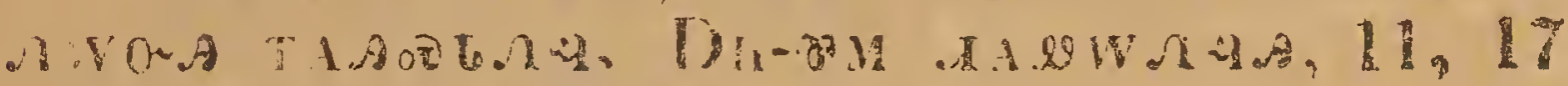

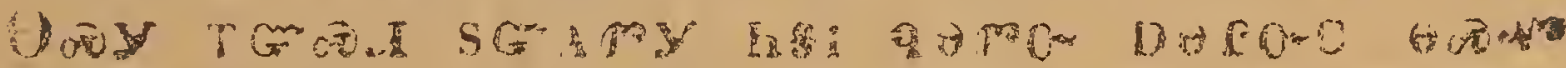

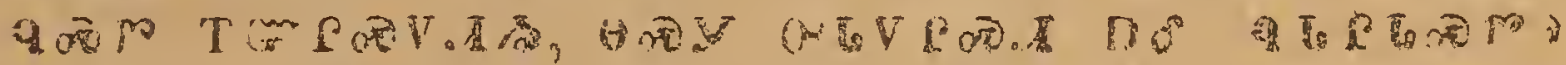

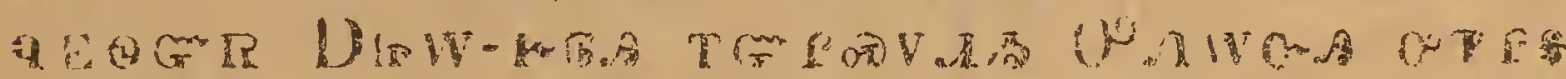
U (4)

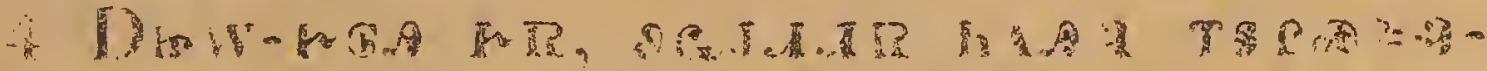

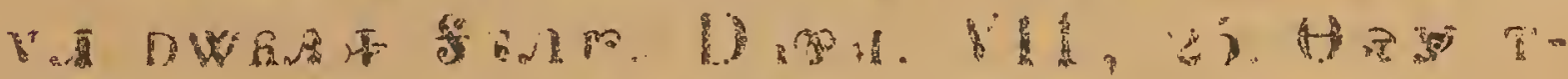

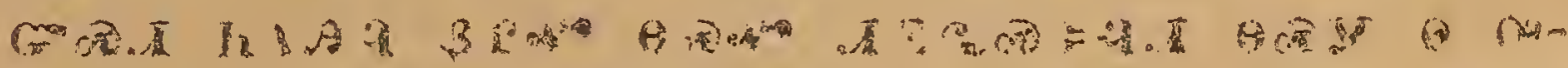

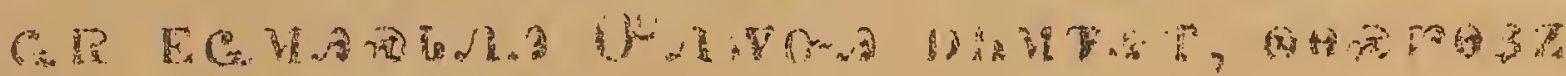

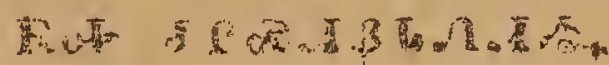

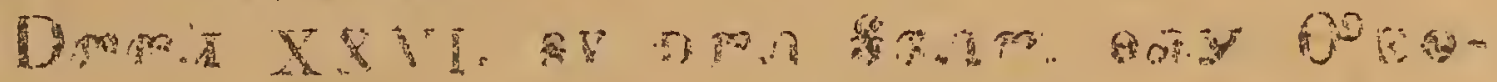

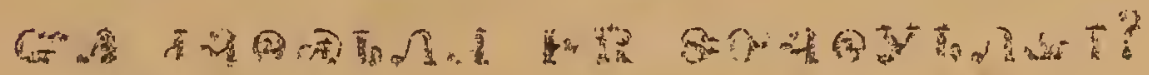

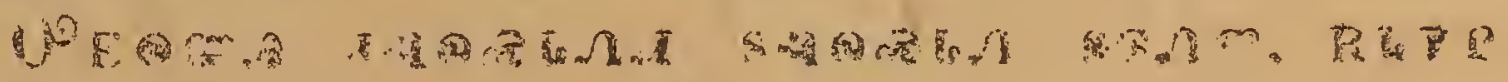

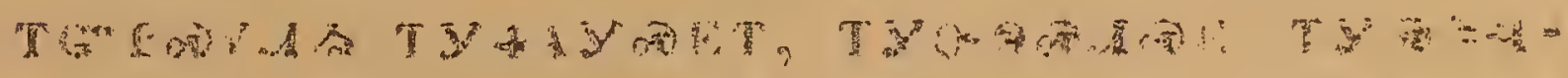

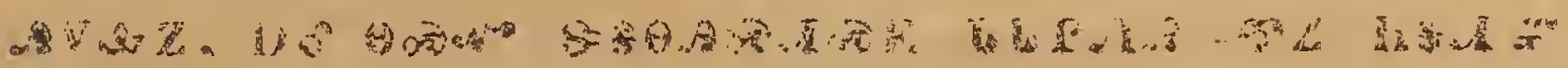

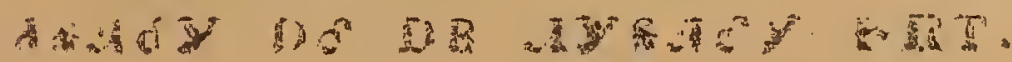




\section{5}

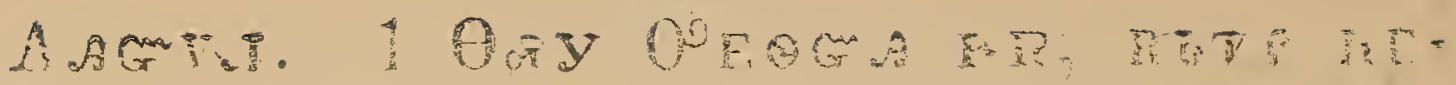

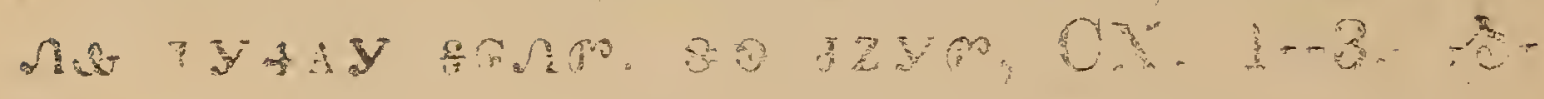
FC A D O Co

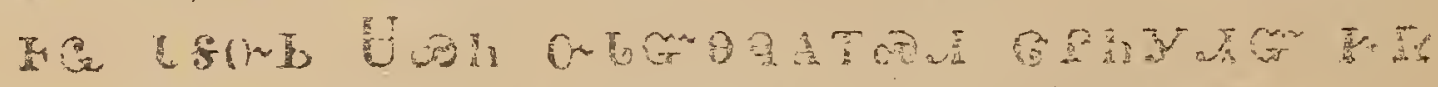

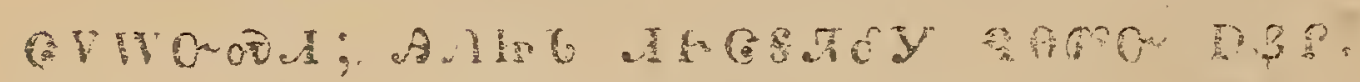

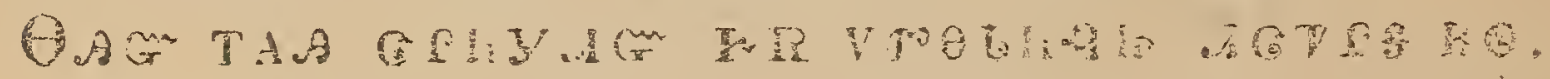

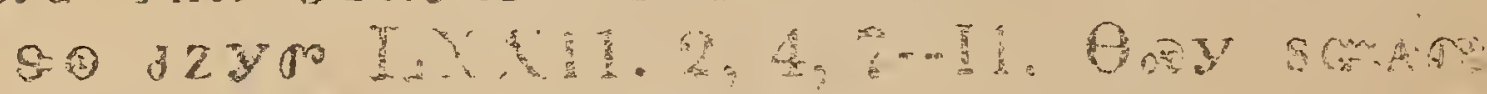

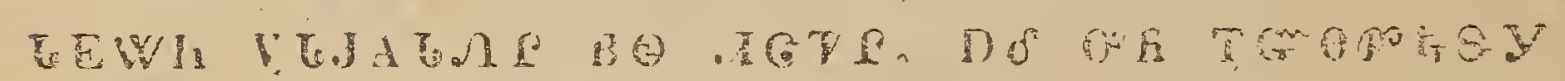

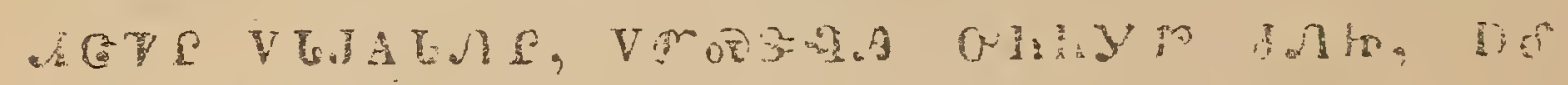

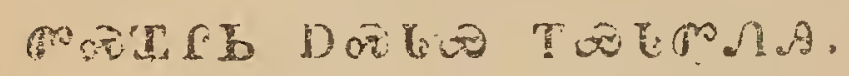

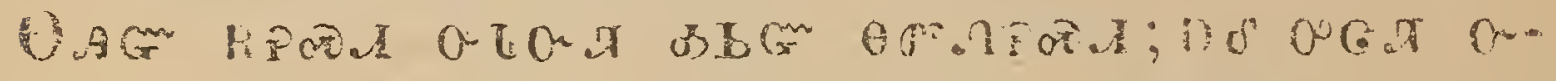

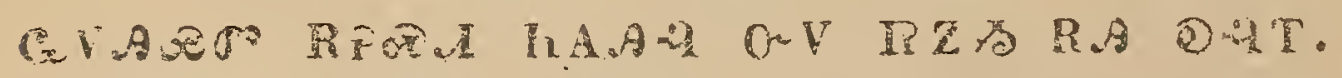

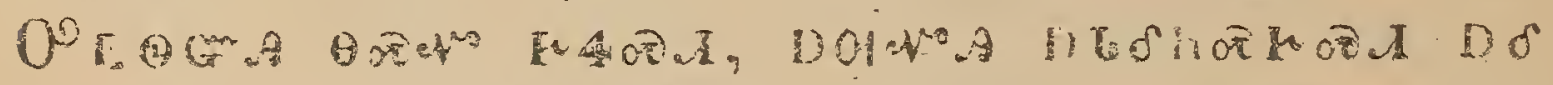

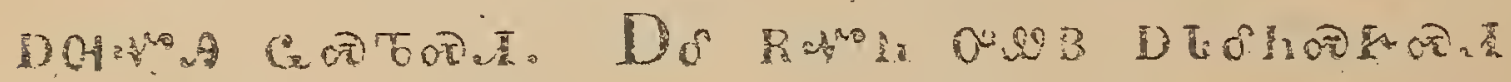

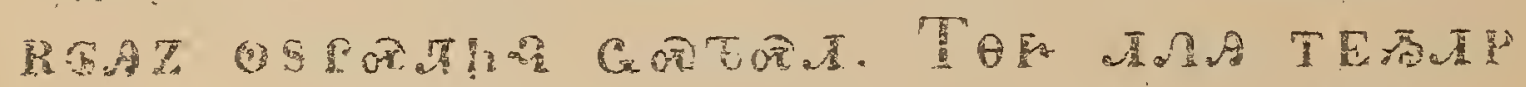

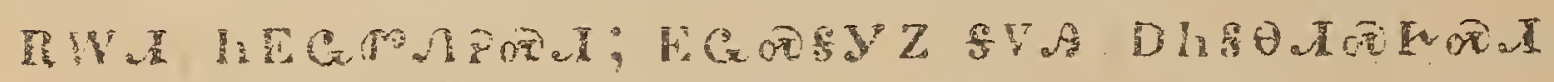

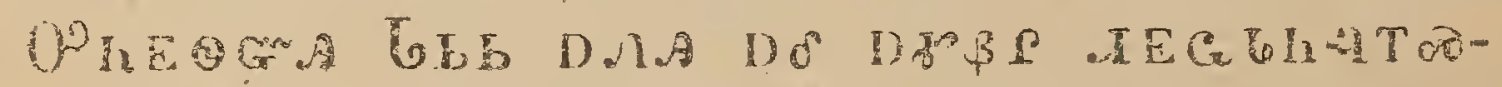

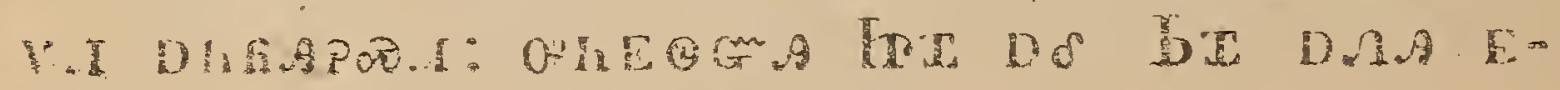

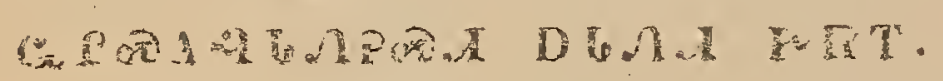

B. He

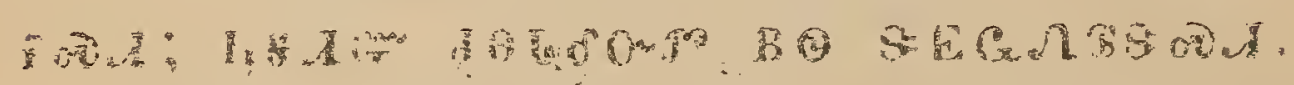

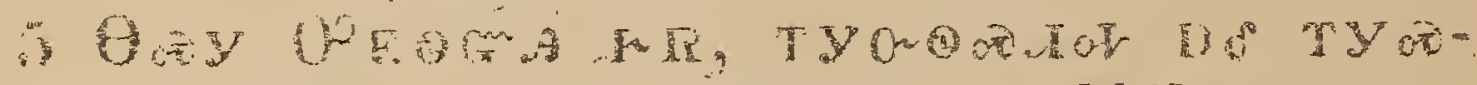

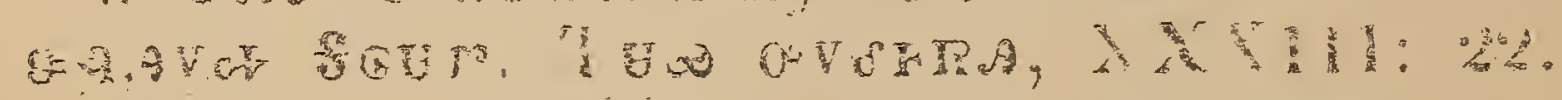

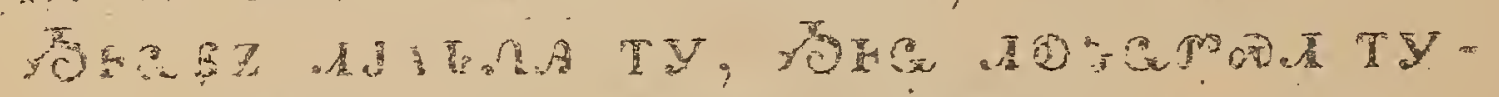

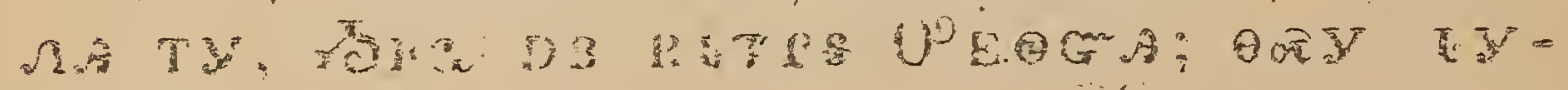

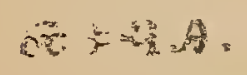

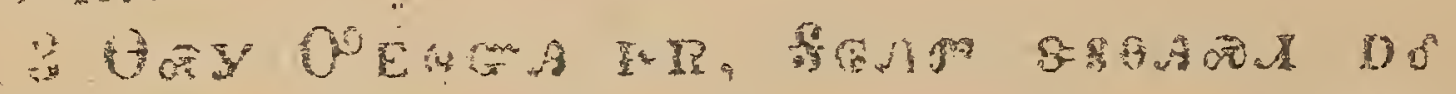

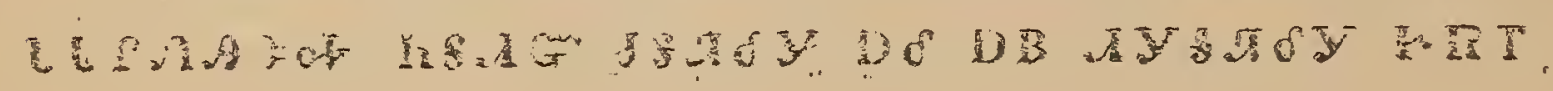


38.

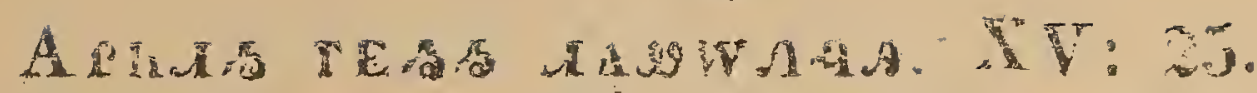

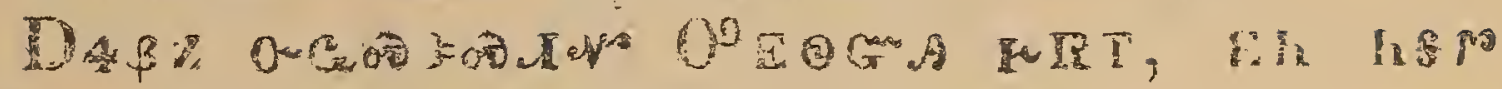

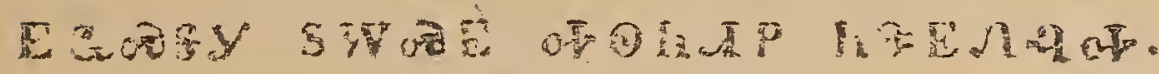

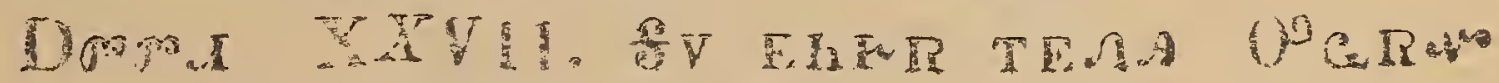

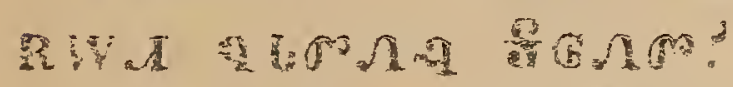

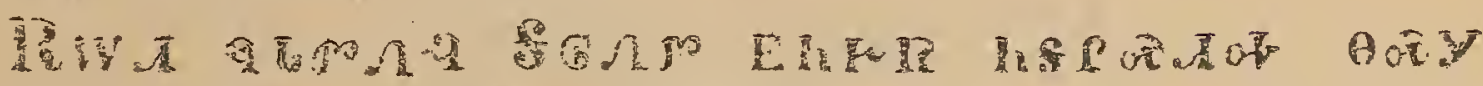

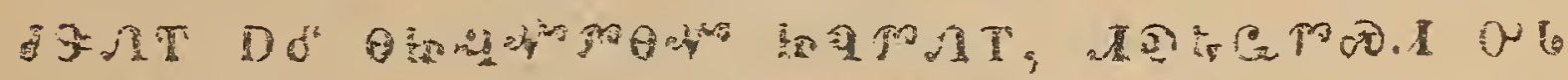

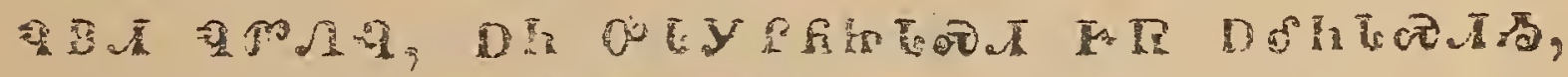

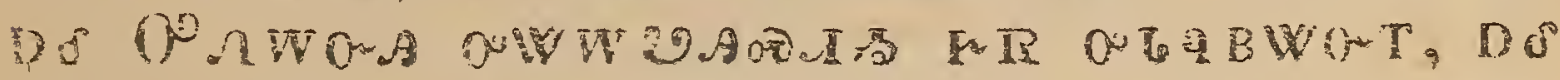
Q Q

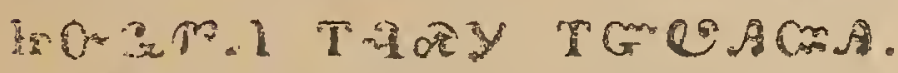

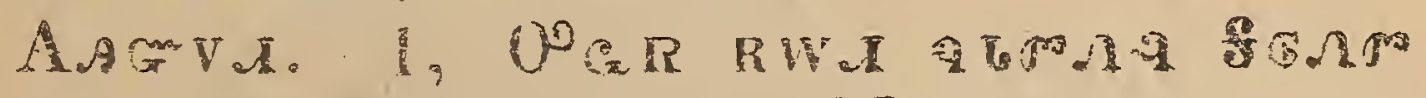

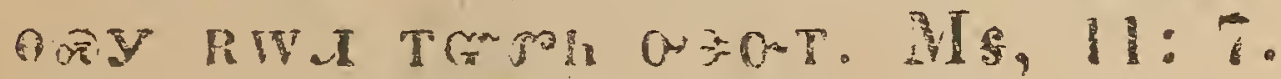

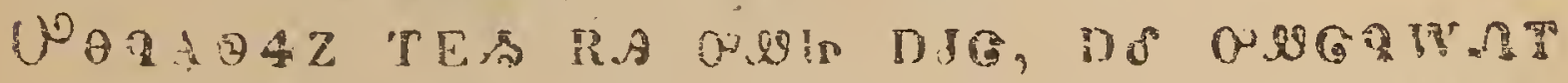

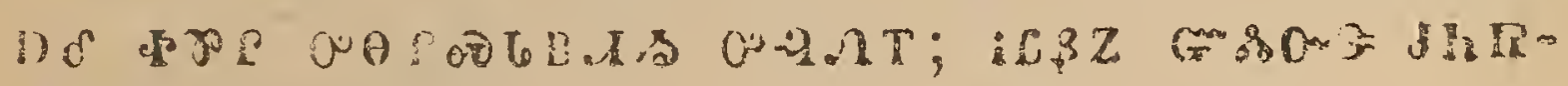

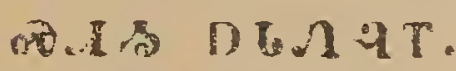

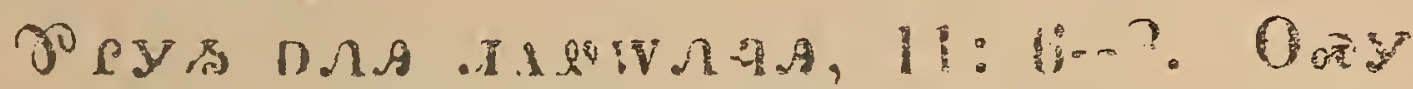

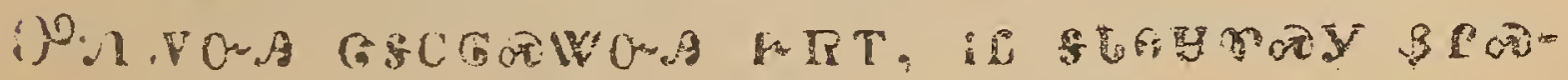

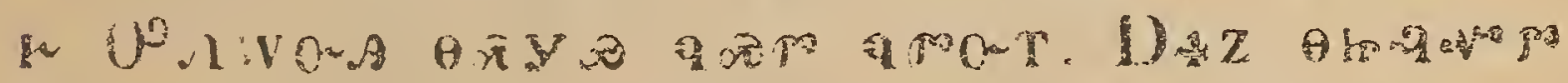

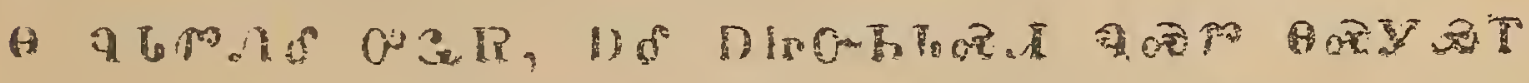

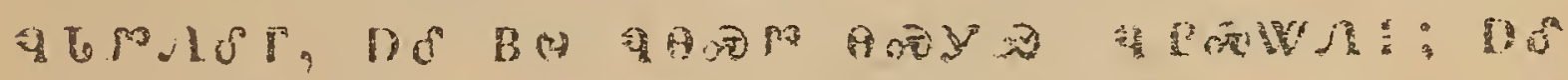

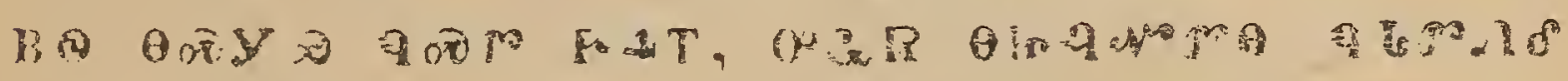

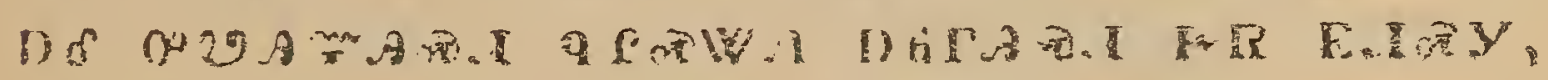
AOEY

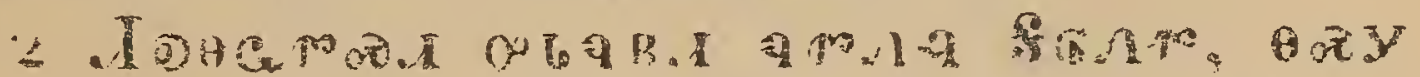

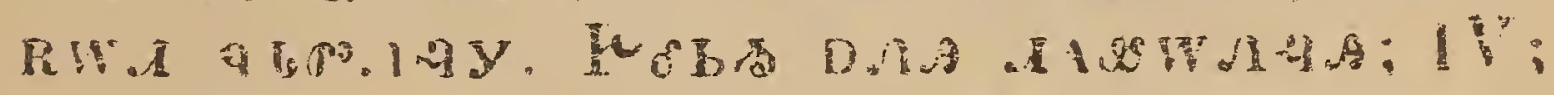
4. D+Z A

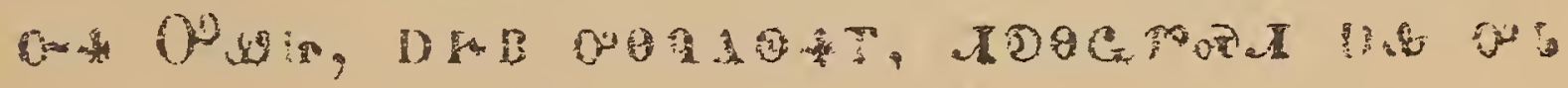




\section{9}

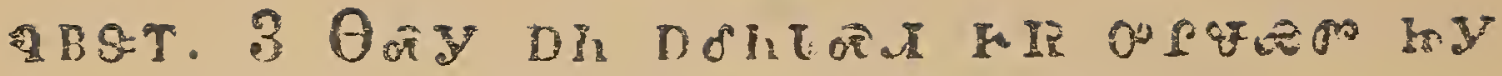

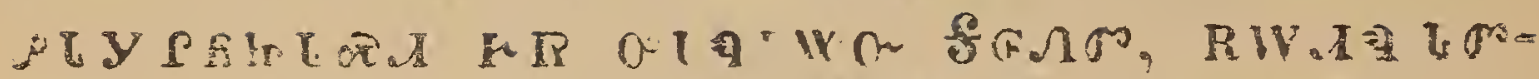

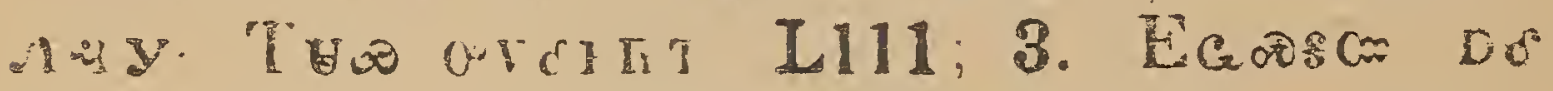
D68 B B

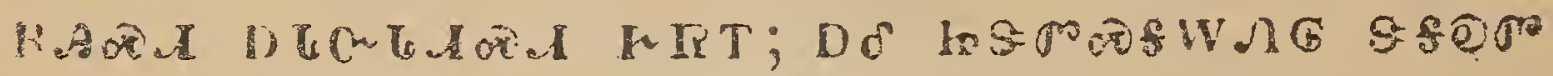

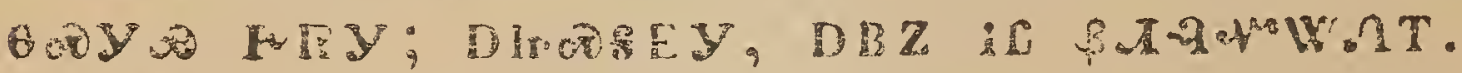

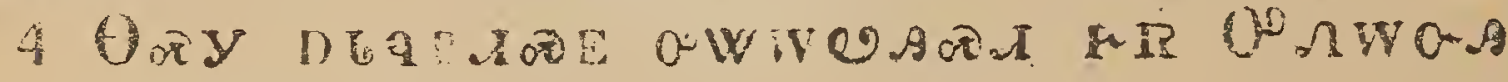

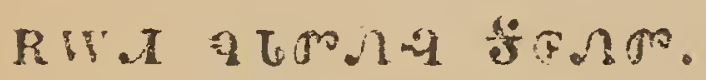

के .

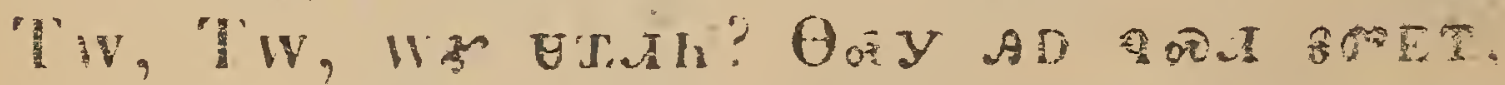

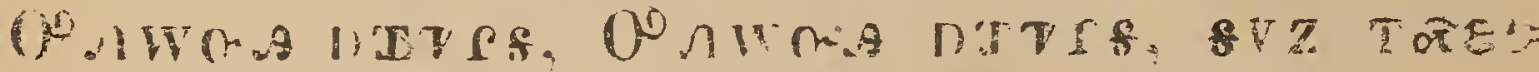

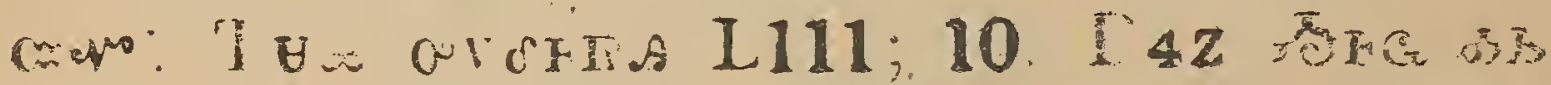

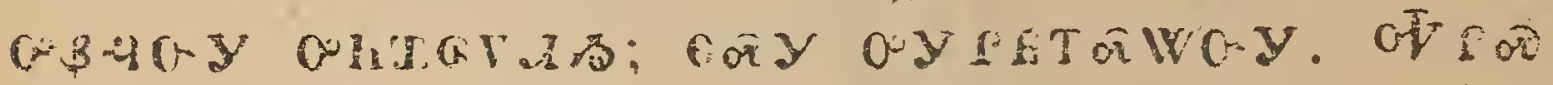

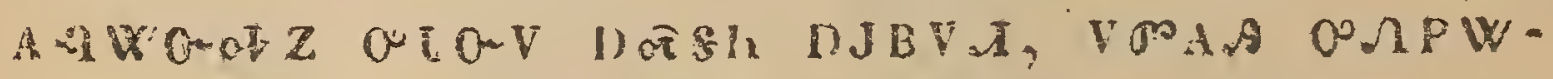

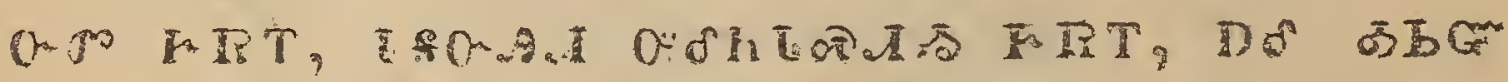

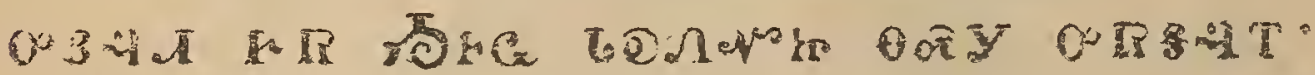

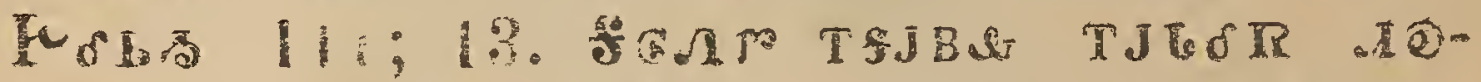
1. COA

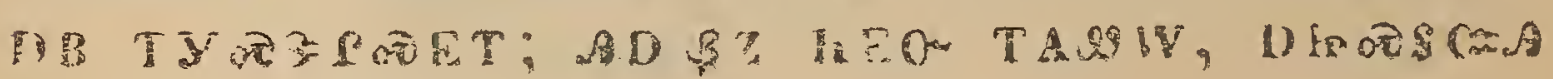

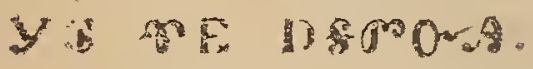

- ODY DL

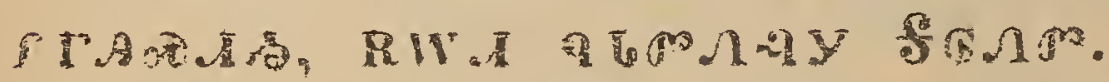

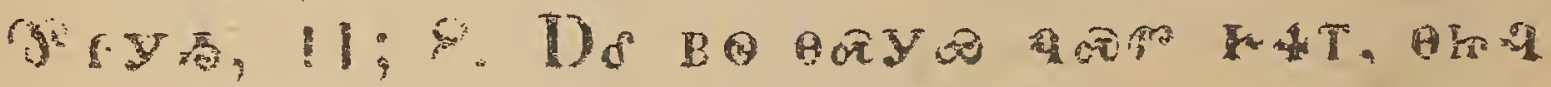
औ"

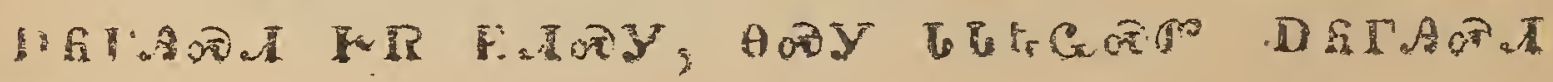
T. RT $\mathrm{T}$.

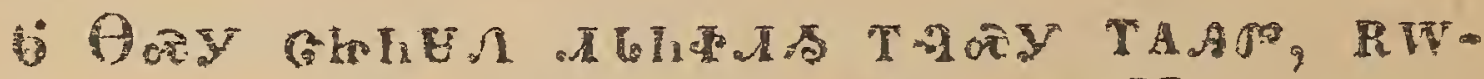

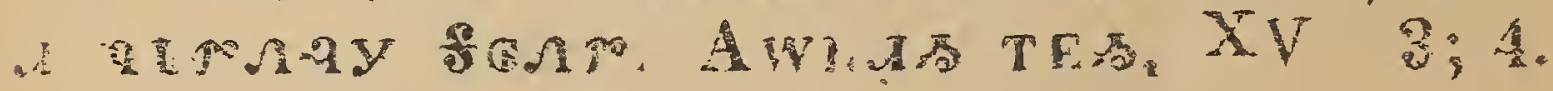




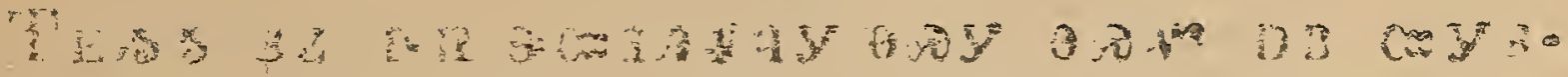

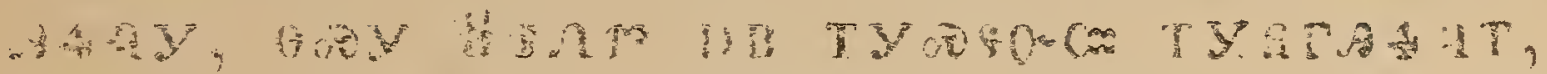

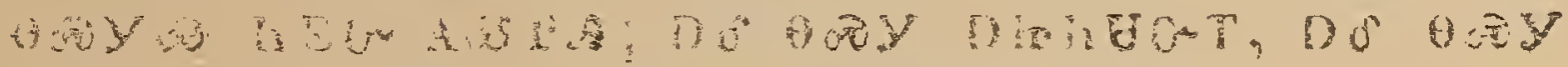
और

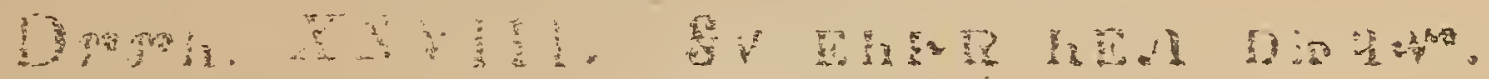

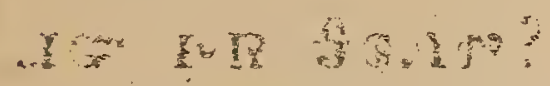

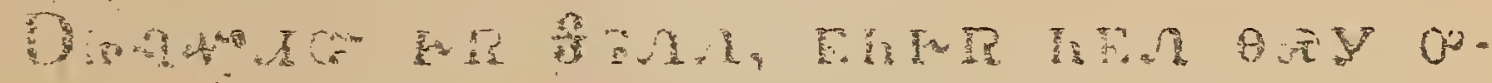

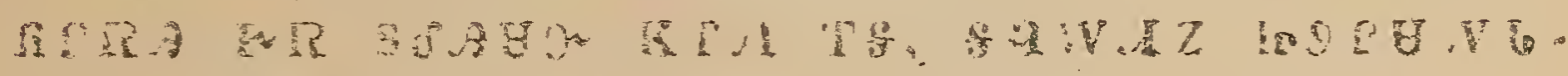

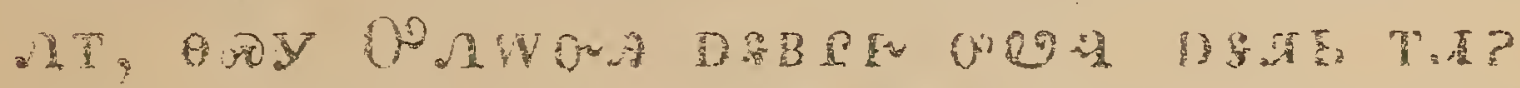

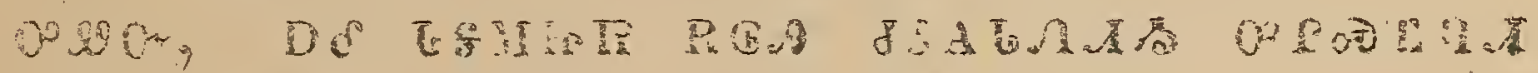

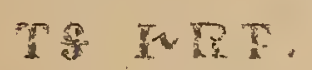

A. A w

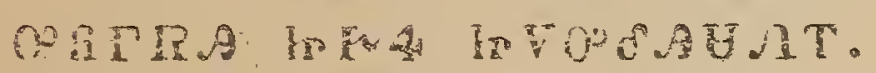

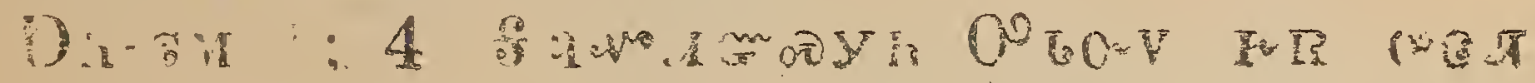

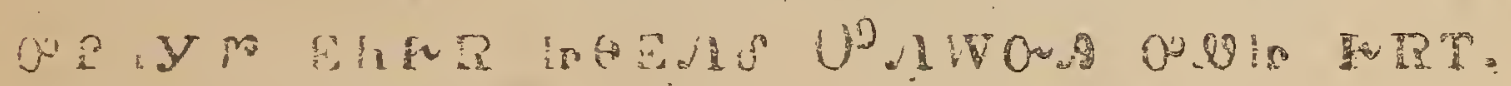

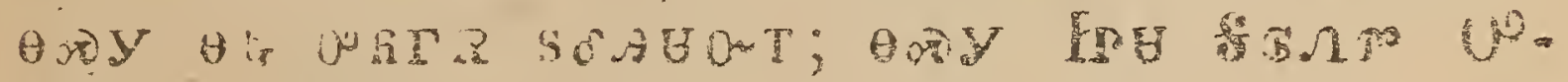

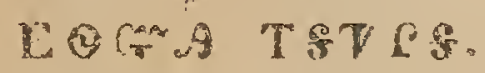

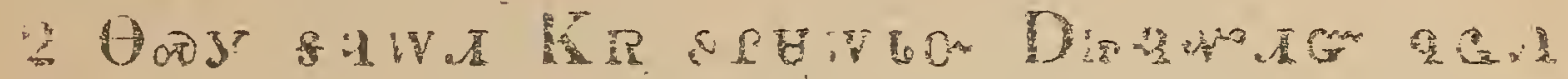

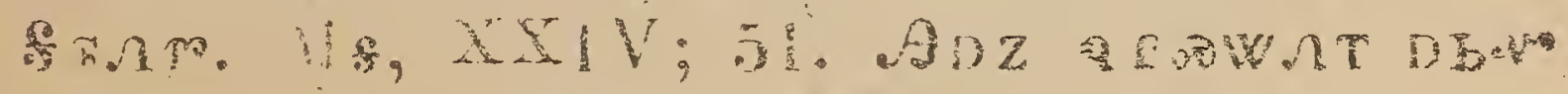

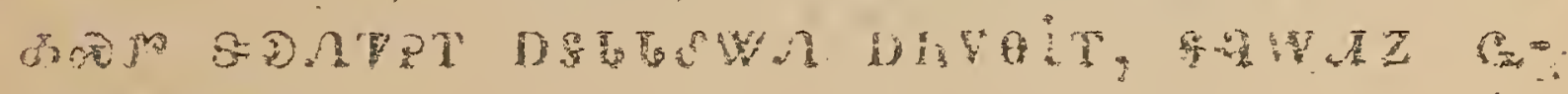
繁

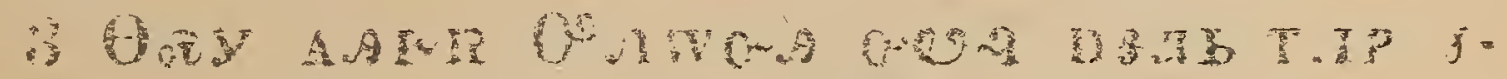

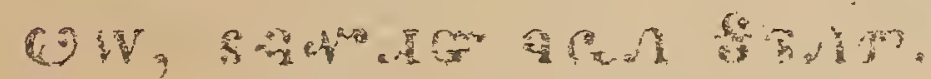

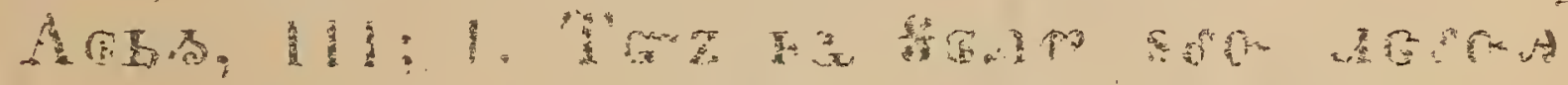

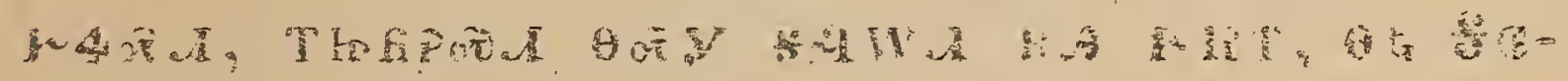

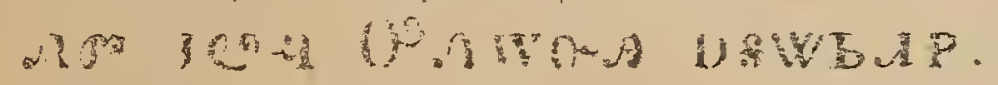

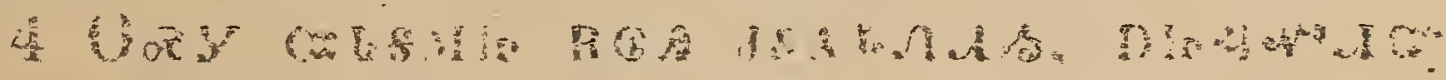

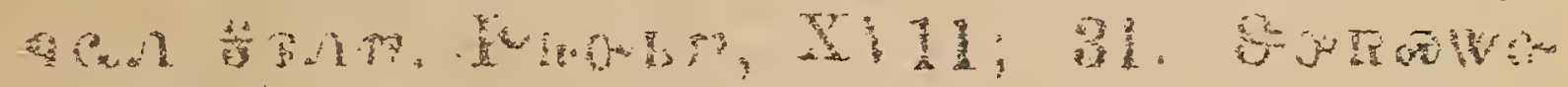

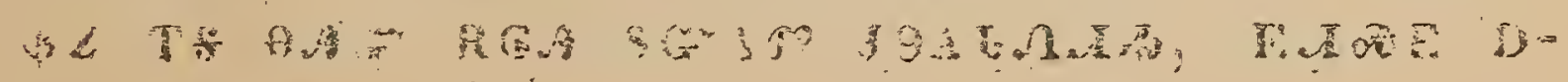




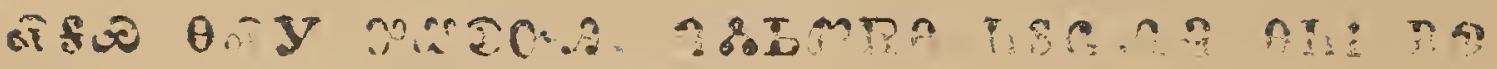

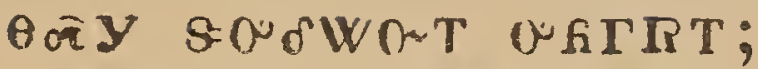

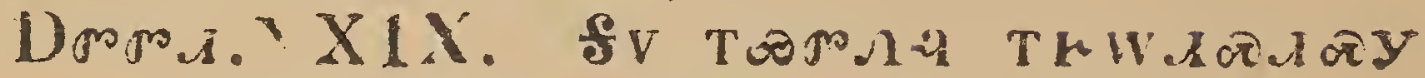

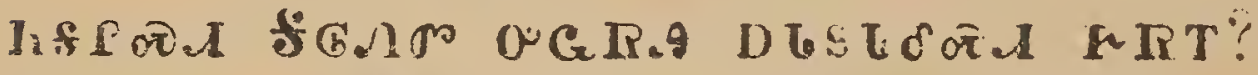

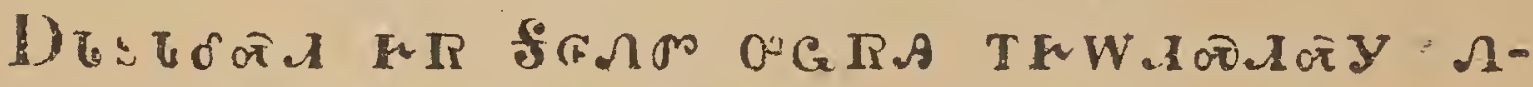

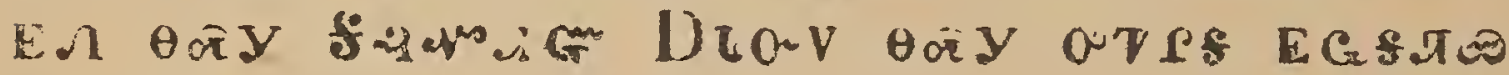
TYAUT.

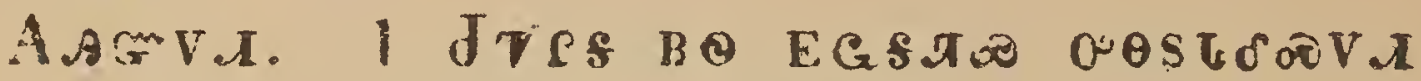

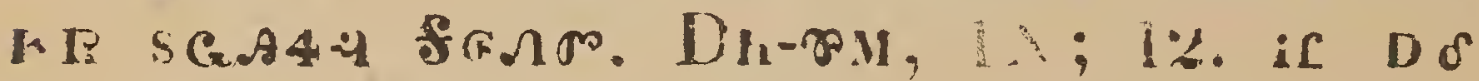

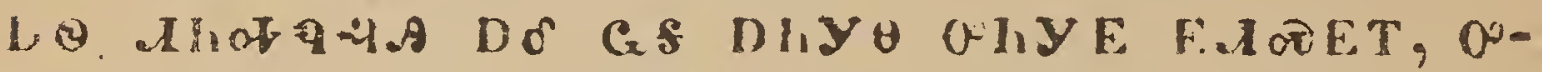

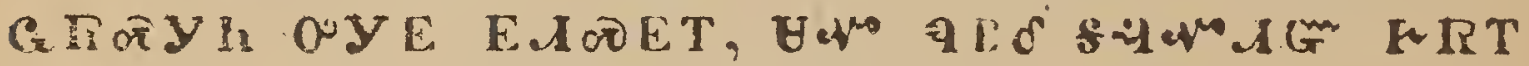
$t_{i}$ en HDy (2)

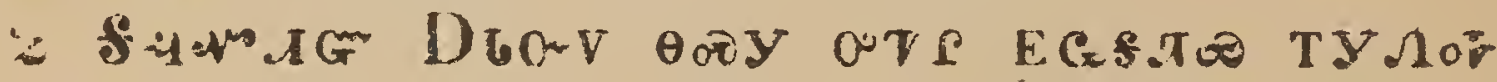

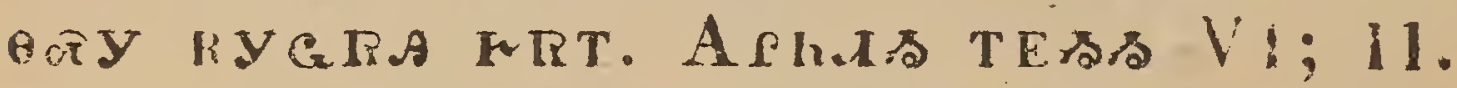

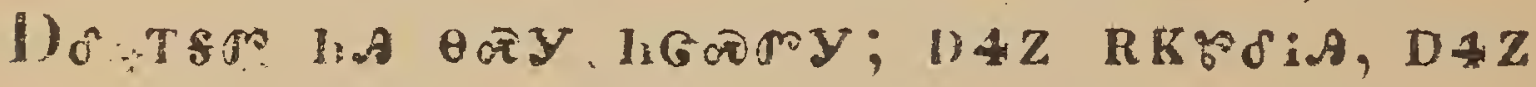
TFLO.T T.3C

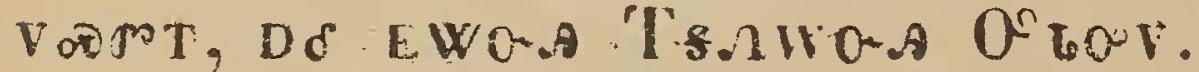

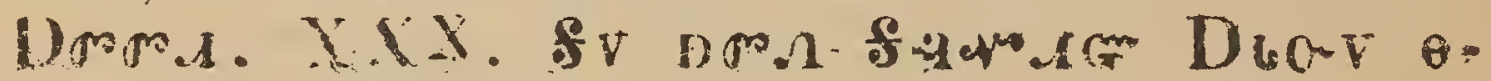

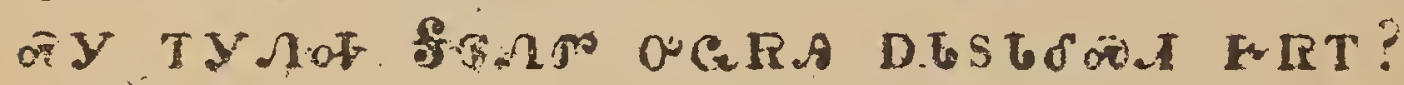

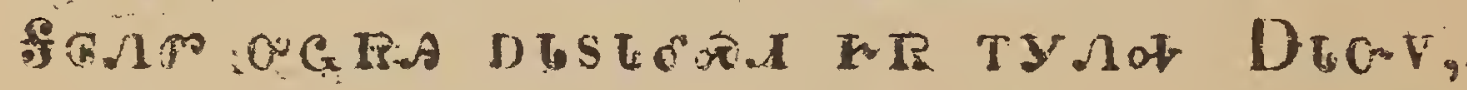

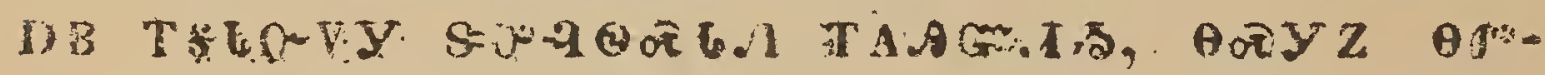

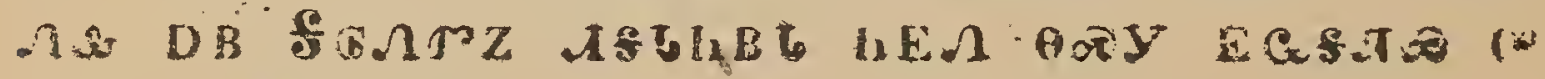

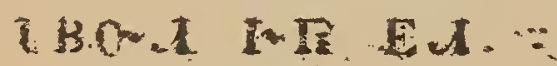

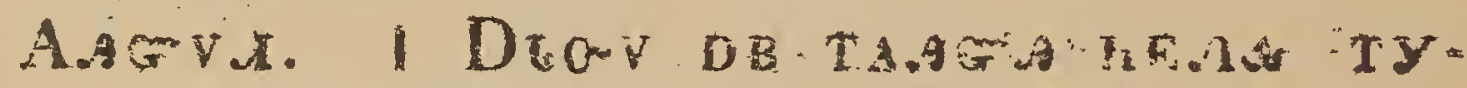
A: DSt

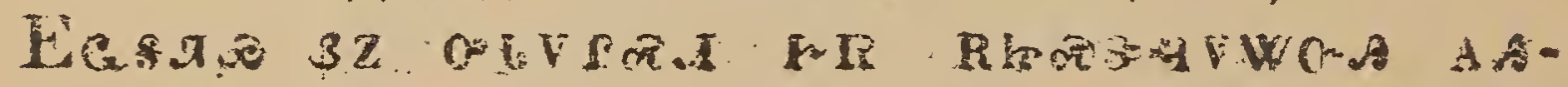

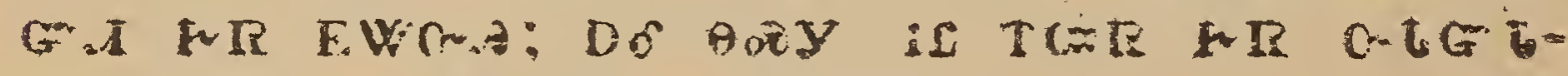

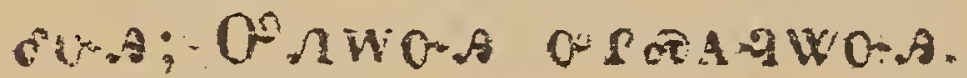

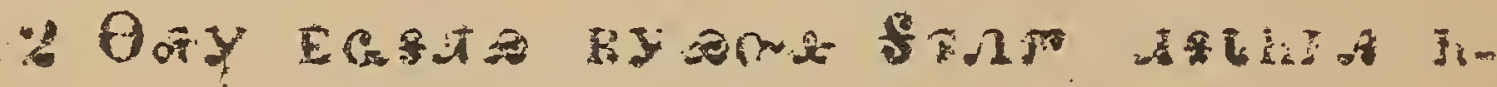




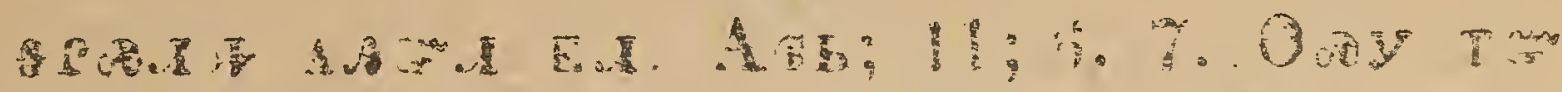

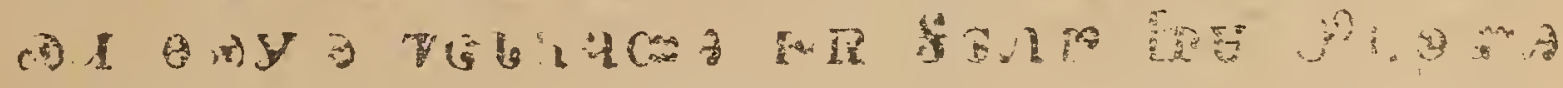

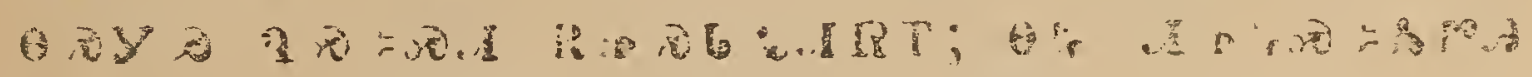

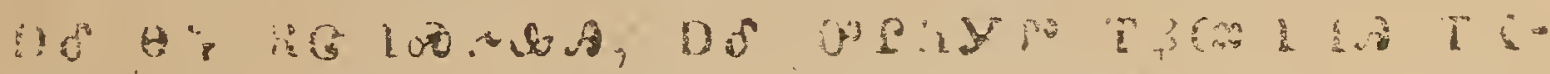

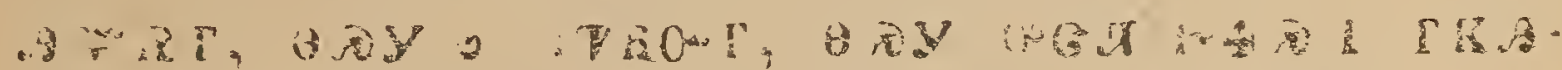

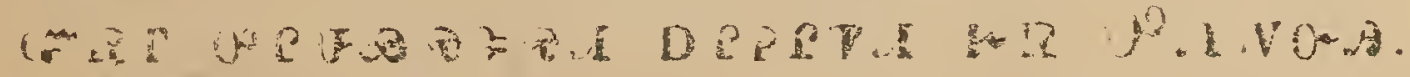

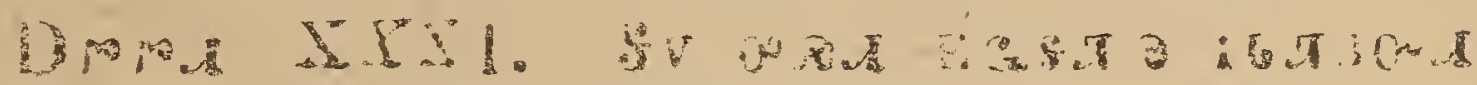

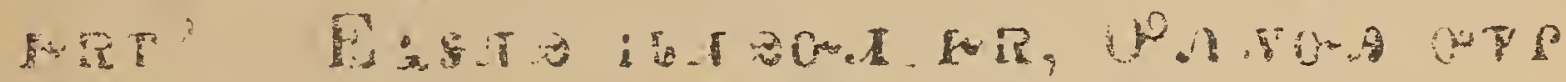

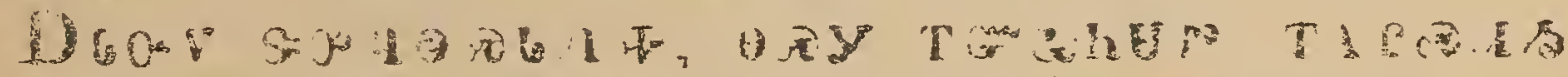

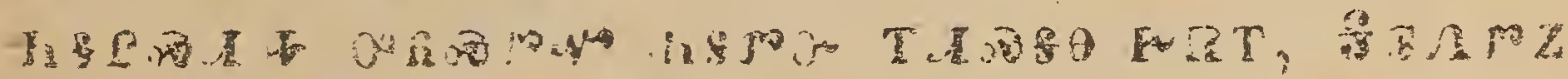

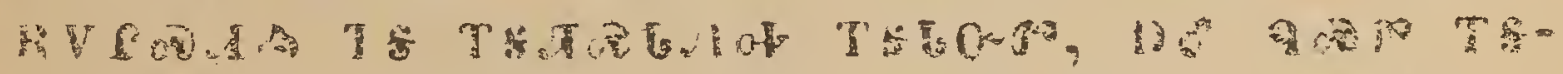

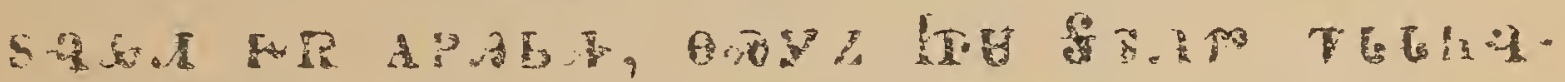

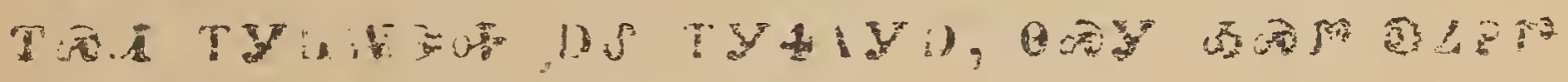

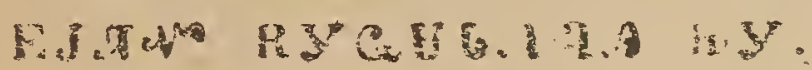

A. A w

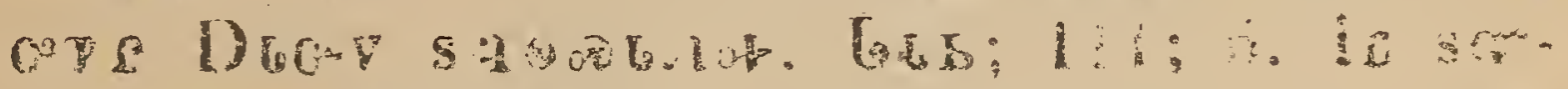

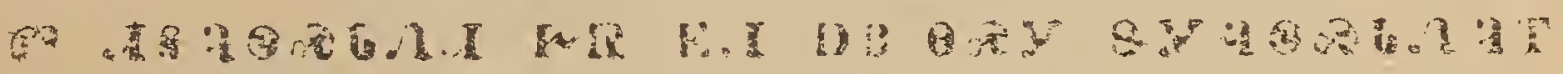

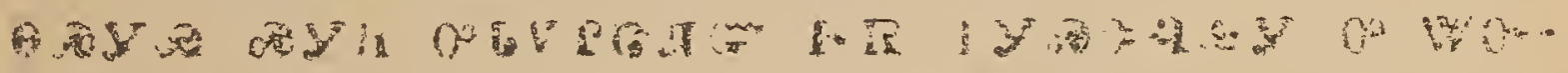
Y W W

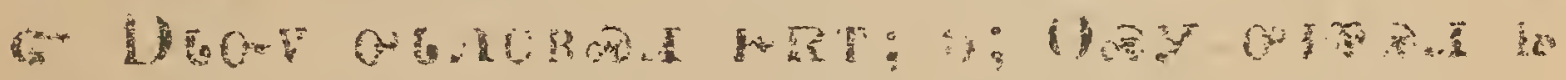

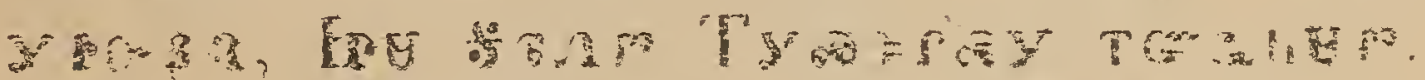

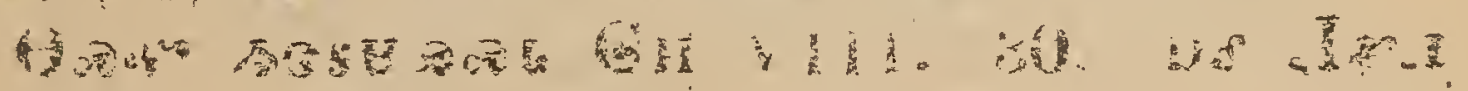
W

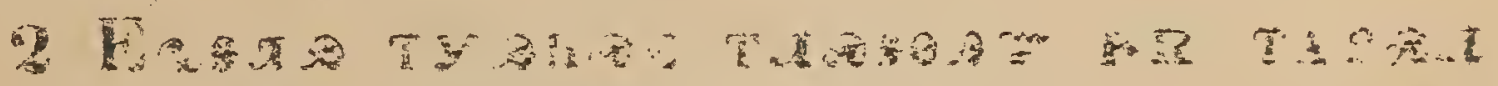

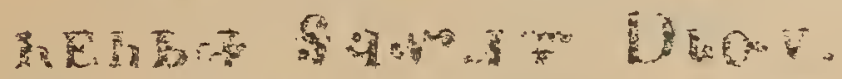

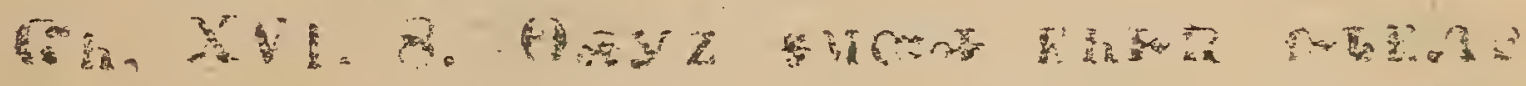

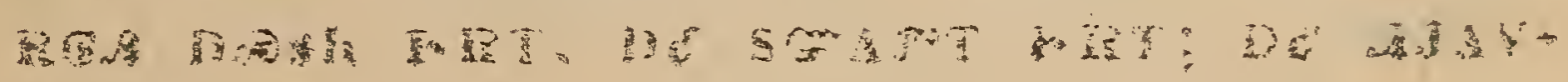

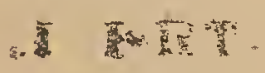

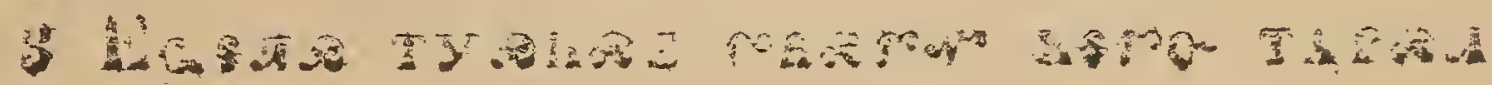




\section{4}

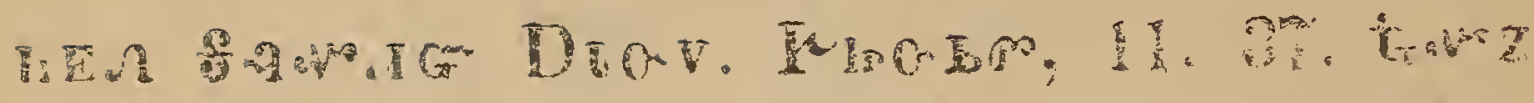

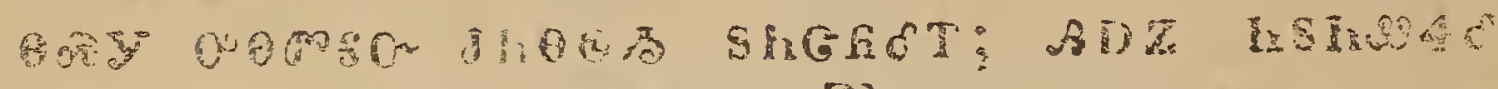
等 Do Dhe

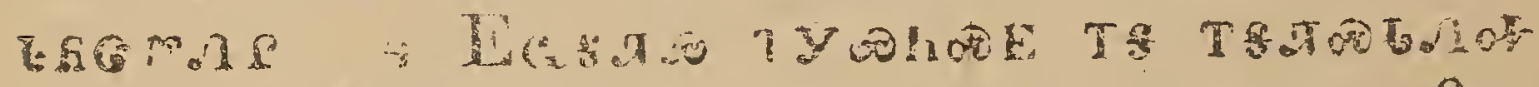

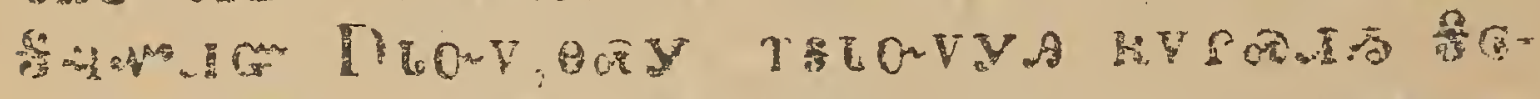

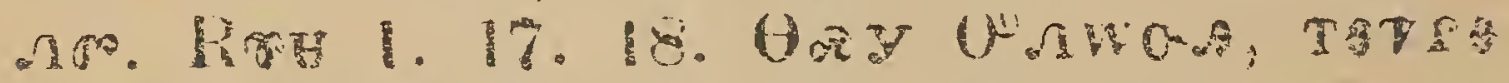

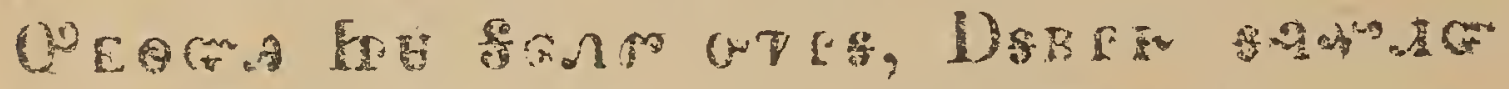

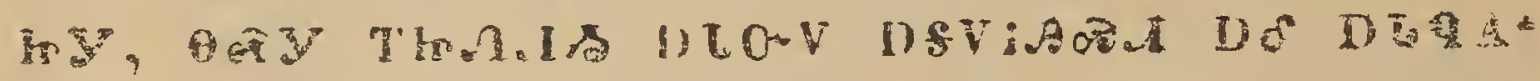

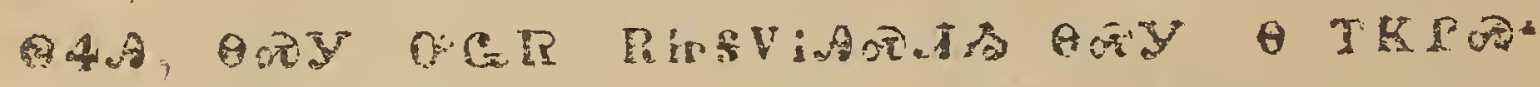

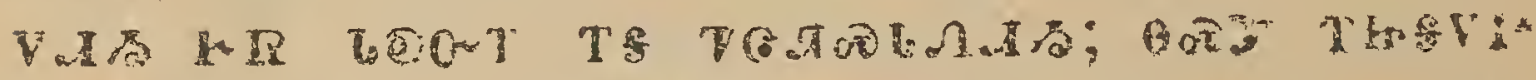

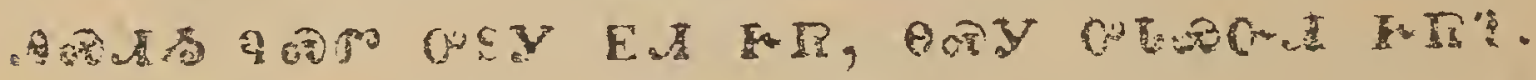
I1. he hi

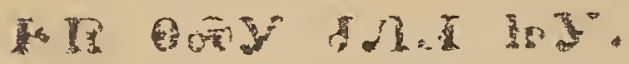

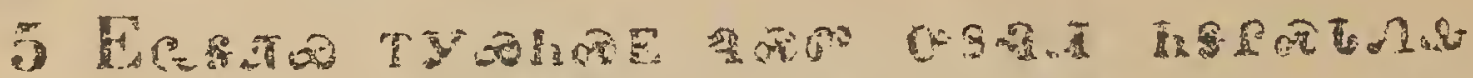
A Wh

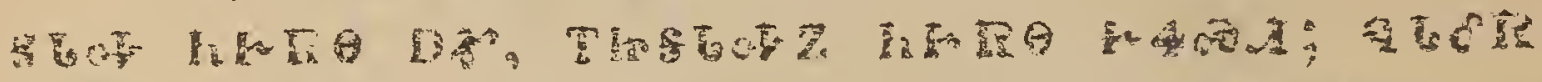

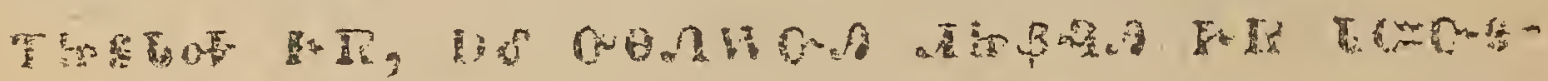

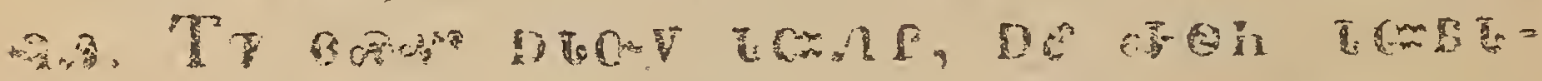

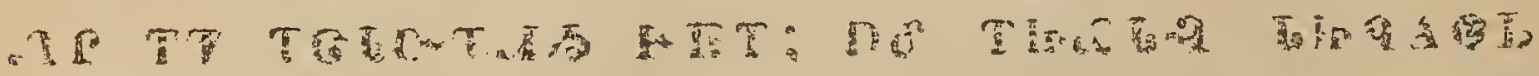

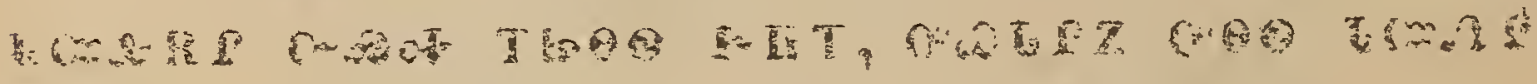

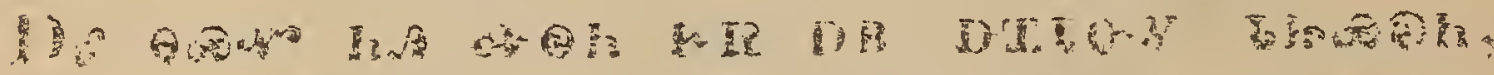
E.

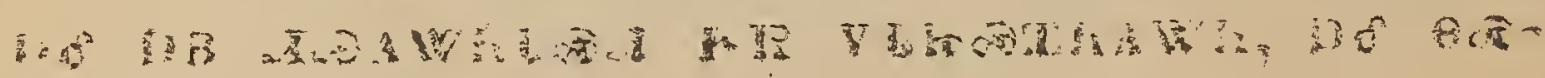

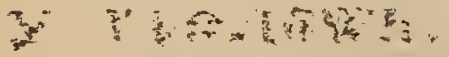

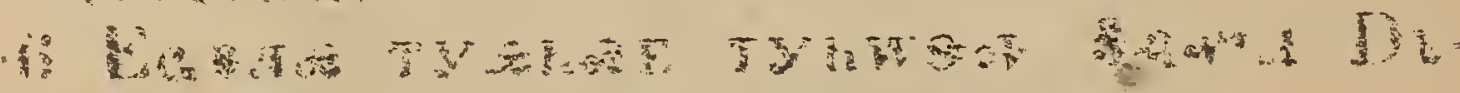

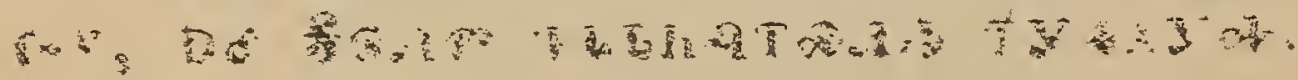

If

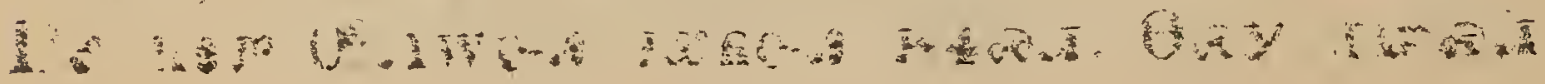




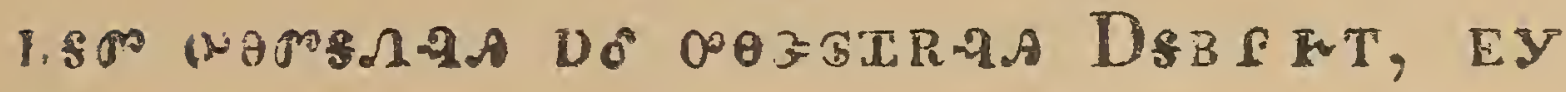
MTFT.

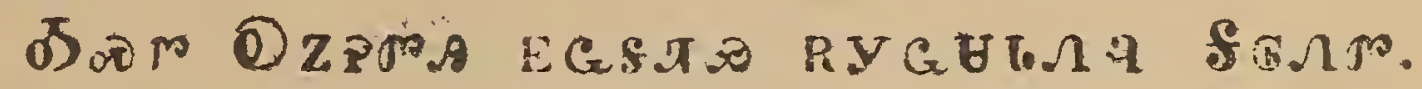

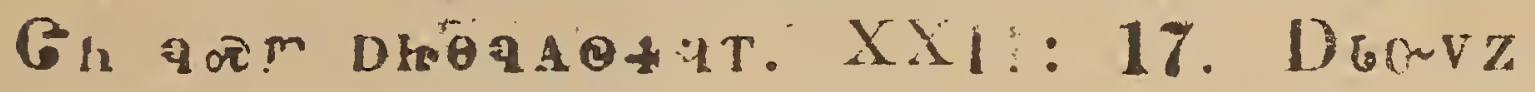

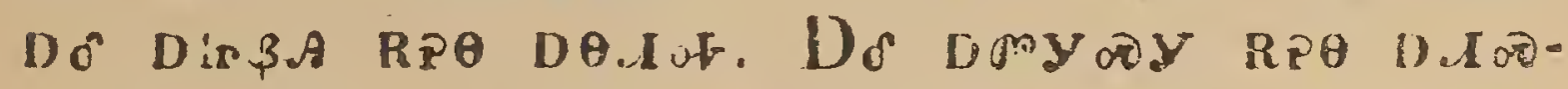

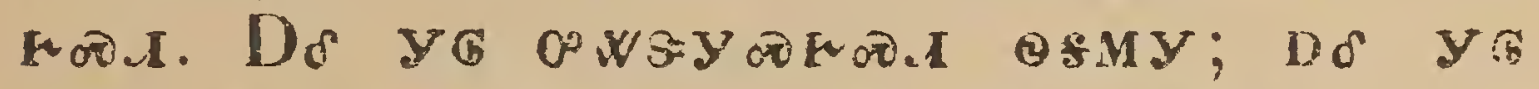

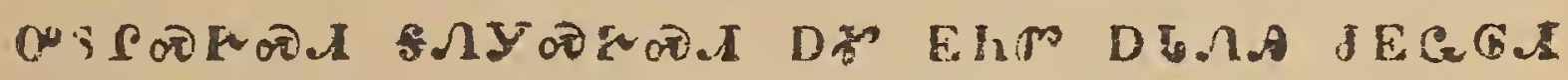

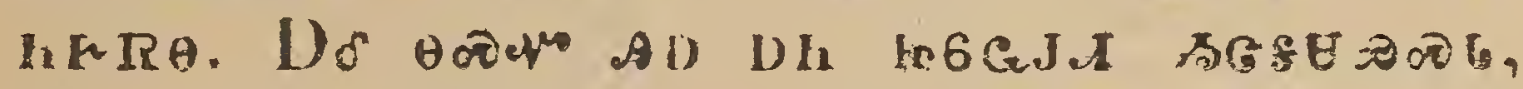
GH DЛА EAWW

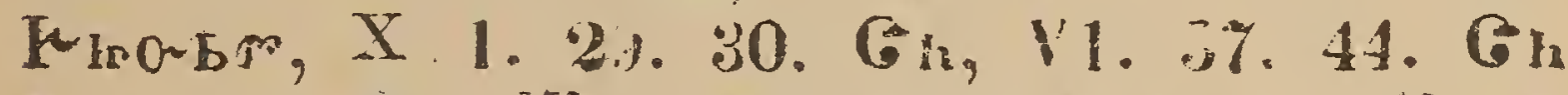

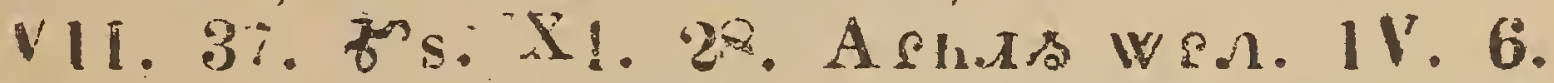

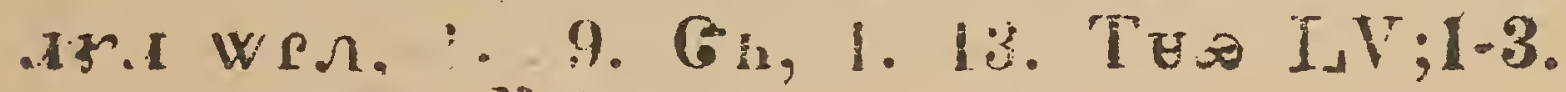

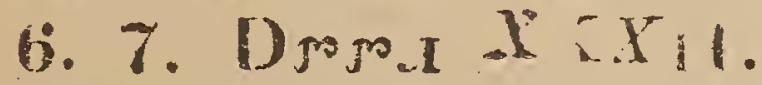

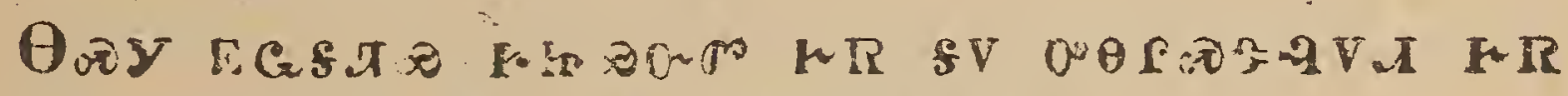

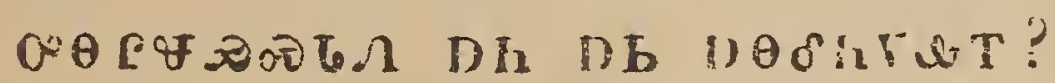

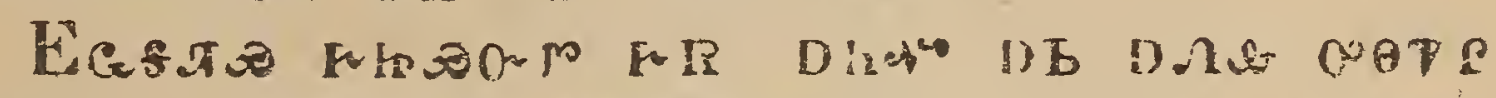

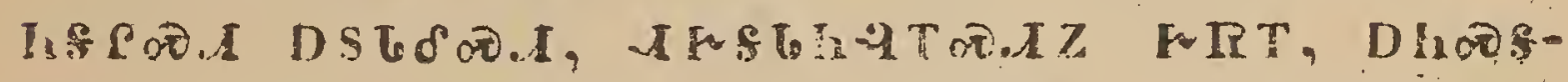

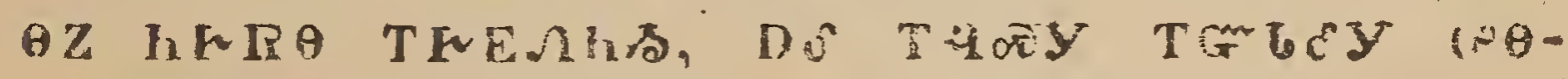

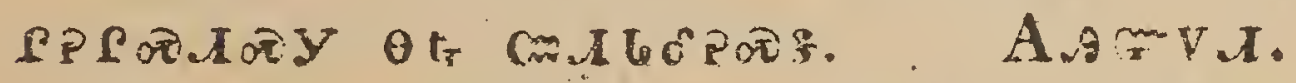

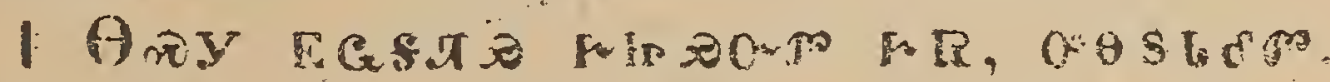

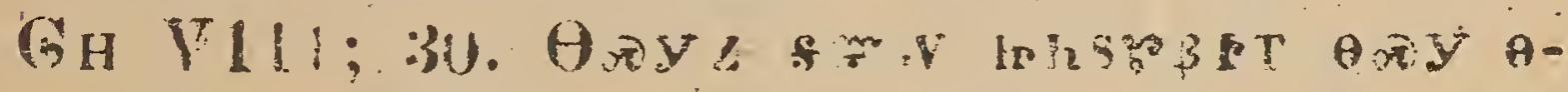

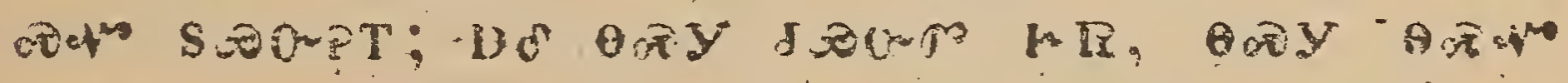

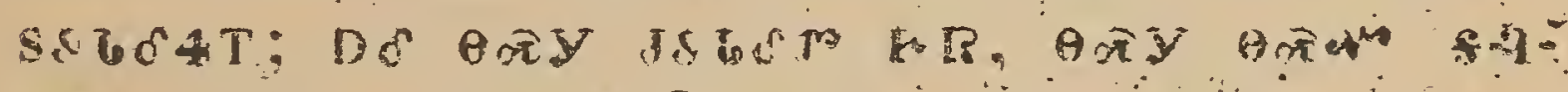

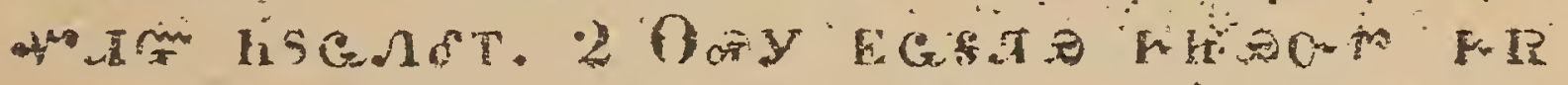
SF

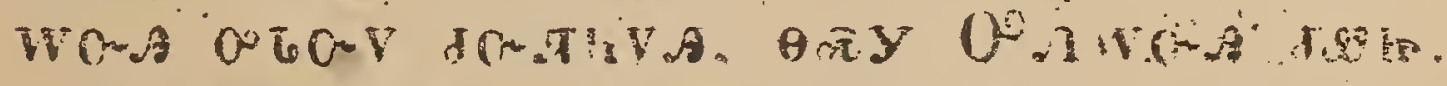

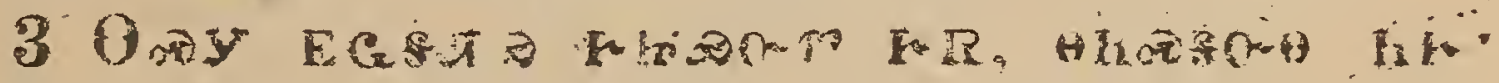

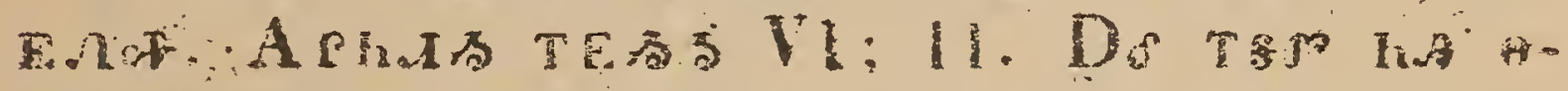

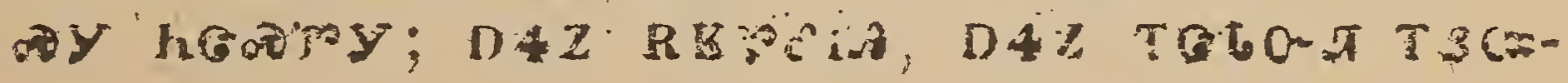

